\title{
On linear segmentation and combinatorics in co-speech gesture: A symmetry-dominance construction in Lao fish trap descriptions*
}

N. J. ENFIELD

Within the unified speech-with-gesture packages that we call utterances (Kendon 1972, 1980), speech and gesture play different roles, as determined in part by intrinsically different semiotic properties. Co-speech representational gestures typically differ from the accompanying spoken linguistic code in displaying holistic and synthetic structuring of meaning, and in lacking hierarchical combinatoric properties or the linearsegmented distribution of information characteristic of spoken language (McNeill 1992: 19-23). The aim of this article is to demonstrate that cospeech gestures nevertheless can and do show combinatoric principles and linear-segmented organization. The claims I want to make are that (a) a given gesture may be structurally related, both in form and function, to a gesture in a neighboring utterance; (b) information may be segmented and supplied linearly with gestures (and not simply as a direct reflection of such linear-segmented structuring in the spoken code); and (c) multiple gestures can occur simultaneously, where the gestures show significantly different relationships (both semantic and pragmatic) to the utterance under way. With video-recorded data from speakers of Lao (a Southwestern Tai language of Laos), I document a two-phase routine that I refer to as the symmetry-dominance construction. Phase 1 is a two-handed symmetrical gesture; in the subsequent phase 2 , one hand holds in position (representing given/topical/backgrounded information from phase 1), while one hand executes a new gesture (representing new/focal/ foregrounded information). This construction shows features of linear segmentation and combinatoric structure that arise from both the affordances and the constraints of the manual/visuospatial modality.

The symbolic system of spoken language is profoundly linearized, due to severe constraints on the number of dimensions along which speech sounds may simultaneously represent information. (This relates to limitations in the capacity of speech sounds to bear iconic and indexical meaning; see below.) Speech phonology facilitates the construction of contrastive lexemes, and patterns of morphosyntax allow linear strings 
of these lexemes to be interpreted hierarchically, yielding complex novel meanings in phrases and sentences (Hockett 1960; Thorpe 1972; Lyons 1972; Levelt 1989, inter alia). Let me suggest two reasons why gestural representations are less subject to linearization and hierarchical organization. First, due to their manual/visuospatial modality, gestures can directly and simultaneously represent a rich variety of non-symbolic information. Included here are fine analogue distinctions in three-dimensional space, thanks to the extraordinary spatial (orientational, axial, topological) flexibility of the arm and hand. Second, gestures are supported online by speech, a symbolic code, and are therefore not required to carry the full propositional load of utterances. They are free to do what they do best, namely represent information analogically, iconically, and indexically. ${ }^{1}$ Gesture's manual/visuospatial modality has rich semiotic affordances, and furthermore gesture is freed from propositional responsibility as a result of fundamental support that it receives from the finely structured symbolic representational system that we call speech. But gesture is not an unlimited resource for the depiction of just any meaning, of any level of complexity, at any moment. Like speech, gesture reaches its representational limits. When it is no longer physically possible to represent the full meaning desired at a given moment, one is forced to segment information and distribute its representation across time. This article documents a systematic mechanism for the combinatoric organization of twohanded and one-handed gestures, where the linearly sequenced gestures are structurally dependent.

In using the term symmetry-dominance construction, I borrow and adapt the terms symmetry and dominance from research on the phonological structure of lexical signs in sign language (Battison 1978; EngbergPedersen 1994; Miller 1994; Emmorey 2002; Sandler 2002). The symmetry condition in sign language phonology states that if both hands of a sign move independently during its articulation, then both hands must be specified for the same hand shape and the same movement (whether performed simultaneously or in alternation), and the specifications for orientation must be either symmetrical or identical' (Sandler 2002: 6). The dominance condition specifies that 'if the hands of a two-handed sign do not share the same specification for hand shape (i.e., they are different), then one hand must be passive while the active hand articulates the movement, and the specification of the passive hand shape is restricted to be one of a small set (6 shapes)' (Sandler 2002: 6). In this article, I use these terms in a different but related sense. In a symmetry phase of cospeech gesture, the two hands are symmetrical or identical in shape, position, and movement (or they enact a two-handed action). In a dominance phase, one hand is passive (i.e., is held still) while the other hand 
articulates some representational gesture. The non-dominant hand inherits its form from a gesture performed in a previous utterance, representing background information introduced in that utterance, while the dominant hand represents new/focal information. Perhaps the most significant point of theoretical interest concerning the relation between gesture and the structuring and production of speech is that the gesture performed by the non-dominant hand does not mirror the spoken utterance semantically or pragmatically (i.e., it is neither semantically nor pragmatically 'synchronous'; cf. McNeill 1992: 26-29).

In the schematic Figure 1, the symmetry-dominance construction appears as a dark-bordered 'half-T' shape. The columns headed HR and HL represent a speaker's right hand and left hand, respectively. ${ }^{2}$ The passage of time runs downward from row to row. Each row represents a new gesture by either hand, where a distinction between one gesture and another is marked by a thick black bordering line.

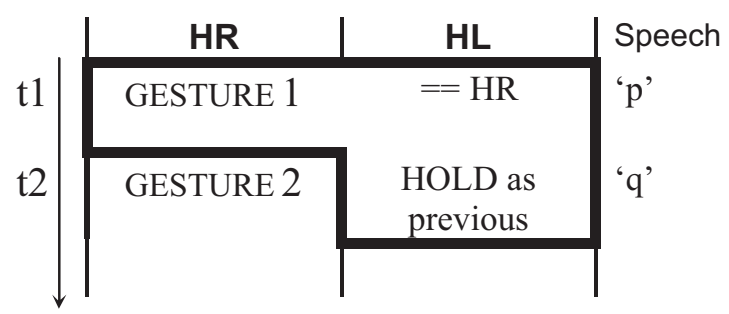

Figure 1. The 'half-T' shape (in bold line) of a symmetry-dominance construction

Thus, in Figure 1, the right hand HR is performing GESTURE 1 at t1, and GESTURE 2 at t2. Now look at the left hand HL. At t1, HL is performing GESTURE 1 in concert with HR. GestuRE 1 is a two-handed gesture. The structure of such a gesture will typically be symmetrical, such that the form of HL can be in some way derived from the form of HR. This is represented in Figure 1 using the symbol ' $==$ '. Accordingly, there is no thick black line separating the cells HR at $\mathrm{t} 1$ and $\mathrm{HL}$ at $\mathrm{t} 1$, because the two cells do not represent 'different gestures'. However, at t2, as HR is employed in making a second gesture, HL maintains a hold in the hand shape and spatial position it acquired at the end of $\mathrm{t} 1$ (marked 'HOLD as previous' in Figure 1). Accordingly, there is no thick black line separating the two cells HL at $\mathrm{t} 1$ and HL at $\mathrm{t} 2$. A symmetrical gesture followed by a hold of the non-dominant hand and a new gesture by the dominant hand 
results thus in a visible 'half- $\mathrm{T}$ ' shape in the diagram. A key component of the construction is the hold of one hand (HL in this case). One contribution of this study is to add to what we know about the function of gesture holds, a category previously identified and discussed (e.g., McNeill 1992: 83), but - like many categories so far established in gesture research not yet fully understood.

The two sequential phases of this construction have a defined structural relationship in both form and meaning. This type of construction is typical in descriptions of complex physical artifacts, where a speaker needs to refer to multiple features of a three-dimensional object. Typically, speakers start an artifact description by introducing the overall shape and size of the artifact. For a speaker to begin by introducing the larger structure of which all else relevant can be said to be a part is well motivated in terms of information supply in discourse. Having established the overall size and shape of an artifact, a speaker then has a context for making finer specifications. The dimensions of the fish traps discussed in examples below make them suitable for speakers to use largish symmetrical gestures when initially establishing their basic whole form. This first step should provide an anchor, or frame, for subsequent information supply in two structured conceptual domains: discourse and threedimensional space. The syntactic dependency between the two phases of this construction operates in these two domains simultaneously, ensuring coherence of both the organization of discourse and the representation of spatial structure.

These points are best brought out with reference to detailed descriptive data. The examples drawn upon in following sections are from a series of video-recorded interviews conducted during fieldwork in semi-urban settings in Vientiane, Laos, July 2002. Speakers were asked to describe a list of different types of locally produced fish-trapping mechanisms, including various sorts of nets, basket traps, drop-door traps, filtering gear, box enclosures, fences, and spearing equipment (see Claridge, Sorangkhoun, and Baird 1997). The recordings yielded rich gesture material, somewhat different in nature to the 'narrative retelling' discourse type on which gesture research has tended to concentrate. In describing fish-trapping artifacts, speakers give complex performances involving a range of iconic and indexical hand gestures, creating virtual objects in shared space. A critical feature of the symmetry-dominance construction in these performances is the semiotic relation between the non-dominant hand (the hand that holds its position and shape established in the symmetry phase) and the dominant hand (the hand that makes the new focal gesture). The non-dominant hand is used extensively as a counterpart and anchor for the dominant hand, providing semiotic support. This support is twofold. 
First, the non-dominant hand provides a stable spatial reference point (or ground) facilitating the depiction of complex three-dimensional spatial representations by the dominant hand. Second, deployment of the non-dominant hand has a discourse pragmatic (or 'prosodic') function, signaling that certain background information continues to be relevant to what is being said. (Meanwhile, the dominant hand directly represents information foregrounded in the current speech; cf. Sandler 2002; Mathur 2002; Liddell 2003: ch. 8.) These functions of the non-dominant hand have consequences not only for relative spatial deployment of the two hands, but also for their respective temporal deployment.

We now turn to descriptions of four video-recorded sequences, beginning with two descriptions of the sòon 5 , a type of basket trap.

\section{Example 1 - sò̀n 5}

The sòn 5 is a cone-shaped woven 'wedge' basket trap, usually a meter or so long. It tapers from a fluted mouth (6-12 inches across) down to a tight end. It is placed in flowing water, such that the water enters the open end, causing any fish swimming into it to be trapped inside and unable to get back out, due mainly to the fish's inability to turn around in a tight space.

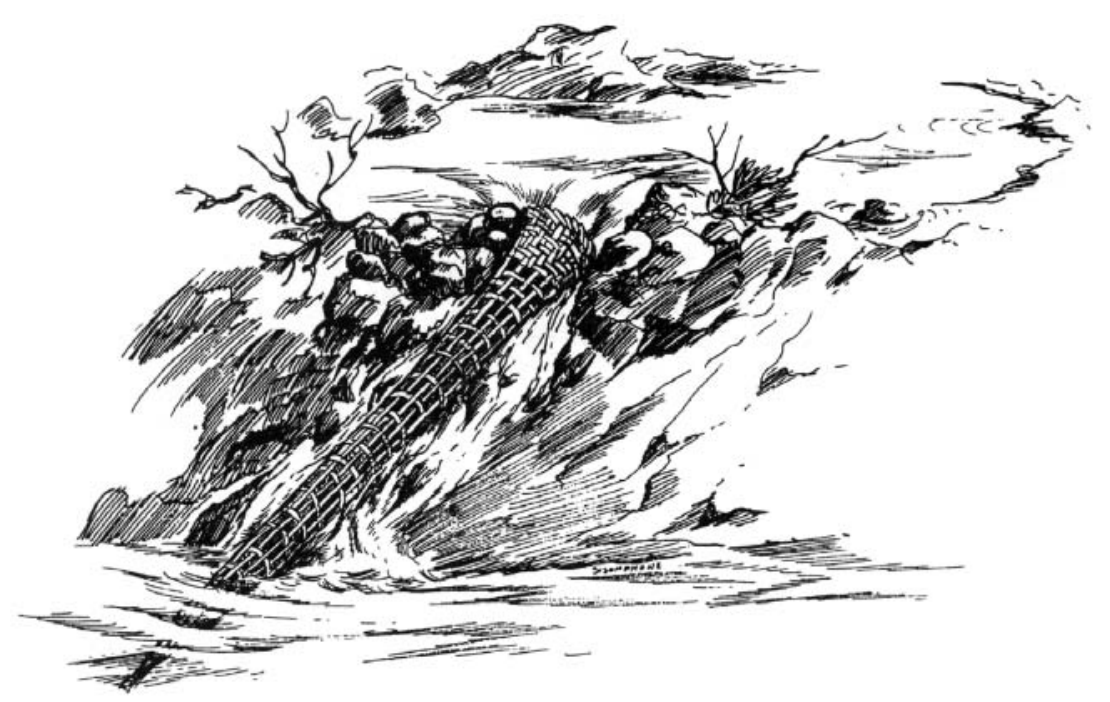

Figure 2. The sòon5, a cone-shaped woven 'wedge' basket fish trap. (Illustration by Sisomphone Hansai [Claridge, Sorangkhoun and Baird 1997: 54].) 


\section{Speaker 1}

The speaker begins his description of the sòon 5 as follows: ${ }^{3}$

(1) khan2 sòòn5 lèèw4 khaw3-

if sòòn PFV 3PL-

khaw3 hêt1 [vee3 thaang2 paak5 man2 na0]

3PL make fluted direction mouth 3SG PCL

'As for the sònn, well they- they make it fluted at the mouth.'

The first recognizable gesture in this sequence occurs when the speaker comes to the word vee 3 'fluted'. The gesture is a two-handed symmetrical representation of the fluted opening of the trap.

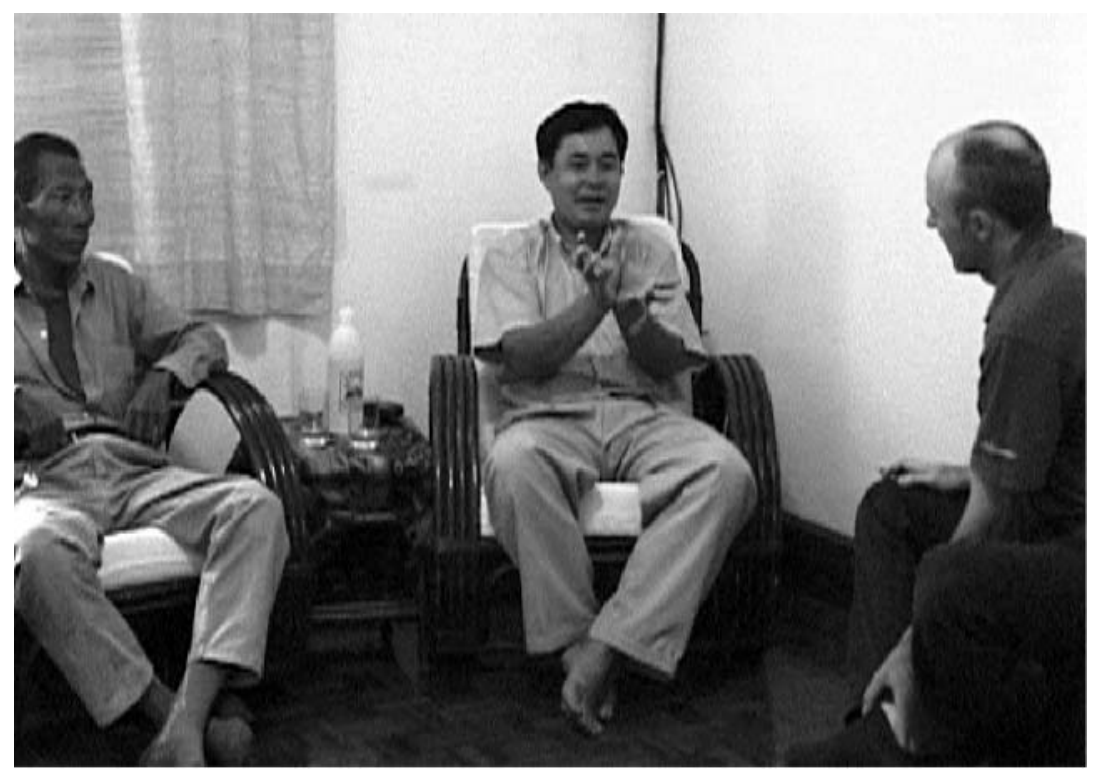

Figure 3. 'As for the sòn4, well they- they make it fluted at the mouth.'

Next, moving into a dominance phase, the left hand is held in position, while the right hand represents the passage of a fish into the mouth and body of the trap. Figures 4 and 5 represent the beginning and end of a single movement.

(2) [hêt1 nòj0-nòòj4] khaw5 paj3

make small-RDP enter go

'(They) make (it) small, going in.' 


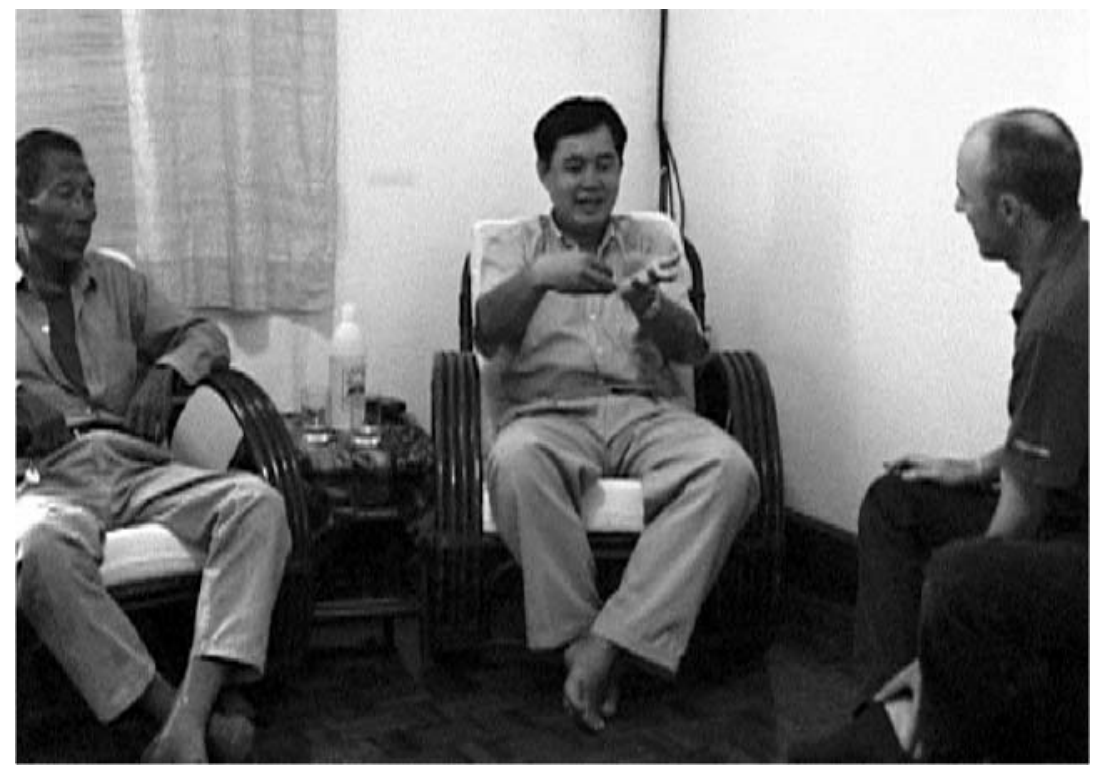

Figure 4. '(They) make (it) small, ...'

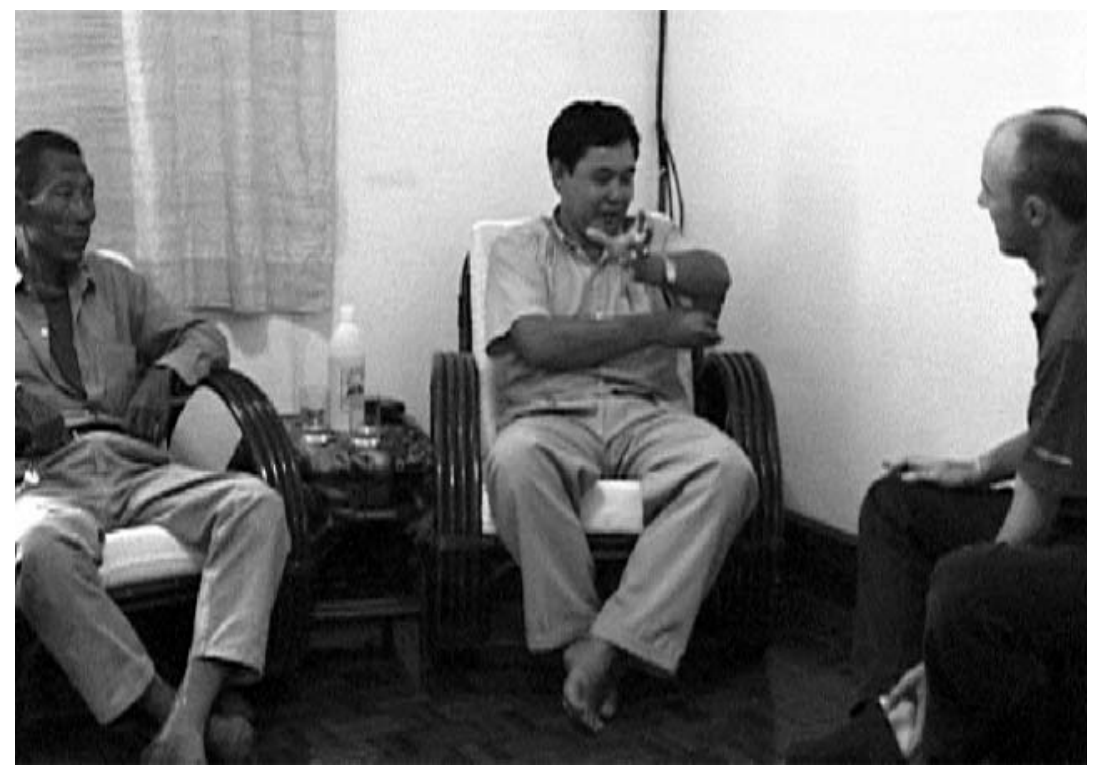

Figure 5. '... going in.' 


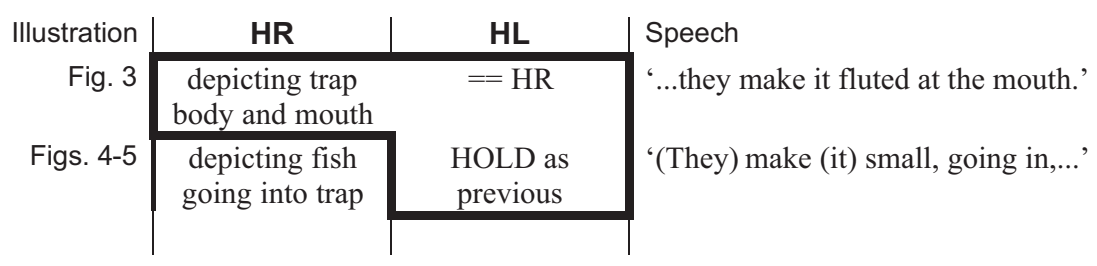

Figure 6. The 'half-T' in the diagram shows a symmetry-dominance construction (Figures 35)

This simple example of the symmetry-dominance construction can be diagrammed as shown in Figure 6.

The example illustrates the typical function of the symmetrydominance construction. First, a two-handed gesture establishes a larger structure that forms a spatial frame of reference for subsequent specifications about the artifact. When the left hand holds in the position established during the symmetry phase, it continues to represent the referent of that phase - i.e., the larger structure - even though by itself it constitutes literally only half of the original signifier. The held left hand indexically signifies what had been represented by the left and right hands together during the symmetry phase. It provides a spatial frame of reference for the elaborating right hand gestures in the dominance phase. Note that at the phase depicted in Figure 3, the focus of interest is the fluted mouth of the trap (note speaker's eye-gaze/head-orientation). The rest of the trap is implied, but its precise length and orientation are not specified. When the speaker releases his right hand from the symmetrical gesture shown in Figure 3 and begins the dominance-phase gesture in Figure 4, his left arm is the only remaining signifier of the trap, and it determines the orientation of the body of the trap. The right hand gesture in Figures 4 and 5 specifies a precise orientation of the body of the trap, namely running from the space at the front and center of the speaker's body back to his left elbow, at the left side of his lower torso. This location is then presupposed in subsequent gestures in this sequence.

Here we see a combinatoric relationship between a gesture and a subsequent gesture, where the subsequent gesture is formally and semantically subordinate to the first. The first gesture sets up a discourse and spatial frame for following gestures, using full available manual semiotic resources (i.e., both hands). This full image persists thanks to a metonymic relation between the degraded (exactly halved) signifier (i.e., just one hand) in Figures 4 and 5, and the fuller conceptual image required for current spatial and discourse cohesion. 
The speaker's next statement concerns the very tight weave at the small end of the trap. The gesture he chooses to accompany his speech in representing this is a two-handed enacting gesture, as if weaving. The gesture is performed at the point in space where the small end of the trap is now established to be located, at the left side of the speaker's lower torso, where his left elbow was in Figure 4.

(3) lèèw4 khaw3 [saan3 nòj0-nòòj] maa2 PFV 3PL weave small-RDP come '... and they weave (it) small, coming (back here) ...'

Here, the speaker has interrupted a dominance-phase because he needed both hands for his next gesture, in this case an enactment of a two-handed action weaving. The next gesture, in Figure 7, leads back to the same symmetrical gesture shown in Figure 3 above.

(4) la0 khaw3 maa2 hêt1 [vee3 thaang2 paak5 man2 PCL 3PL come make fluted direction mouth 3SG nòq1]

PCL

'... and they come (and) make (it) fluted at the mouth, right.'

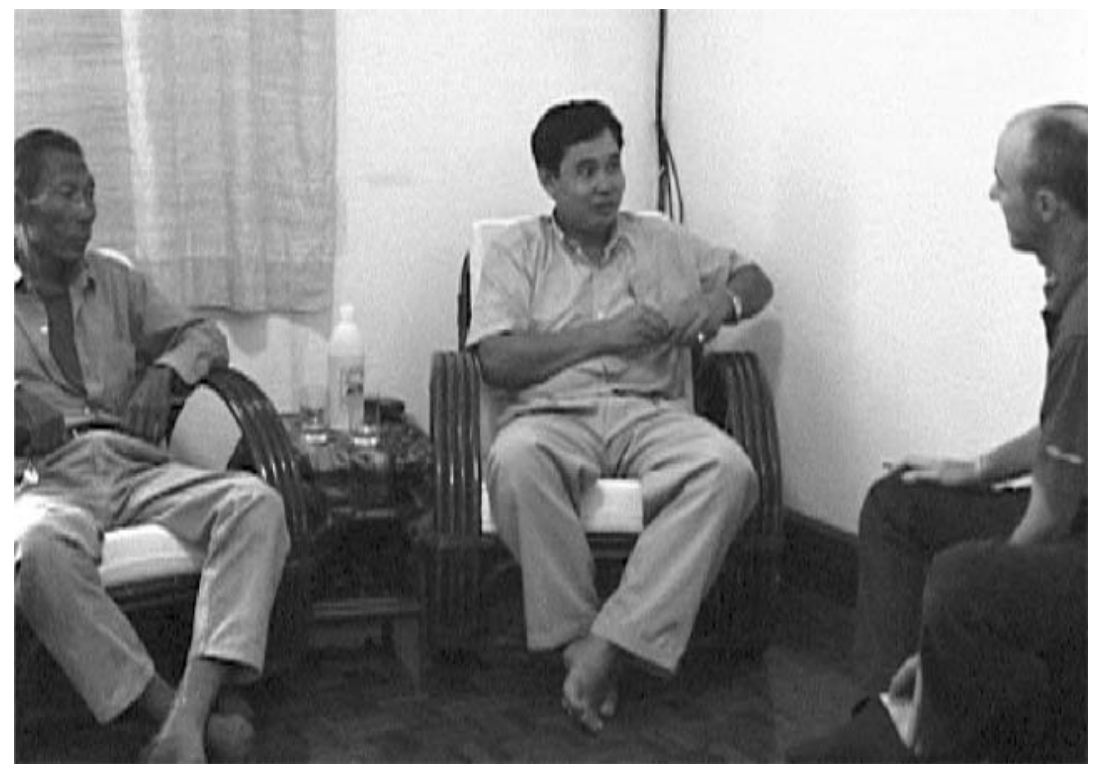

Figure 7. '... and they weave (it) small, coming (back here)...' 


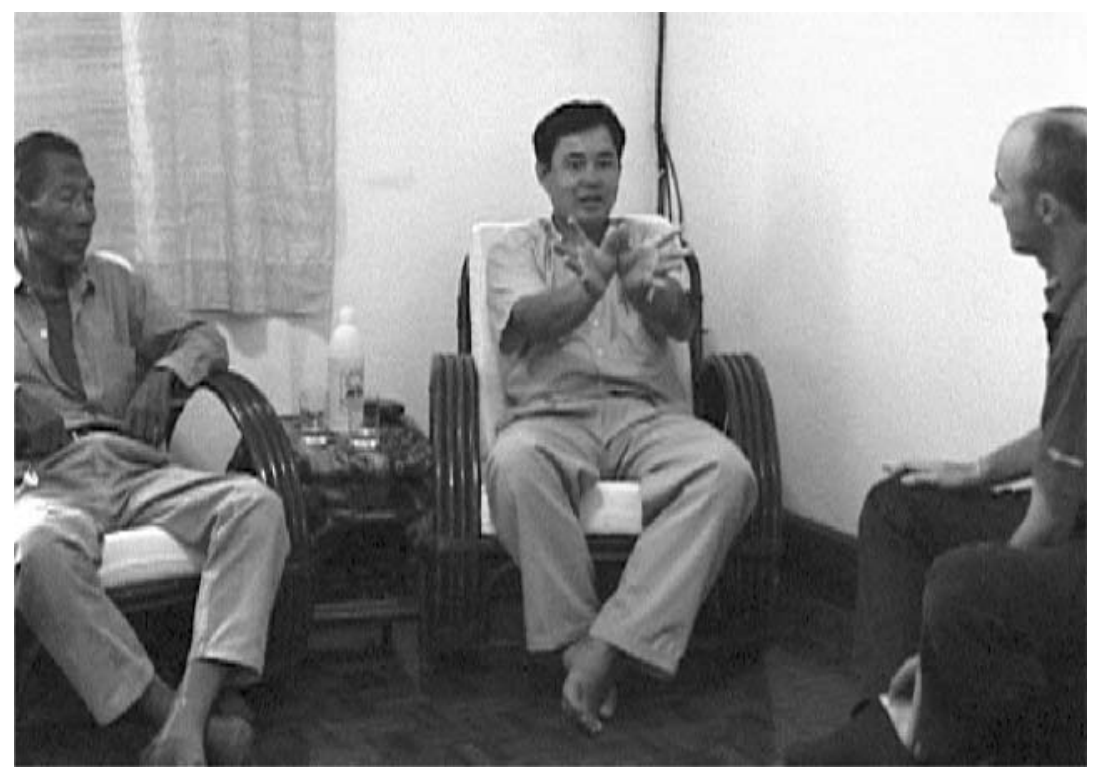

Figure 8. '... and they come (and) make (it) fluted at the mouth, right.'

This symmetrical gesture provides the basis for an entry into another dominance-phase with the left hand held, this time for longer than the sequence shown in Figures 4 and 5 above. The speaker now wants to talk about how the trap is actually used. Still in symmetrical phase, the speaker moves his body forward, maintaining the symmetrical and held two-hand gesture, shifting it forward and down, as if placing the trap down:

(5) lèka0 qaw3 paj3 [saj1 thaang2 naa2 khùù2-kan3]
PCL take go put direction paddy same-RCP
'And (they) place it in the rice fields, also.'

The left hand now holds, as the speaker enters a dominance phase, using his right hand to represent a fish that gets caught in the trap. The following three lines and accompanying illustrations depict the entry of the fish into the trap and its getting stuck inside. Note that the speaker's gaze follows the right hand all the way in.

(6) vêlaa2 [paa3 si0 long2] baat5+ni0 time fish IRR descend PCL

'Now, when a fish is going to go down (into it) ...' 


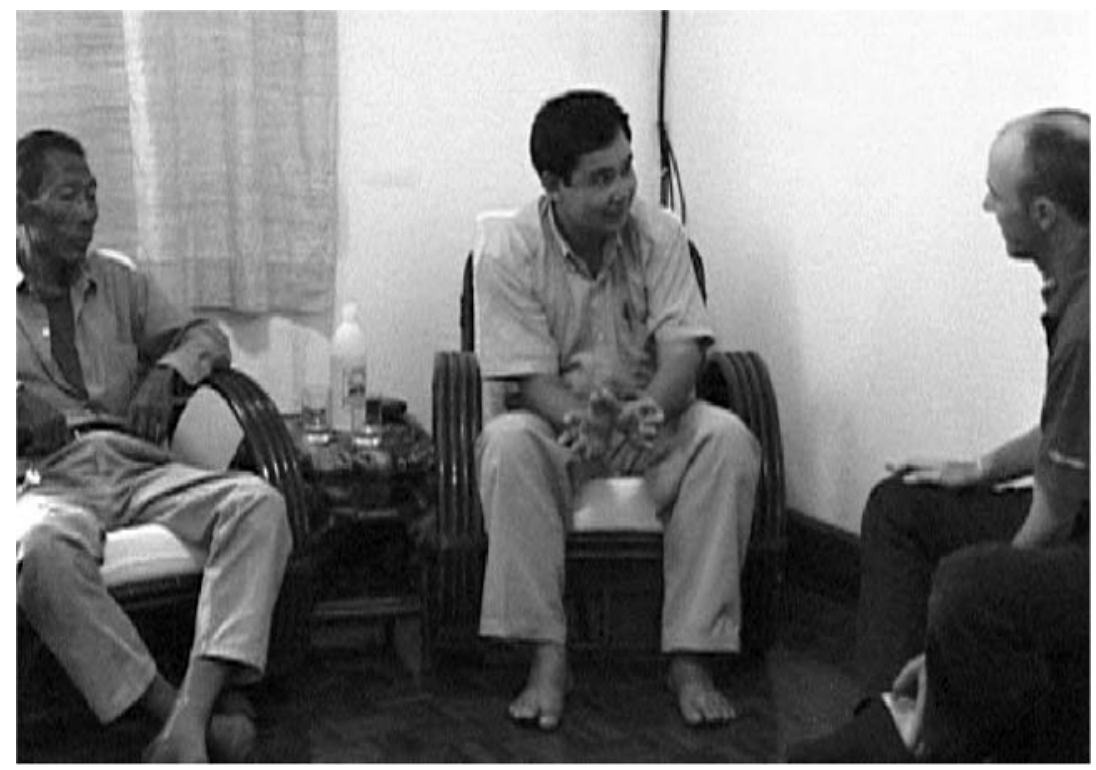

Figure 9. 'And (they) place it in the rice fields, also.'

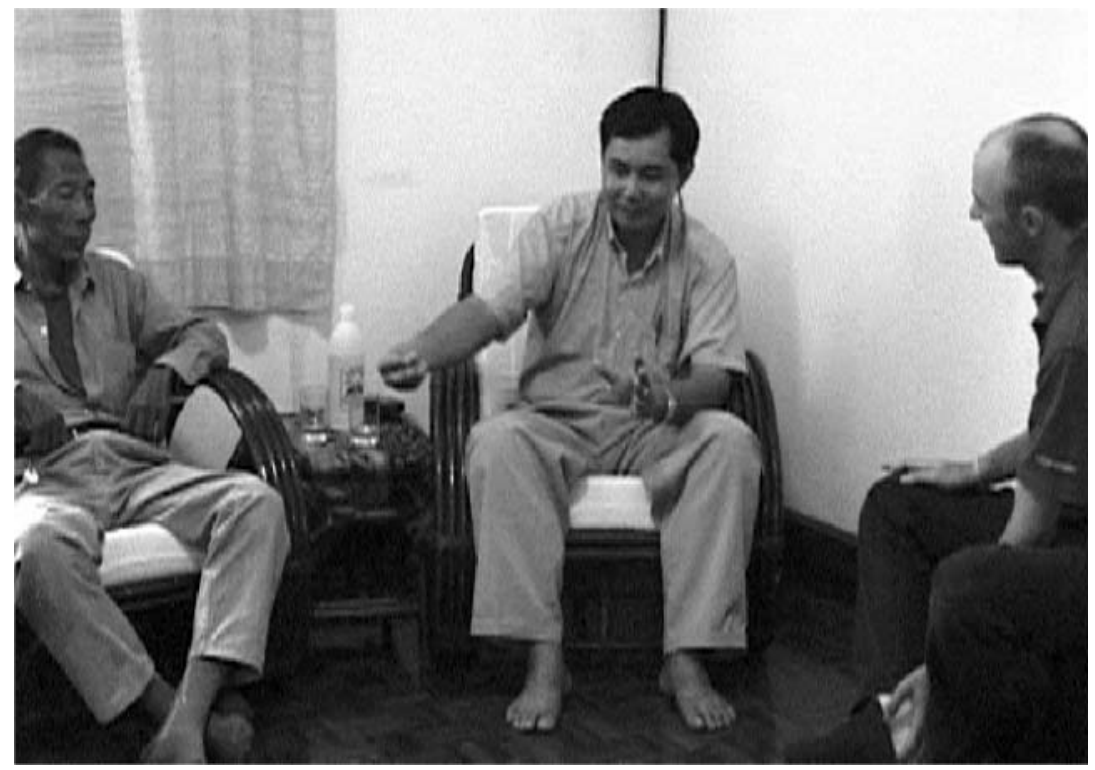

Figure 10. 'Now, when a fish is going to go down (into it) ...' 


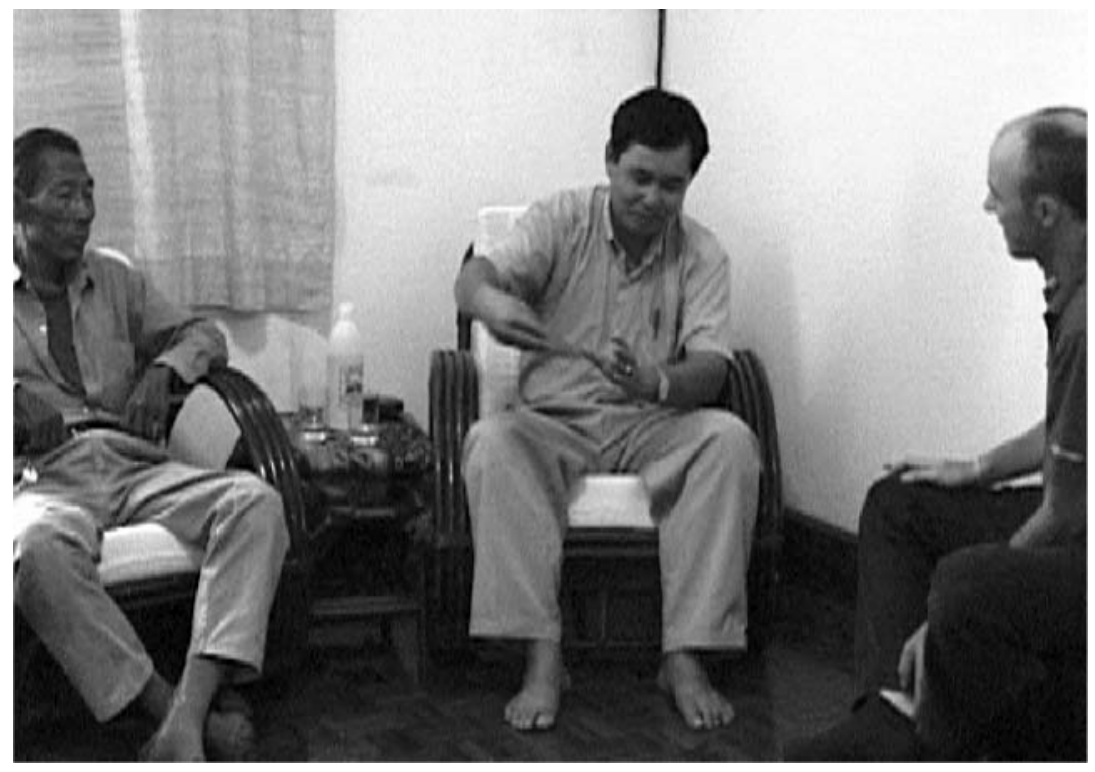

Figure 11. '... (when) a fish is going to go down (into it),...'

(7) paa3 si0 long2 la0 man2 [khaw5 paj3]

fish IRR descend PCL $3 \mathrm{SG}$ enter go la0 paj3 [sup1] juu1 han5

PCL go insert be.at there

'... (when) a fish is going to go down (into it), it goes in and is inserted there ...'

Then, the speaker states that the fish cannot get back out. His right hand, moving quickly forward and away from his body, represents a fish coming out, while his speech provides the clausal negation (cf. Engle 1998):

(8) la0 man2 [khùùn2 bò0 daj4] na0 PCL 3SG return NEG can PCL '... and it can't go back.'

Before finishing the sequence, the speaker reiterates the fate of the fish - stuck inside the trap - depicting it once again with a right hand gesture, using a repeated jamming-in movement of his right hand:

(9) khaw5 paj3 la0 paj3 [ñat1 juu1 naj2 han0] lèq1 enter go PCL go jam be.at inside there PCL '(It) goes in and (it) gets jammed in there.' 


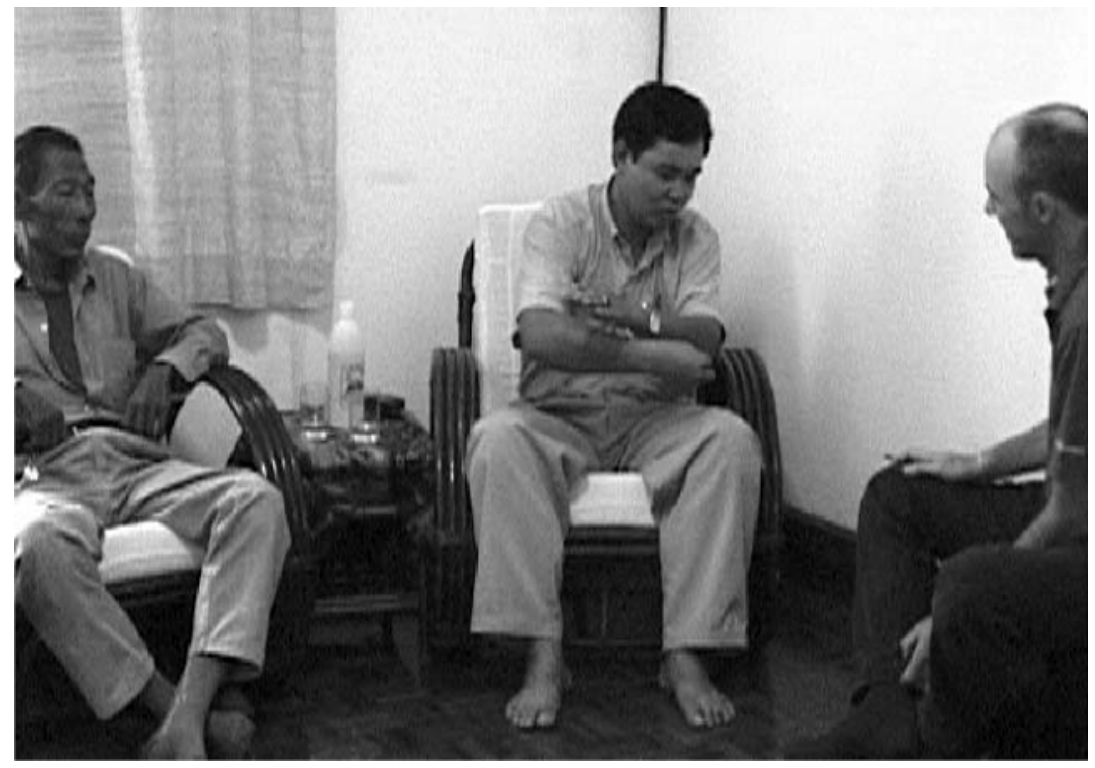

Figure 12. '... it goes in and is inserted there...'

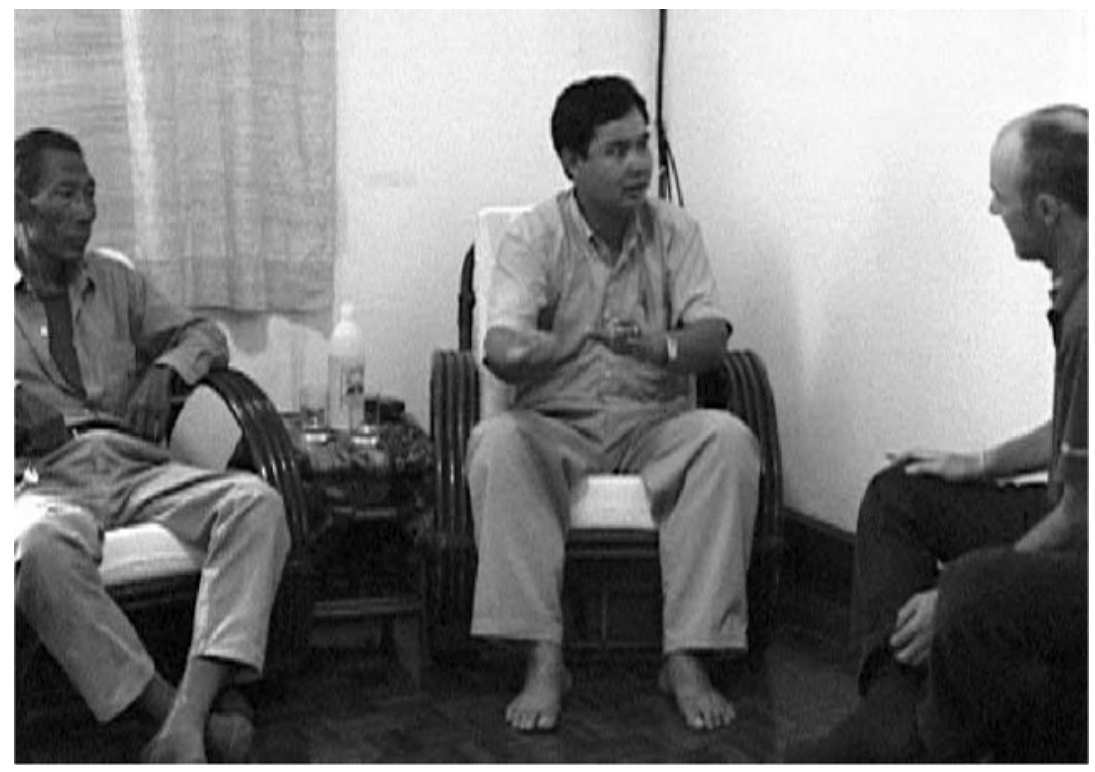

Figure 13. '... and it can't go back.' 


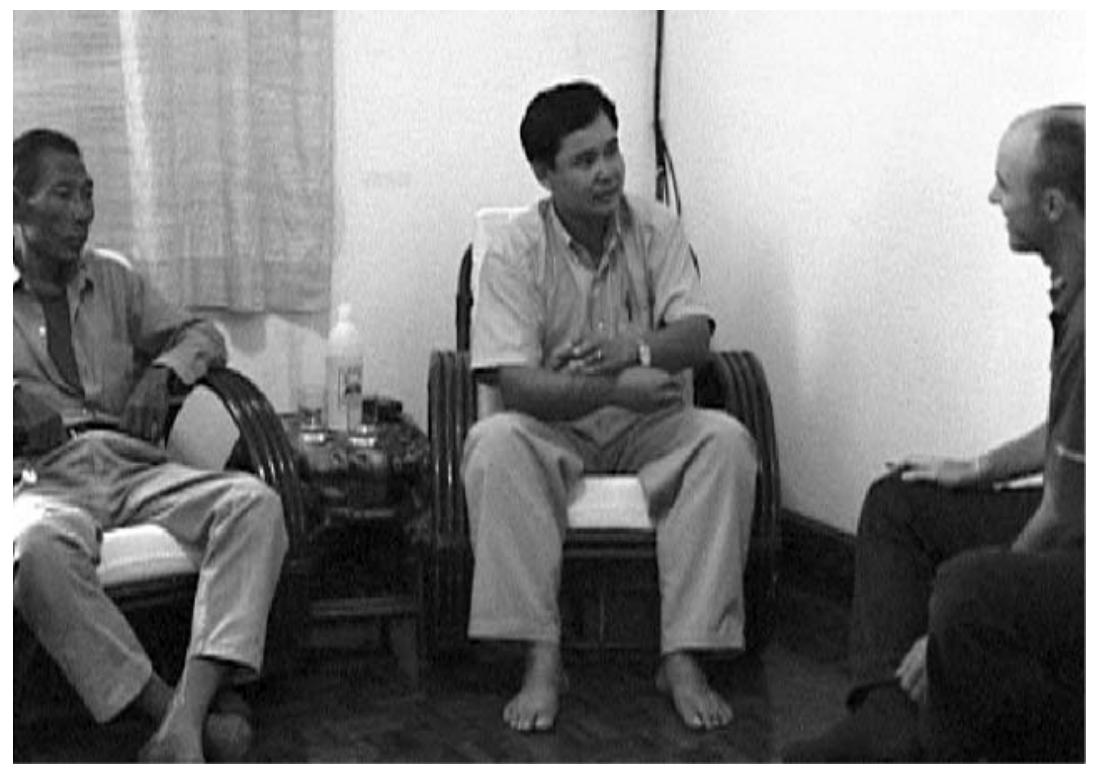

Figure 14. '(It) goes in and (it) gets jammed in there.'

Figure 15 shows a diagram of the sequence depicted in Figures 9 through 14, where the heavy-bordered area depicting the symmetrydominance cycle forms a 'half- $T$ ' shape.

The speaker is now apparently satisfied that no further elaboration is necessary. As he makes a closing comment as to the yield of this type of trap (not great), his two hands go to rest as he settles his body back in his chair (Figure 16).

(10) ka0 bò0 daj4 laaj3 qan0-ni0 daj4 nòòj5 PCL NEG get much CLF-DEM.GEN get little '(You) don't get many (fish), (with) this one, (you) get a little.'

The physical act of assuming a resting posture has what might be called a 'prosodic' function (in the sense of Sandler 1993, 2002). Putting the hands to rest can signify a discourse boundary, a 'putting down' of the current topic. This is achieved semiotically by an indexical relation between one's commitment to a communicative project, on the one hand, and the degree to which one is expending physical effort in carrying out that project, on the other. The latter information is typically directly perceptible (Levy and Fowler 2000). When one's hands assume a resting posture after a stretch of gesture in discourse, one displays that one is 


\begin{tabular}{|c|c|c|c|}
\hline Illustration & HR & HL & Speech \\
\hline Fig. 9 & $\begin{array}{l}\text { Depicting trap move forward } \\
\text { and low, as if being placed }\end{array}$ & $==\mathrm{HR}$ & 'And (they) place it in the rice fields, also.' \\
\hline Figs. $10-12$ & $\begin{array}{l}\text { depicting fish swimming } \\
\text { into trap }\end{array}$ & \multirow[t]{3}{*}{$\begin{array}{l}\text { HOLD as } \\
\text { previous }\end{array}$} & \multirow{3}{*}{$\begin{array}{l}\text { 'Now, when a fish is going to go down (into } \\
\text { it) ...(when) a fish is going to go down (into } \\
\text { it), it goes in and is inserted there' } \\
\text { 'and it can't get back.' } \\
\text { '(It) goes in and (it) gets jammed in there.' }\end{array}$} \\
\hline Fig. 13 & $\begin{array}{l}\text { depicting fish coming out of } \\
\text { trap, hold outside trap }\end{array}$ & & \\
\hline Fig. 14 & $\begin{array}{l}\text { depicting fish going inside } \\
\text { trap, with repeated } \\
\text { movement of 'jamming', } \\
\text { holding inside trap }\end{array}$ & & \\
\hline
\end{tabular}

Figure 15. Diagram of the symmetry-dominance construction shown in Figures 9-14 


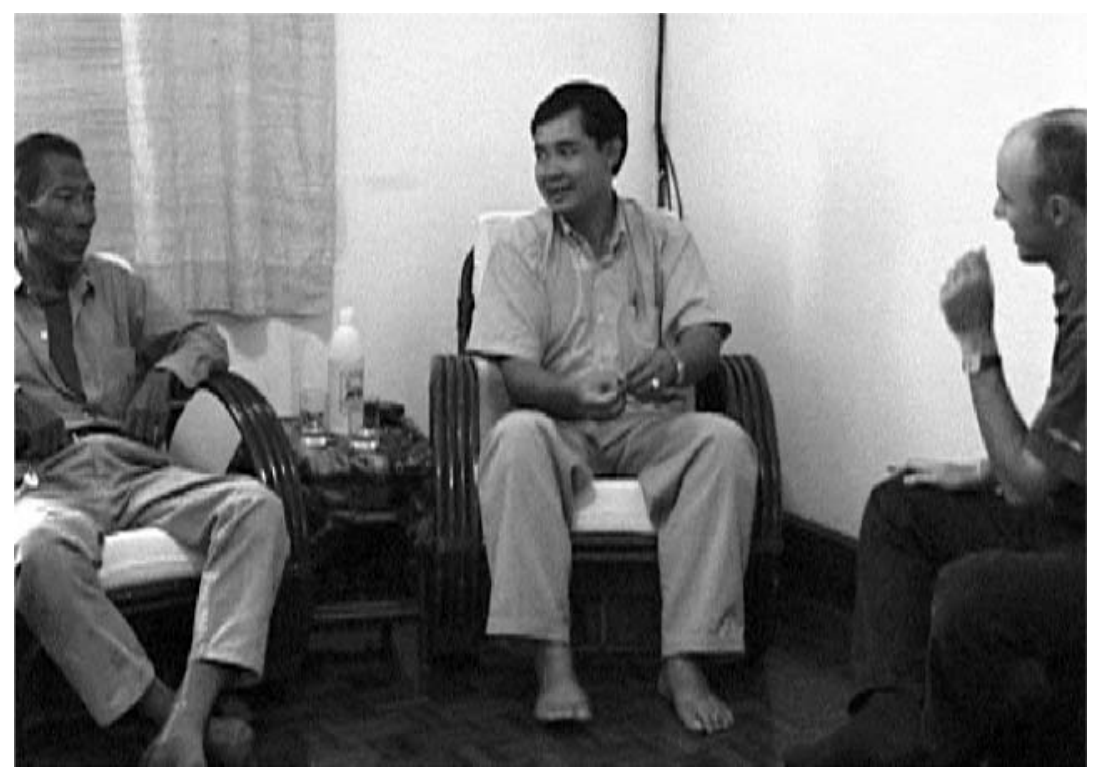

Figure 16. '(You) don't get many (fish), (with) this one, (you) get a little.'

momentarily finished (although the display is not necessarily recognized by addressees as 'significant' in the same way as the intentionally communicative actions preceding it; Kendon 1978: 305). By contrast, the message conveyed by the non-resting posture of a held gesture - as in a dominance phase - is one of 'not putting down' the current topic. The message conveyed by the poised non-dominant hand throughout the dominance-phase illustrated in Figure 15 is that the speaker is not yet done with the topic of the sòn 5 fish trap. Keeping the non-dominant hand 'in play' requires a persistent expenditure of effort, and this serves as a perceptible signal that the information represented is relevant for current discourse purposes (Levy and Fowler 2000).

\section{Speaker 2}

Our second example of a description of the sòon 5 has compelling similarities to the example just discussed. This speaker begins with a description of the overall shape of the conical trap, making a two-handed 3Dtracing gesture running his hands symmetrically forward and upward 
along the body of the imagined trap, from tight-woven base to fluted opening. Eye-gaze follows gesture all the way.

[nòj0-nòòj4 [suaj0-suaj3]
small-RDP taper-RDP vee3 lòò 5 cang1-sii4,
paak5 man2]
mouth 3sG
'(It's) small and tapered, fluted like this, the mouth of it.'

The symmetrical gesture phase depicted in Figures 17 through 19 ends with a hold (shown in Figure 19). This is followed by a long dominance phase, in which the speaker's right hand plays the non-dominant role, maintaining more or less the hand shape established in Figure 19. As in the previous example (cf. Figures 3 through 5 above), the switch into the dominance phase anchors the body of the trap in the non-dominant arm, thus orienting it to the side of the speaker's body rather than to the center (where it seems to be in the first instance; cf. Figures 17 and 18).

The speaker now elaborates on the shape of the trap, using the shape of his non-dominant arm as a point of reference, as he 'shapes' it with his dominant (in this case left) hand (Figure 20).

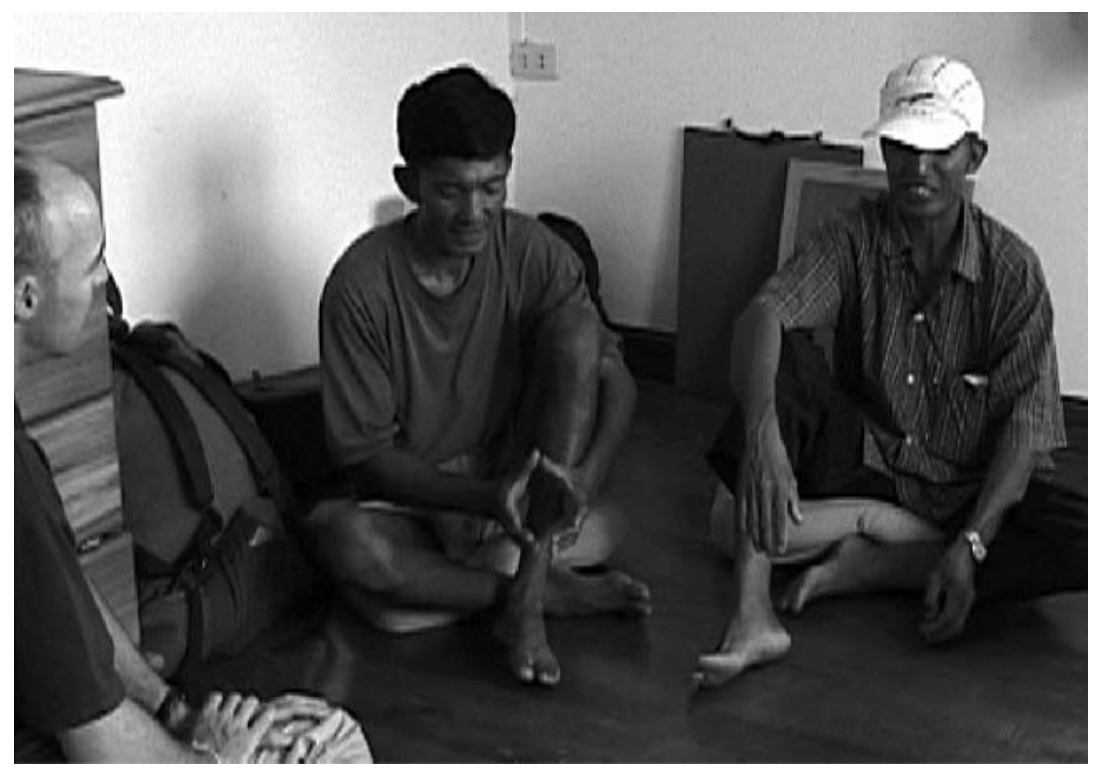

Figure 17. '(It's) small ...' 
$74 \quad$ N. J. Enfield

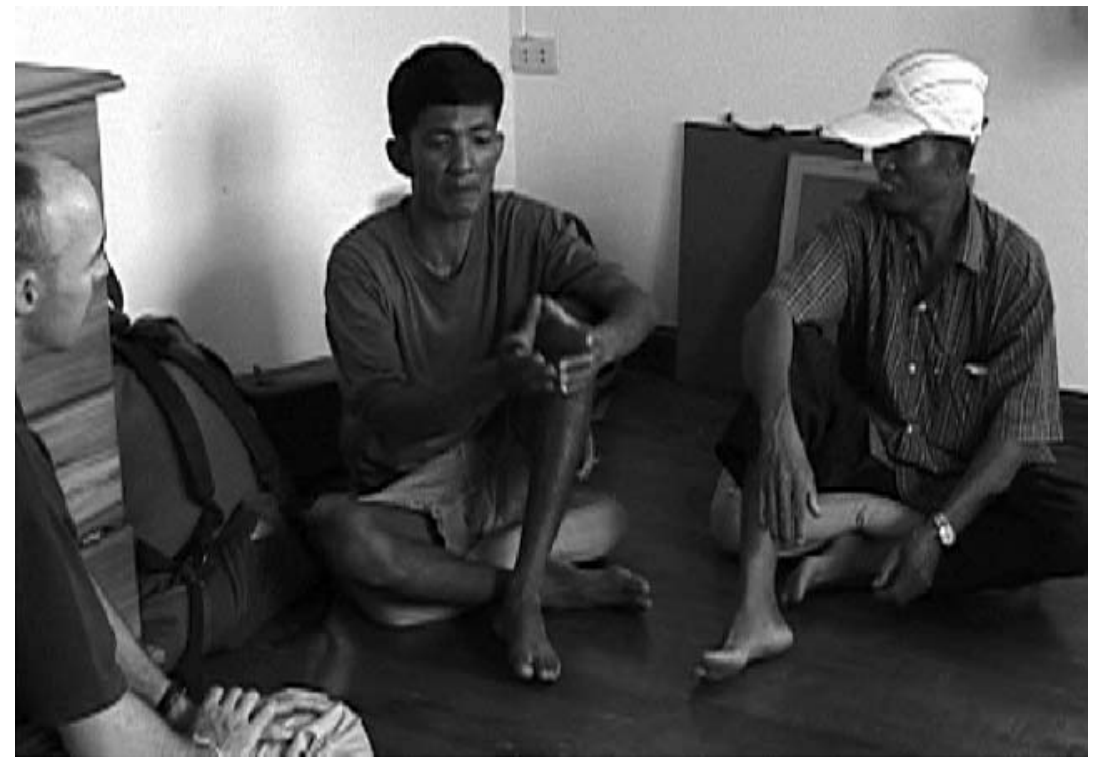

Figure 18. '... and tapered, ...'

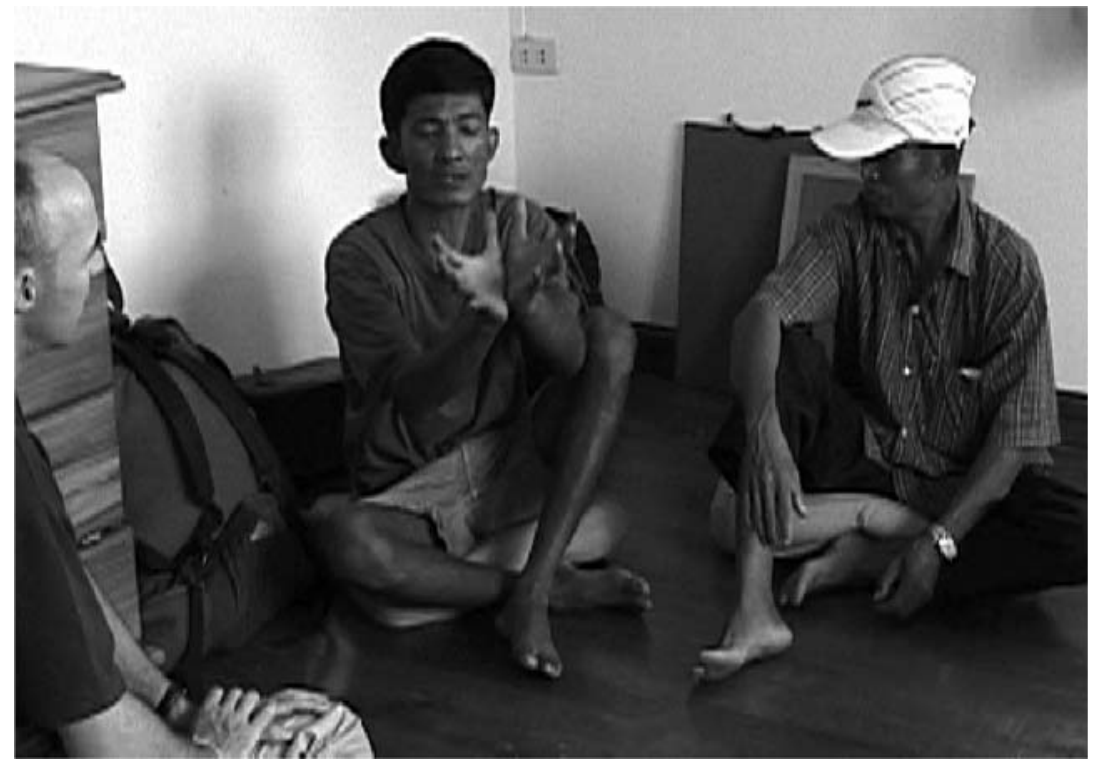

Figure 19. '... fluted like this, the mouth of it.' 


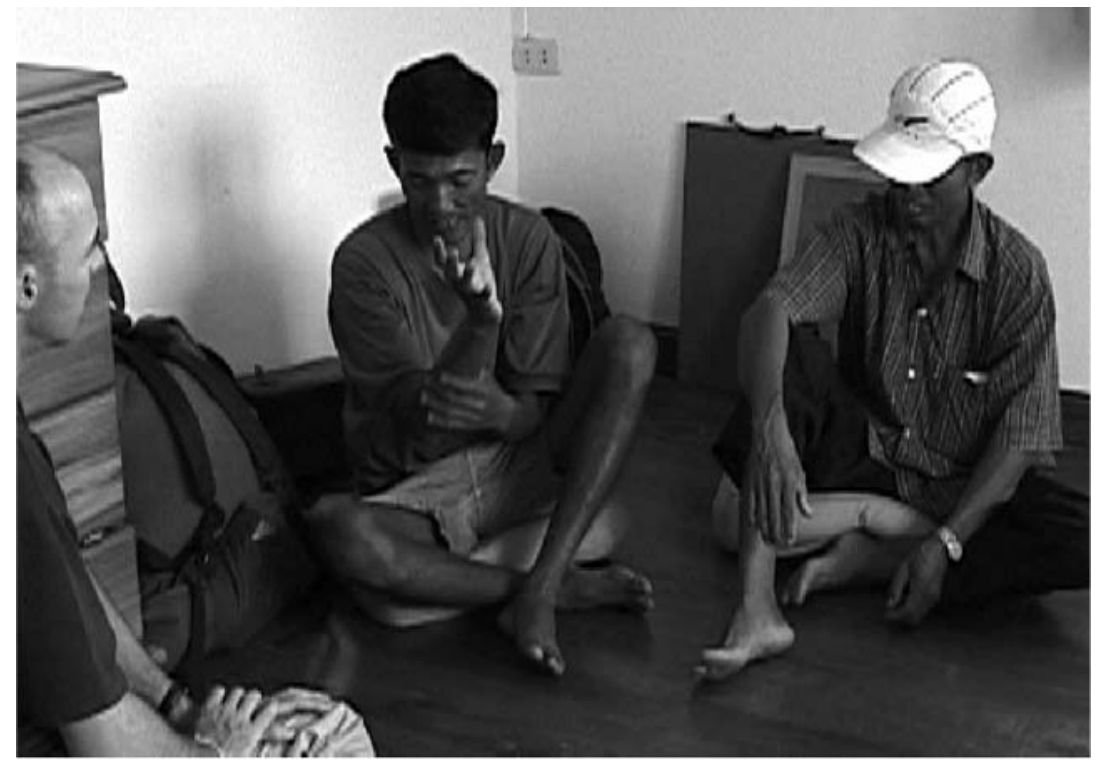

Figure 20. 'And it tapers down like the arm, like this.'

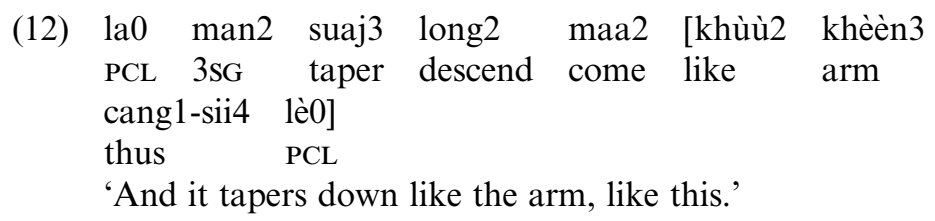

The speaker then turns his attention to the manner in which a fish becomes stuck in the trap. As the next example shows, after a moment of disfluency, he begins explaining the fate of a fish that enters the mouth of the trap. As he utters the key word supl 'inserted', he uses his left (currently dominant) hand to represent the fish moving down and inserting itself inside the trap (cf. Figures 4 through 5 and 10 through 12 above):

(13) qan0-nòj0-nòòj4- khan2-

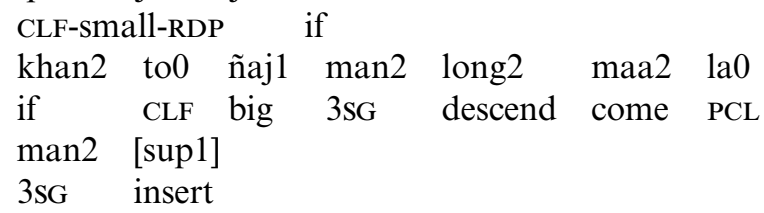

'Smallish ones- If- if a big one it comes down it gets inserted.' 


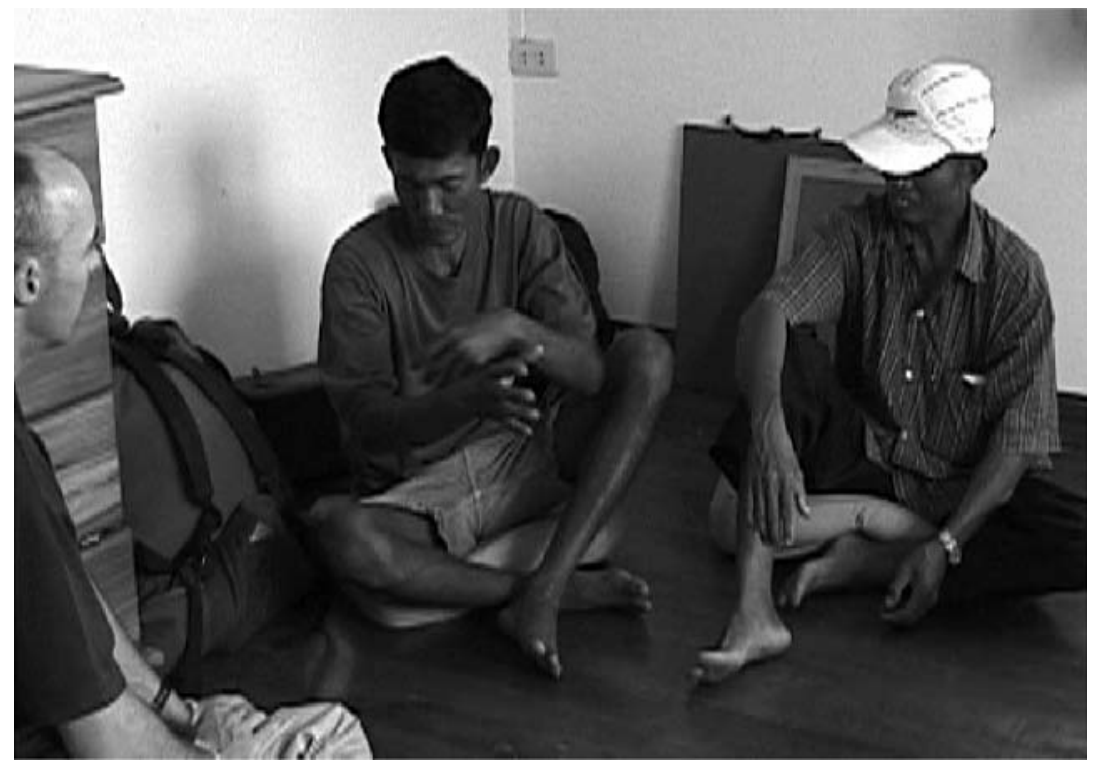

Figure 21. 'Smallish ones- If- if a big one it comes down it gets inserted.'

He remarks that the fish cannot then turn around. As he says this, he works his left elbow back and forth as if trying to extract his left hand (i.e., the fish), without success.

$\begin{array}{lllll}\text { (14) la0 man2 } & \text { [quaj3] } & \text { bò0 } & \text { daj4 } \\ \text { PCL } 3 \text { sG } & \text { turn.around } & \text { NEG } & \text { can } \\ \text { 'and it can't turn around' } & & \end{array}$

He reiterates the consequence of the fish's inability to turn around, namely its inability to get out of the trap. This is accompanied by movement of the left hand forward, upward, along, and finally away from his still held non-dominant (right) arm. This movement represents passage of the fish out of the trap (shown in Figure 23, where the left hand is blurred due to its fast movement away from the speaker). This outward passage is negated in the speech (cf. Figure 13 above).

(15) quaj3

bò0 daj4 thùù3 vaa1 [khùn5] bò0 daj4 turn.around NEG can regard COMP ascend NEG can '(It) can't turn around, that is (it) can't go up.'

The sequence illustrated in Figures 17 through 23 is another typical symmetry-dominance construction, very similar to the one illustrated in 


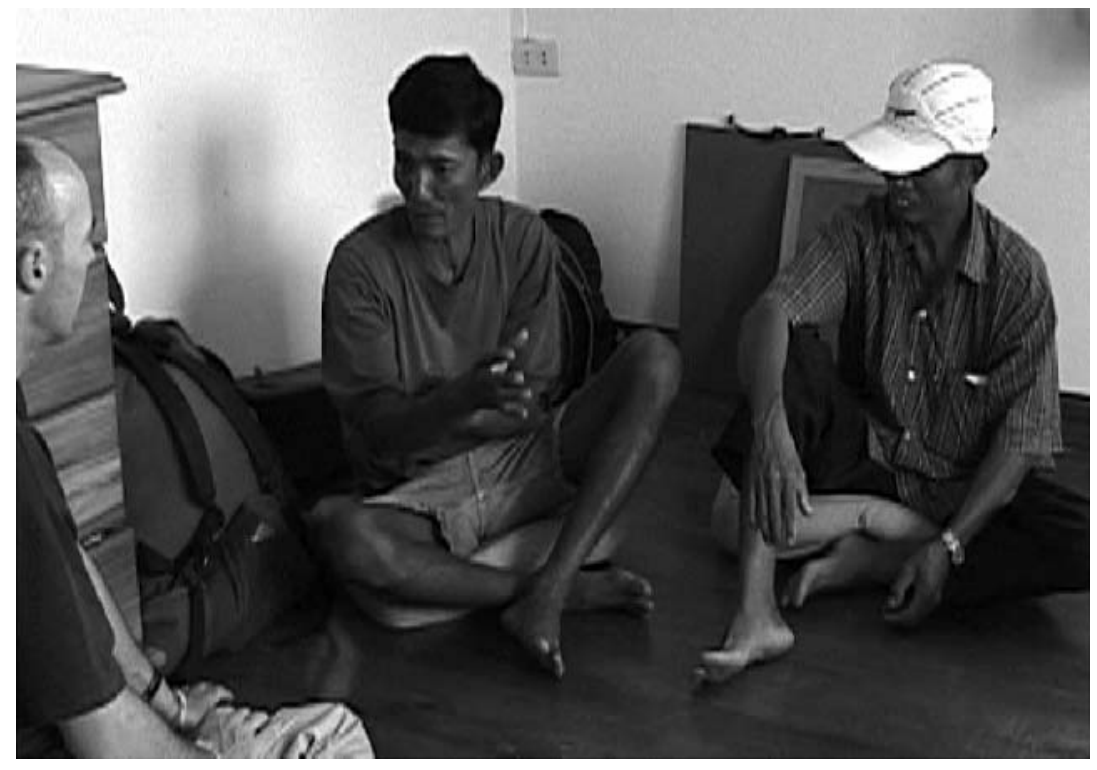

Figure 22. ' $\ldots$ and it can't turn around.'

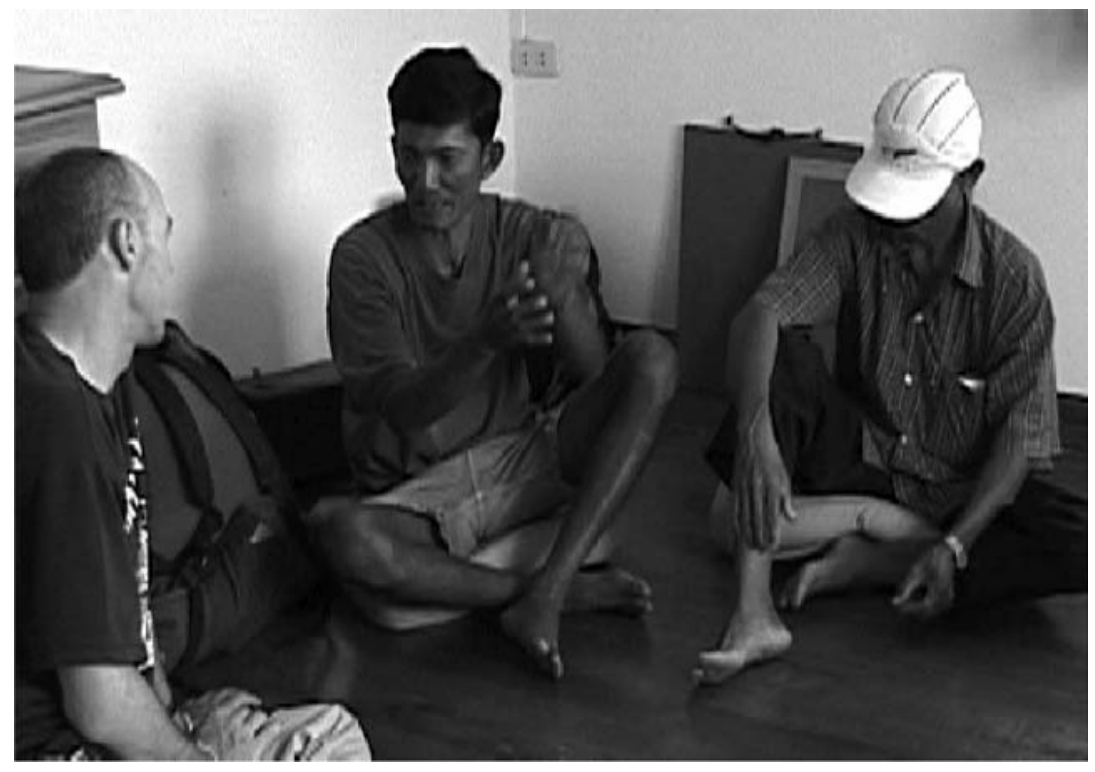

Figure 23. '(It) can't turn around, that is (it) can't go up.' 
Figures 3 through 5 above. In the symmetry phase (Figures 17 through 19), a two-handed gesture establishes size, shape, and overall structure of the artifact. The dominance phase begins when one hand holds still while the other proceeds to make new/focal gestures (beginning in Figure 20). The information that was focal during the symmetry phase now becomes background/topic information for the dominance phase. The nondominant hand indexically, metonymically, represents the larger structure established in the symmetry phase, even though it constitutes literally only half the original signifier.

The speaker now seems to be considering bringing his description to an end. He says 'That one', referring to the trap, as a kind of punctuation mark. This is an idiomatic way of wrapping up a small stretch of discourse in Lao (cf. English That's it.). Suggesting imminent closure of a discourse segment, the speaker brings his hands to a more relaxed position. Note, however, that his non-dominant (right) hand does not go to complete rest, but continues to assume a hand shape much like the one established in the symmetry phase (Figure 19 above), i.e., a slightly clawed 5-hand.

$\begin{array}{ll}\text { [to0-nan0 } & \text { na0] } \\ \text { PCL-DEM.NONPROX } & \text { CLF } \\ \text { 'That one.' } & \end{array}$

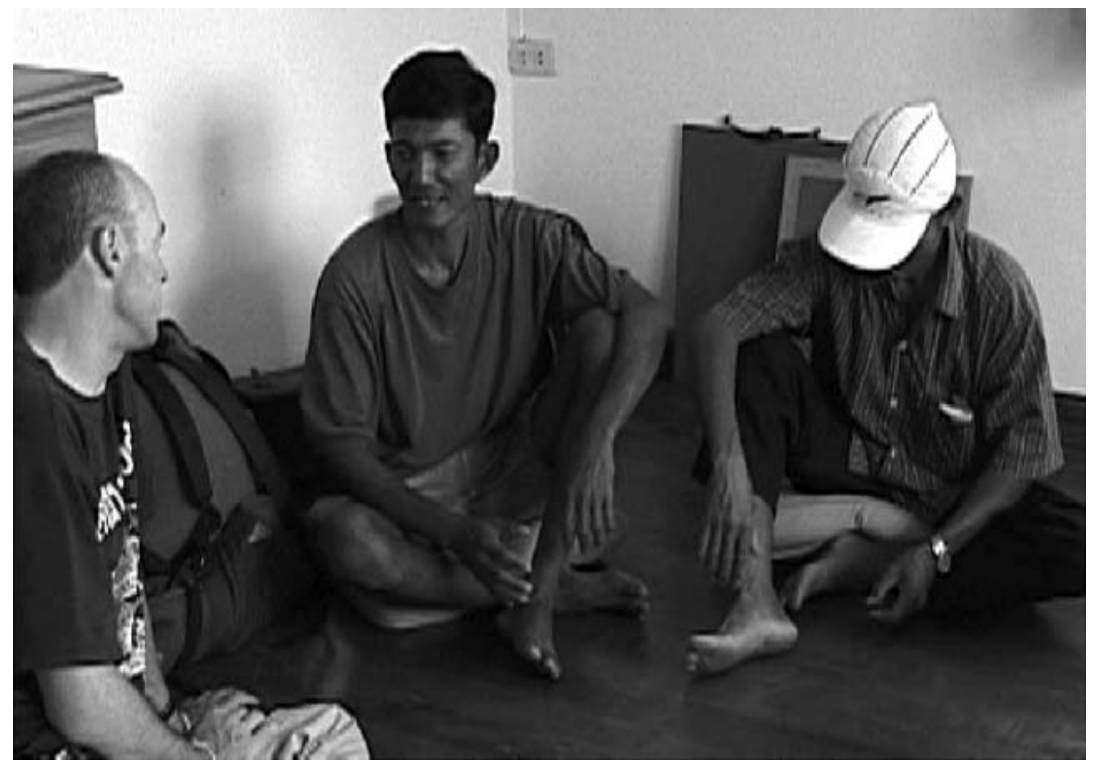

Figure 24. 'That one.' 


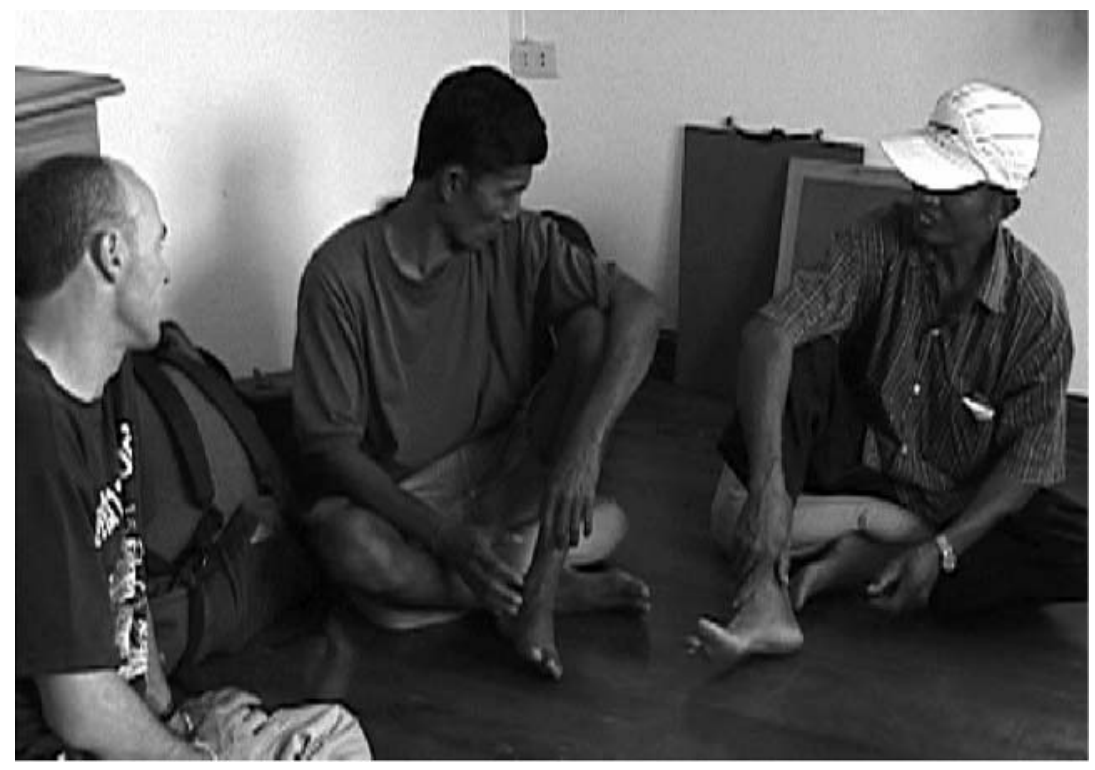

Figure 25. 'A khêng1 fish, why can't it ...'

The speaker is not finished, however. He now elaborates further on a point he has made once already, namely, the inability of the fish to turn itself around inside the trap. But now he assumes a complete change of perspective in representing the scene. He now takes on a 'character perspective' (McNeill 1992) in 'surrogate space' (Liddell 1995). That is, he acts as if his whole body is positioned within the frame of representation, 'on stage', as if he himself is a fish caught in the trap. He mimics the fish's attempts to turn around, by turning his head first to his left (Figure 25) and then his right (Figure 26).

$$
\begin{aligned}
& \text { pa0-khêng1 pên3.ñang3 man2 [quaj3 bò0 daj4] } \\
& \text { CM.fish-sp. why 3SG turn.around NEG can } \\
& \text { 'A khêngl fish, why can't it turn around?' }
\end{aligned}
$$

The speaker explains that the fish's gills are what prevent it from moving backward. As he does so, he points with his left hand to his own neck, i.e., where his gills would be were he a fish (Figure 27).
(18) man2 [khaa2 ngeep4 man2] 3sG stuck gill 3sG
'It's stuck (on) its gills.' 


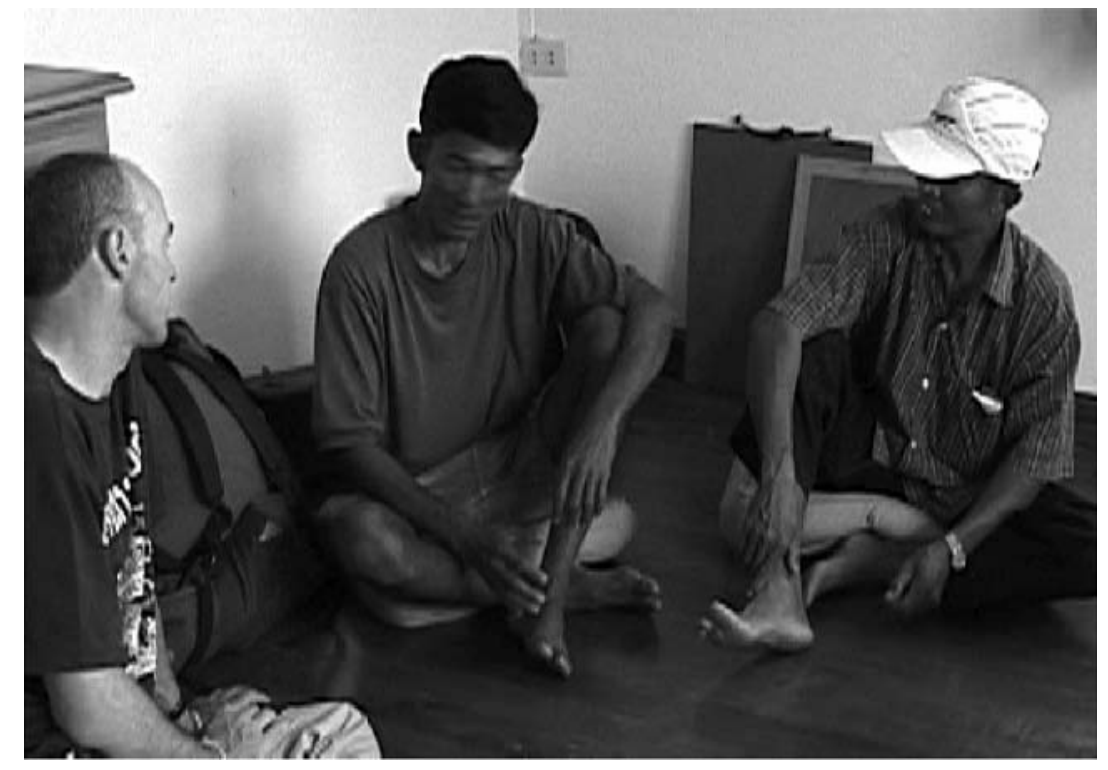

Figure 26. '... turn around?'

In the short sequence shown in Figures 25 through 27, the speaker has made a dramatic change in perspective, but he has nevertheless kept in play the structure that was introduced at the beginning of the sequence (Figures 17 through 19 above). This is achieved by continued visibility of the non-dominant (here, right) hand, which, while lowered in Figure 24, maintains the relaxed 5-hand shape that it inherited from the original symmetrical gesture that began this sequence (Figure 19). The speaker now switches back from this parenthetical stretch in character perspective and adopts once again the earlier 'token space' or 'viewer' perspective. This is done by simply raising the non-dominant hand (without having to adjust its shape) and returning it to its position immediately prior to the aside (i.e., as in Figure 23). The speaker thus brings the temporarily backgrounded trap back 'on stage', where it now may serve as a frame for further elaboration of how it is that a fish gets stuck in this type of trap. The speaker's following comments are accompanied by a gesture whereby the dominant (left) hand represents a fish coming down into the trap (Figures 28 and 29).

(19) man2 qaw3 [hua3 long2] 3SG take head descend 'It goes down head first.' (lit. 'It descends with the head'.) 


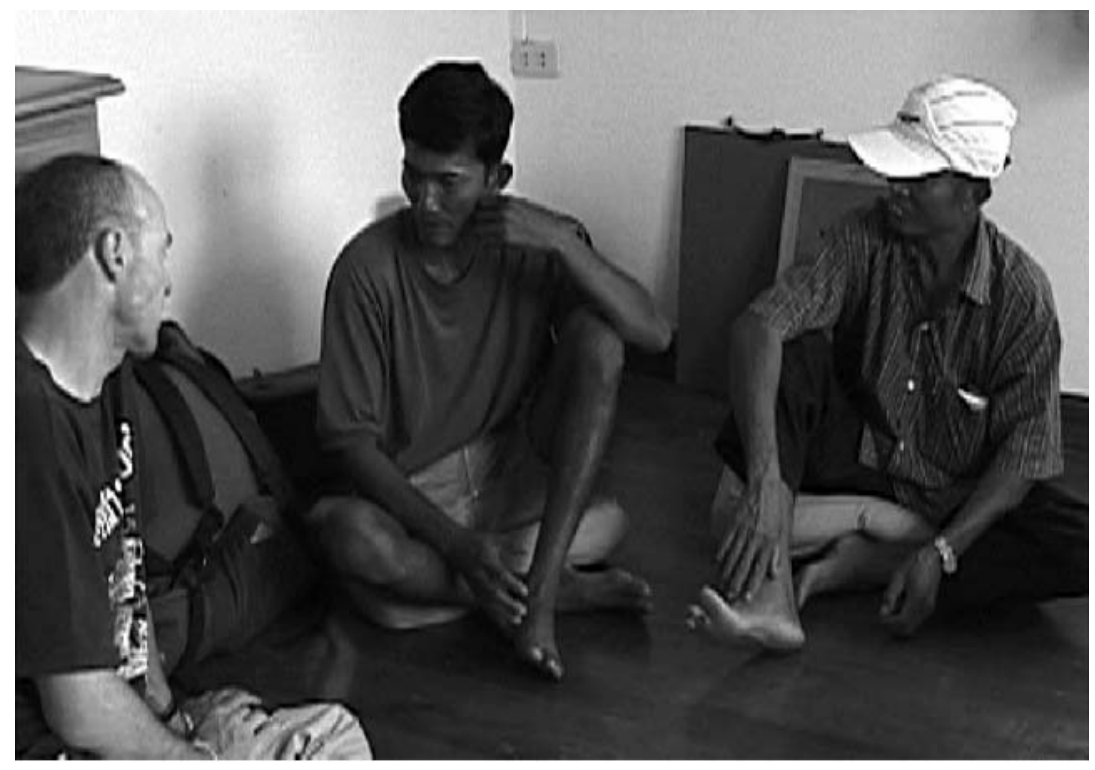

Figure 27. 'It's stuck (on) its gills.'

The non-dominant hand alone is enough here to representationally invoke the entire trap. It represents only one half of the signified object, but by a metonymic relation to the fuller representation shown in Figure 19 above, it is able to represent the whole of it. In Figures 28 and 29, this is necessary, because the speaker does not have three hands (i.e., two to represent the trap as in Figure 19, and one to represent the fish going in). In this way, representational constraints of the manual/visuospatial modality force segmentation and linearization of information. The speaker first establishes the larger structure with full use of manual/visuospatial resources (Figures 17 through 19). Subsequently, half of these resources are kept in play, thereby serving to remind the addressee (and probably the speaker himself) of that larger structure. The other half of the resources used in the first stage are now freed for representational elaboration. For this to work, two things are presupposed. Addressees must be able to retrieve reference to larger structures when they are only partially represented by available signifiers (i.e., they must be able to comprehend metonymic relations). Second, and relatedly, distinct gesture structures must be viewable as semiotically/structurally dependent across time. The half-signifier structure in the second stage (Figure 20 onward in this diagram) would be hard to comprehend unless you had already been ex- 
82 N. J. Enfield

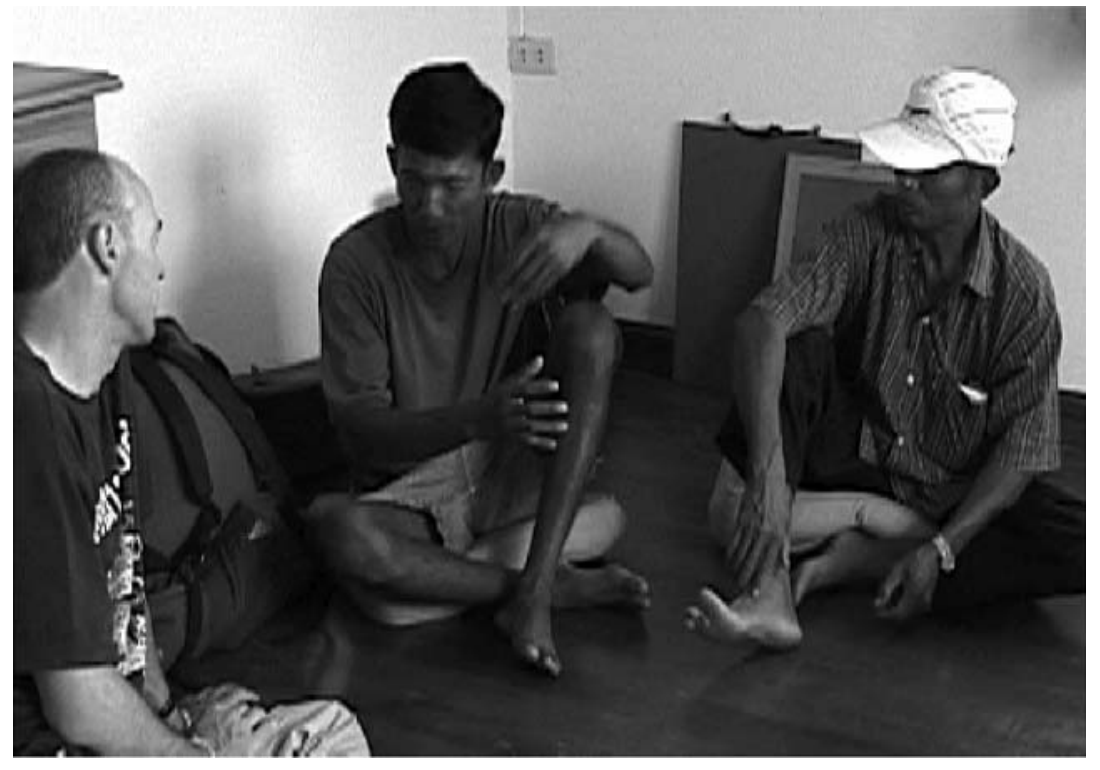

Figure 28. 'It goes down ...'

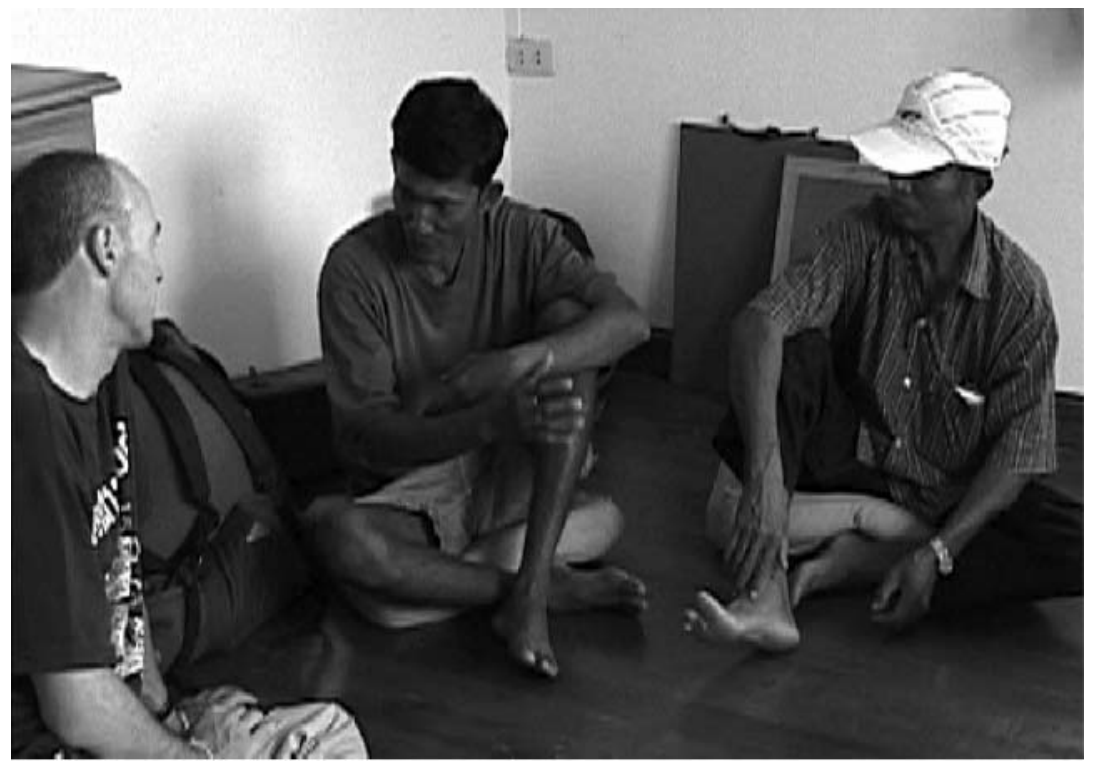

Figure 29. '... head first.' 
posed to the first stage of fuller representation (Figures 17 through 19). During the dominance phase, the non-dominant hand is syntactically subordinate to the two-handed gesture in the preceding symmetry phase. Here, gesture performs a kind of 'simultaneous construction' (cf. the same in sign language; Engberg-Pedersen 1994; Miller 1994), as part of a larger interclausal structure that strives to conform to principles governing the supply of information over time. It is because the trap was 'fully' represented by the symmetrical gesture that opened this sequence (Figures 17 through 19) that it could later be evoked by the presence of one hand only (Figure 20 onward).

The speaker now moves toward completion of his description. As he utters the following, he performs a gesture that is a repeat of Figures 28 and 29 (gesture not shown here due to space limitations):
qaw3 too3 long2 man2 tòòng qaw3 hua3 long2 take body descend 3SG must take head descend '(To) get (its) body down, it must take (its) head down (first).'

The speaker once again lets both hands down, yet still does not abandon the hand shape assumed by the non-dominant hand.

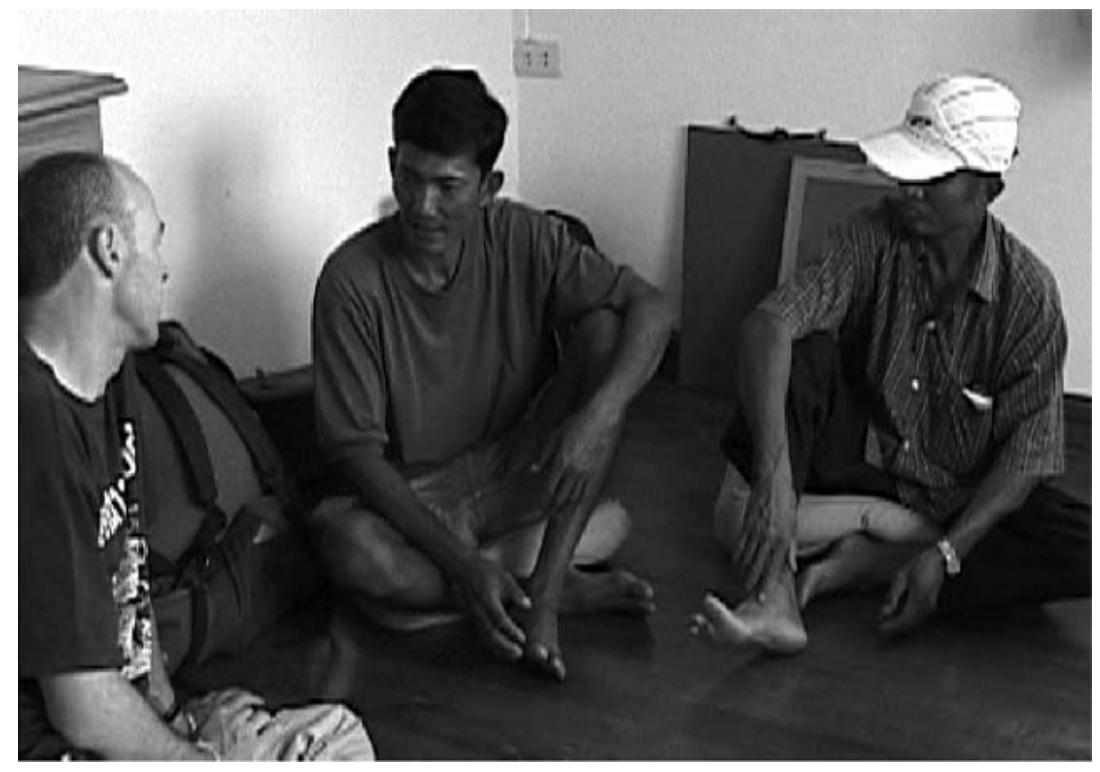

Figure 30. 'And they- they can't get out, (of) that one.' 
(21) la0 man2- man2 khùn5 bò0 daj4, qan0-nan0 PCL 3SG 3SG ascend NEG can CLF-DEM.NONPROX 'And they- they can't get out, (of) that one.'

The speaker is now finished with his account of the sònn. His closure of this sequence involves a repeat of the name of the trap - again as a kind of punctuation mark - as he finally disengages the non-dominant (right) hand from its persistent representational role, using it now to scratch his left arm, thus causing there to be no longer any perceptible trace of the referent that was established in Figure 19 and that had persisted up until this point.

(22) sòòn5

sòòn 5

'(That's the) sòon5.'

The following diagram depicts the entire sequence, illustrated in Figures 17 through 31 and accompanying linguistic examples. The symmetry-dominance construction is observable as a tall 'half- $T$ ' shape.

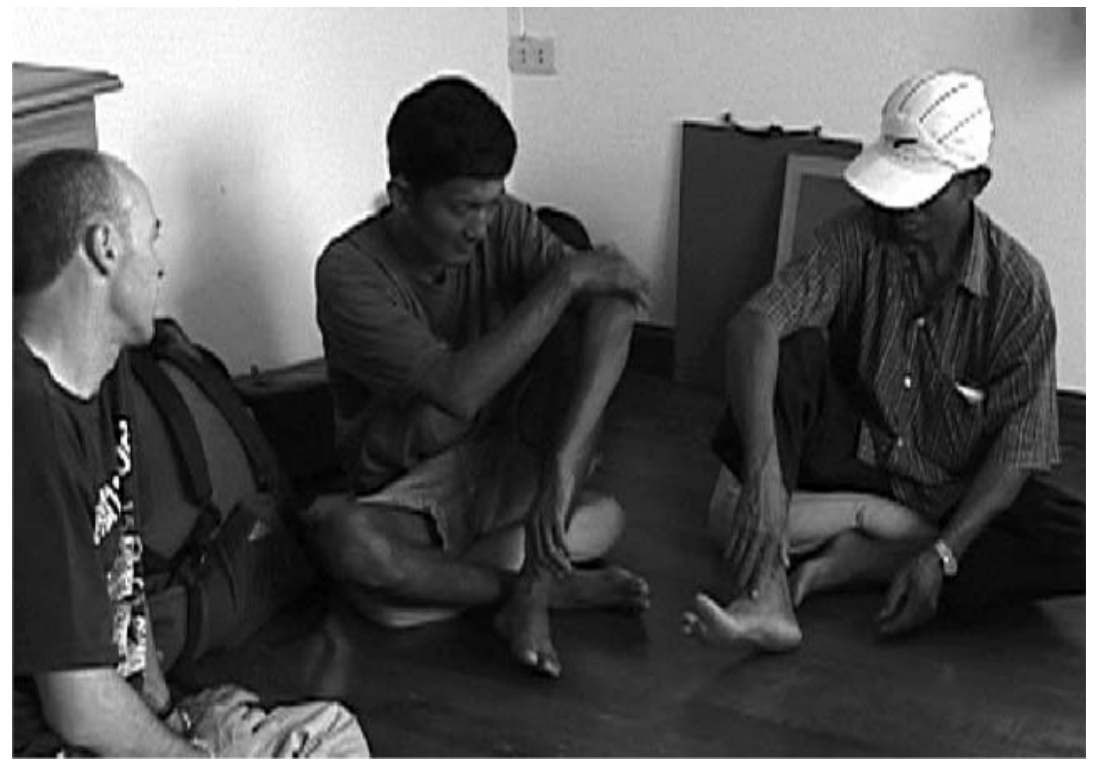

Figure 31. '(That's the) sòòn5.' 


\begin{tabular}{|c|c|c|c|}
\hline Illustration & HR & HL & Speech \\
\hline Figs. $17-19$ & $==\mathrm{HL}$ & $\begin{array}{l}\text { 3D-trace, merging into depiction of } \\
\text { mouth of trap }\end{array}$ & $\begin{array}{l}\text { '(It's) small and tapered, fluted like } \\
\text { this, the mouth of it.' }\end{array}$ \\
\hline Fig. 20 & $\begin{array}{l}\text { HOLD as } \\
\text { previous }\end{array}$ & $\begin{array}{l}\text { running hand along HR arm to } \\
\text { demonstrate tapering }\end{array}$ & $\begin{array}{l}\text { 'And it tapers down like the arm, } \\
\text { like this.' }\end{array}$ \\
\hline Fig. 21 & & depiction of fish going into trap & $\begin{array}{l}\text { 'Smallish ones- If- if a big one } \\
\text { come down it gets inserted' }\end{array}$ \\
\hline Fig. 22 & & depiction of fish trying to turn & 'and it can't turn around' \\
\hline Fig. 23 & & depiction of fish going up out of trap & $\begin{array}{l}\text { '(It) can't turn around, that is (it) } \\
\text { can't go up.' }\end{array}$ \\
\hline Fig. 24 & (lowers) & TO REST & 'That one.' \\
\hline Figs. $25-26$ & & $\begin{array}{l}\text { moving head to left then to right, taking } \\
\text { character perspective (self as fish) }\end{array}$ & $\begin{array}{l}\text { 'A khêngl fish, why can't it turn } \\
\text { around?' }\end{array}$ \\
\hline Fig. 27 & & pointing to own neck (fish's gills) & 'It's stuck (on) its gills.' \\
\hline Figs. $28-29$ & (lifts) & depiction of fish going into trap & 'It goes down head first.' \\
\hline (not shown) & & depiction of fish going into trap & $\begin{array}{l}\text { '(To) get (its) body down, it must } \\
\text { take (its) head down (first).' }\end{array}$ \\
\hline Fig. 30 & (lowers) & TO REST & $\begin{array}{l}\text { 'And they- they can't get out, (of) } \\
\text { that one.' }\end{array}$ \\
\hline Fig. 31 & TO REST & as previous & '(That's the) sò̀n5.' \\
\hline
\end{tabular}

Figure 32. Diagram of the symmetry-dominance construction shown in Figures 17-31 


\section{Example 2 - tum4 thoong2}

The tum4 thoong2 is a rare and old-fashioned type of large basket-woven fish trap.

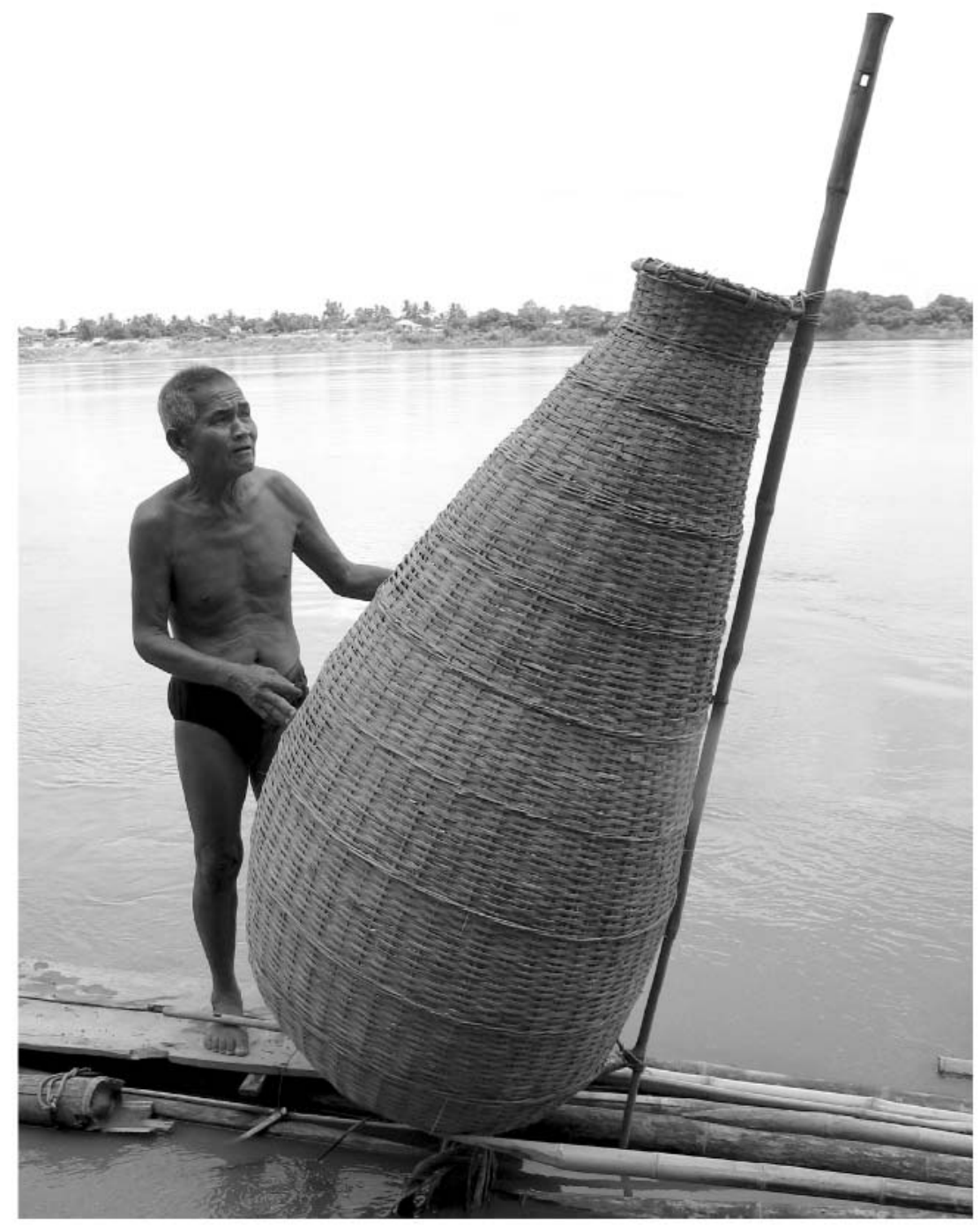

Figure 33. Resident of a village near Vientiane, Laos, prepares to place a tum4 thoong2 in the Mekong River. The trap's base features an open hole with inward/upward pointing 'tusks'. 
It is a type of tum4 'upright basket trap'. The tum4 thoong2 is more or less spherical, but with an opening of about 6 inches in diameter in the base. Around the rim of this opening, 'tusks' stick up into the interior of the trap, allowing fish to enter the opening easily but exit with difficulty. A long stake is tied on fast to the trap body, such that the stake protrudes from both above and underneath the trap body. The stake is then wedged into a riverbed, such that the trap is fully submerged, but suspended above the riverbed. The entry through the base of the trap is poised 6 inches or so above the river floor. Bait is placed inside the trap, around the entry hole, enticing fish to enter the trap from below. After fish are inside the trap, they are free to swim around in the large, open body of the trap interior. They are unlikely to escape, thanks to the uninviting inward-pointing 'tusks' surrounding the entry hole.

I now describe excerpts from two different speakers' descriptions of this trap.

\section{Speaker 1}

In the first part of this sequence, the speaker discusses the type of location where a tum 4 thoong 2 would normally be placed and elaborates on the manner of fixing it to the riverbed. We begin here at the point when he starts to discuss the shape and structure of the trap and the manner in which fish find themselves caught in it. The speaker makes a complex symmetrical gesture, first a 3D-trace of the body of the trap (Figures 34 and 35), followed by a two-handed depiction of the circular hole at the base of the trap (each hand representing one half of the hole), with upturned fingers standing for the 'tusks' around the entry hole (Figures 36 and 37).

$\begin{array}{llllll}\text { tum1 } & \text { [bak2]-[ñaj1] } & \text { la0 } & \text { [hêt1] } & \text { [ngaa2 } & \text { saj1 } \\ \text { upright.basket.trap } & \text { very-big } & \text { PCL } & \text { make } & \text { tusk } & \text { put } \\ \text { thaang2 lum1] } & & & & & \\ \text { direction below } & & & & & \end{array}$

'(It's a) big tum, and (they) make tusks at the base.'

In Figure 37, the speaker is depicting the 'tusks' at the trap base that allow fish easily up and in, but not easily out. This is a symmetrical pose, forming the entry to a dominance phase. The speaker now holds his left hand in place, representing the topical element of the opening in the trap's base, while using his right hand to introduce new and focal information (matching the speech), enacting with a counter-clockwise circular motion the placement of bait in the area around the hole on the interior floor of the trap. 
88 N. J. Enfield

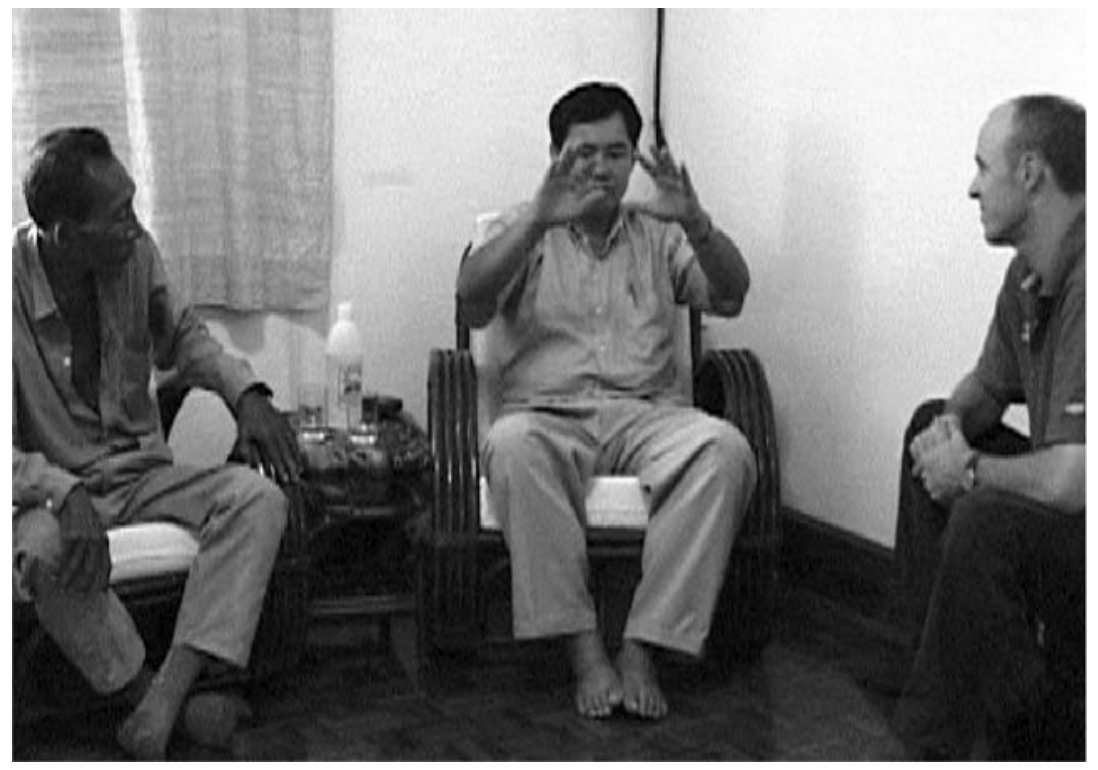

Figure 34. '(It's a) big ...'

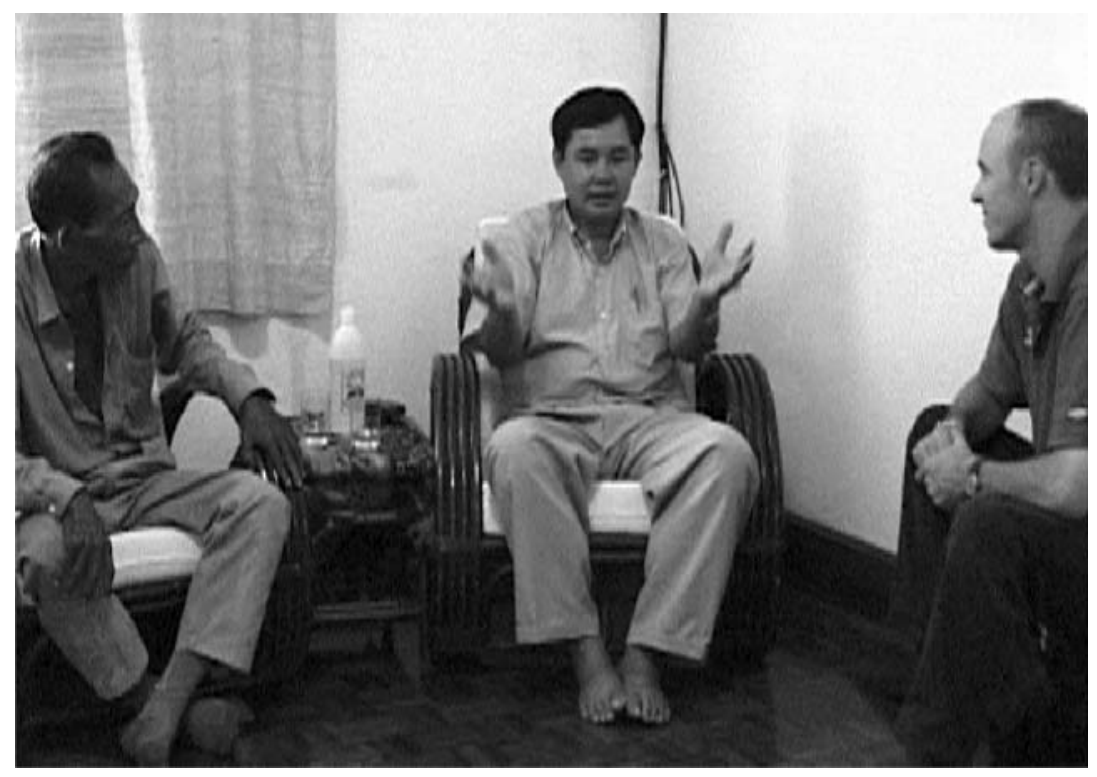

Figure $35 . \quad$. . . tum, ...' 


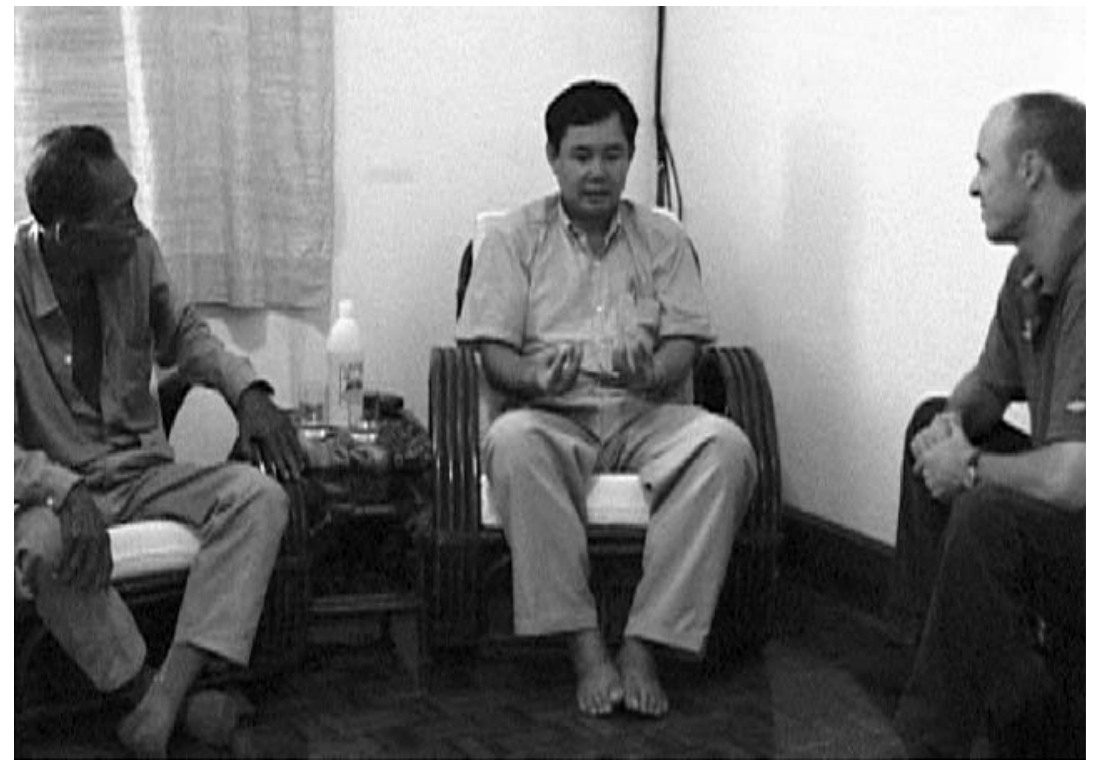

Figure 36. '... and (they) make...'

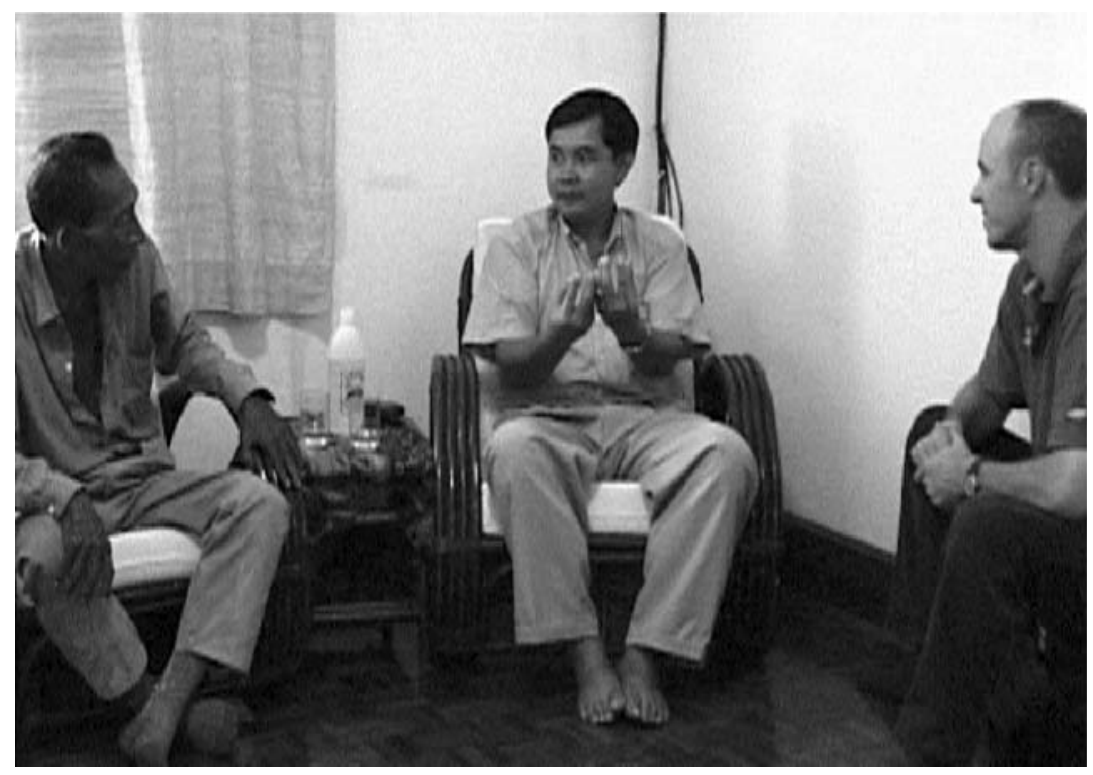

Figure 37. '... tusks at the base.' 


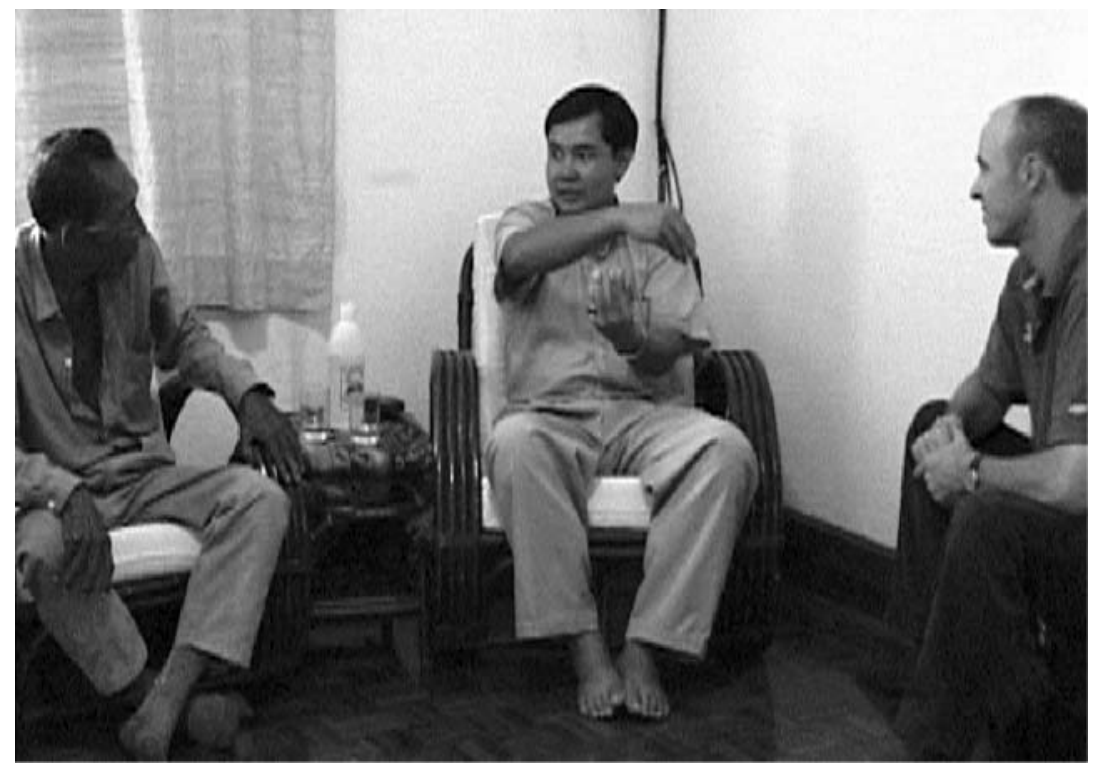

Figure 38. '(They) take toasted rice...'

qaw3 [khaw5-ciil] [saj1 han0]
take rice-toast put there
'(They) take toasted rice (and) put (it) there.'

This is another typical example of the symmetry-dominance construction as observed in these recordings (cf. Figures 6, 15, and 32 above). Figure 40 shows it in diagrammatic form.

The speaker next elaborates on a number of matters, which for reasons of space I will summarize here. He talks about placing the bait, in preparation for lowering the trap into the water and fixing it to the riverbed by means of a stake fixed on to it. The speaker elaborates on how the stake is tied to the trap and how the stake is measured such that the trap will be positioned at the right height in the water.

Now the speaker is going to describe the manner in which he lowers the trap (which is now tied on to a long stake) down into the water. The speaker's representation of this event is a semiotic composite consisting of a strip of speech and a two-handed gesture. The gesture is not literally symmetrical, but it does feature the two hands signifying a single idea (by enactment of the activity of lowering the trap down into the water; Figure 41). 


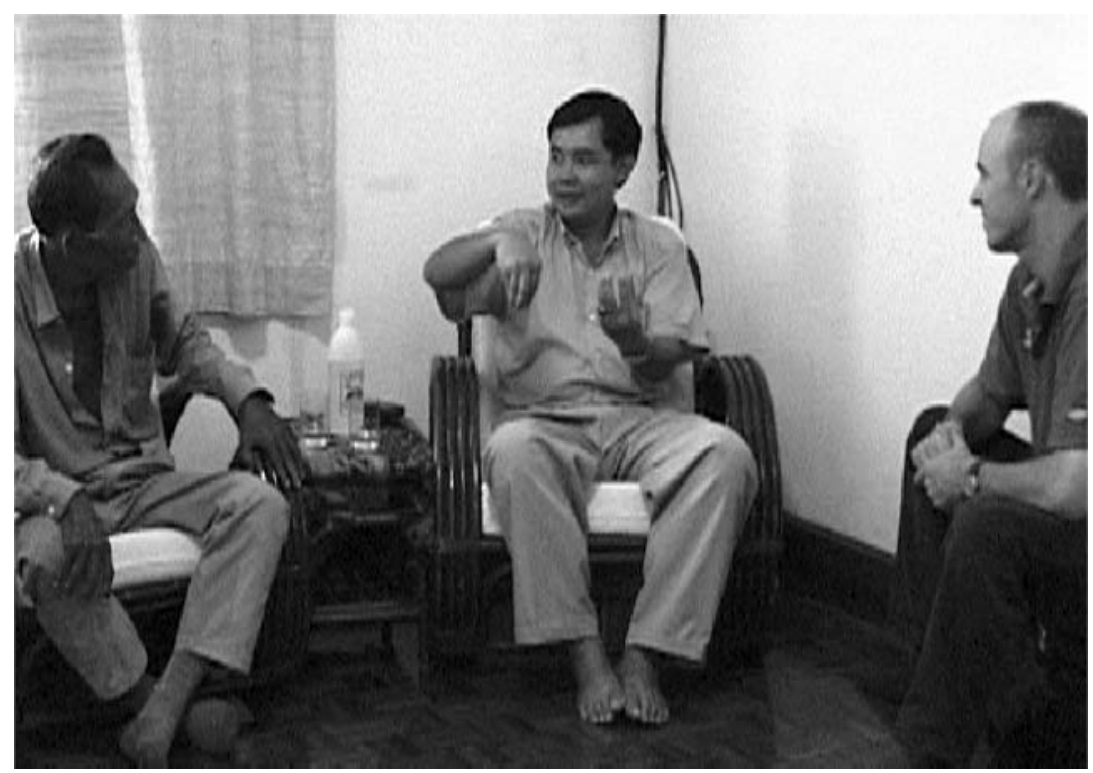

Figure 39. '... (and) put (it) there.'
(25) pòòn1 long2 paj3 taam3 qan0 [lak2] han0 lè̀w4 feed.in descend go follow PCL.HES stake PCL PFV paj3-
go

'(We) feed (it) down along um the stick, and then (we) go (and)-'

Then, the right hand is held, and with his left hand now in a B-hand shape (i.e., flat palm and extended fingers, fingers together), palm-down, fingers pointing forward, the speaker depicts the riverbed (Figure 42). Why does he choose to use his left hand for this dominance-phase move? He may be anticipating an immediate reversal of role of his left hand, from its status as the one active hand in a phase immediately following a two-handed gesture (Figure 42) to its status as the non-dominant hand, constituting a spatial and discourse-topical point of reference for a long series of right-hand gestures to come (beginning in Figure 43):

(26) ka 0 [qan0-nii4 mèèn1 mèèn 1 mèèn1 mèèn1] PCL CLF-DEM.GEN be be be be [khii5-din3] earth

'So, this is- is- is- is the earth.' 


\begin{tabular}{|c|c|c|c|}
\hline Illustration & HR & HL & Speech \\
\hline Figs. 34-35 & $\begin{array}{c}\text { 3D-trace, creating large } \\
\text { spherical object in } \\
\text { centre front }\end{array}$ & $==\mathrm{HR}$ & '(It's a) big tum4, \\
\hline Figs. 36-37 & $\begin{array}{l}\text { depicting fingers up } \\
\text { imitating 'tusks' at base } \\
\text { of trap }\end{array}$ & $==\mathrm{HR}$ & and (they) make tusks at the base.' \\
\hline Figs. 38-39 & $\begin{array}{l}\text { enacting, circling, } \\
\text { imitating placement of } \\
\text { bait around hole }\end{array}$ & $\begin{array}{c}\text { HOLD as } \\
\text { previous }\end{array}$ & '(They) take toasted rice (and) put (it) there.' \\
\hline
\end{tabular}

Figure 40. Diagram of the symmetry-dominance construction shown in Figures 34-39 


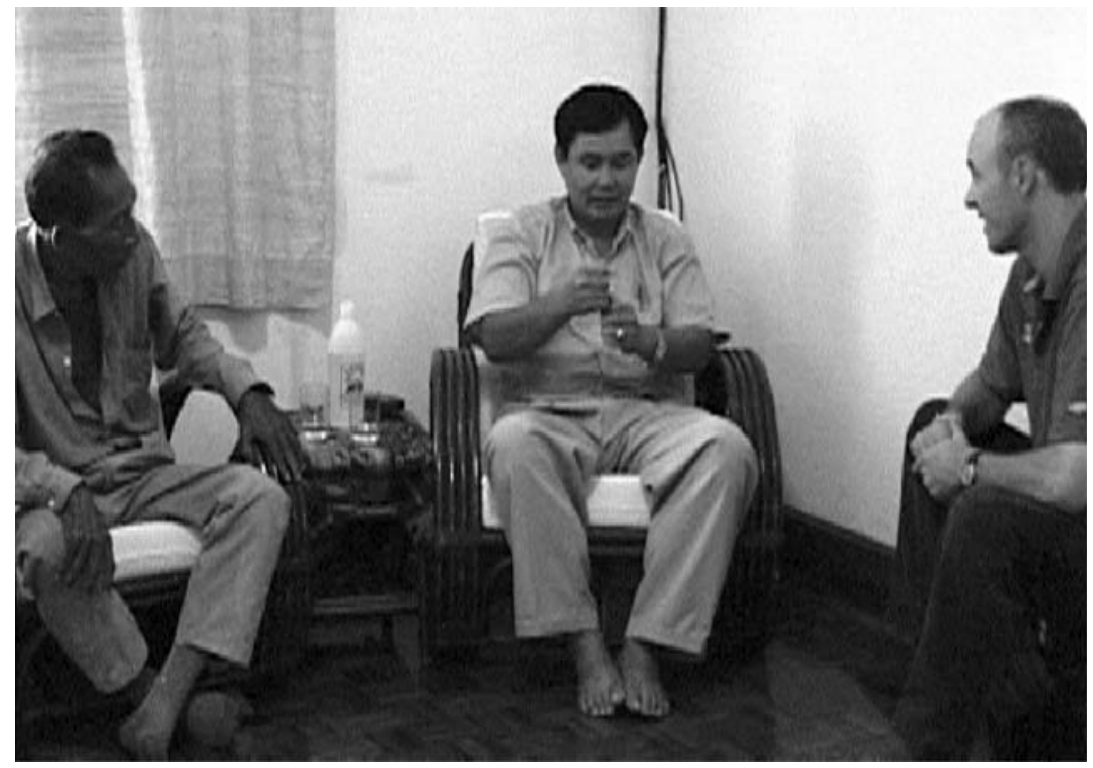

Figure 41. '(We) feed (it) down along um the stick, and then (we) go (and)-'

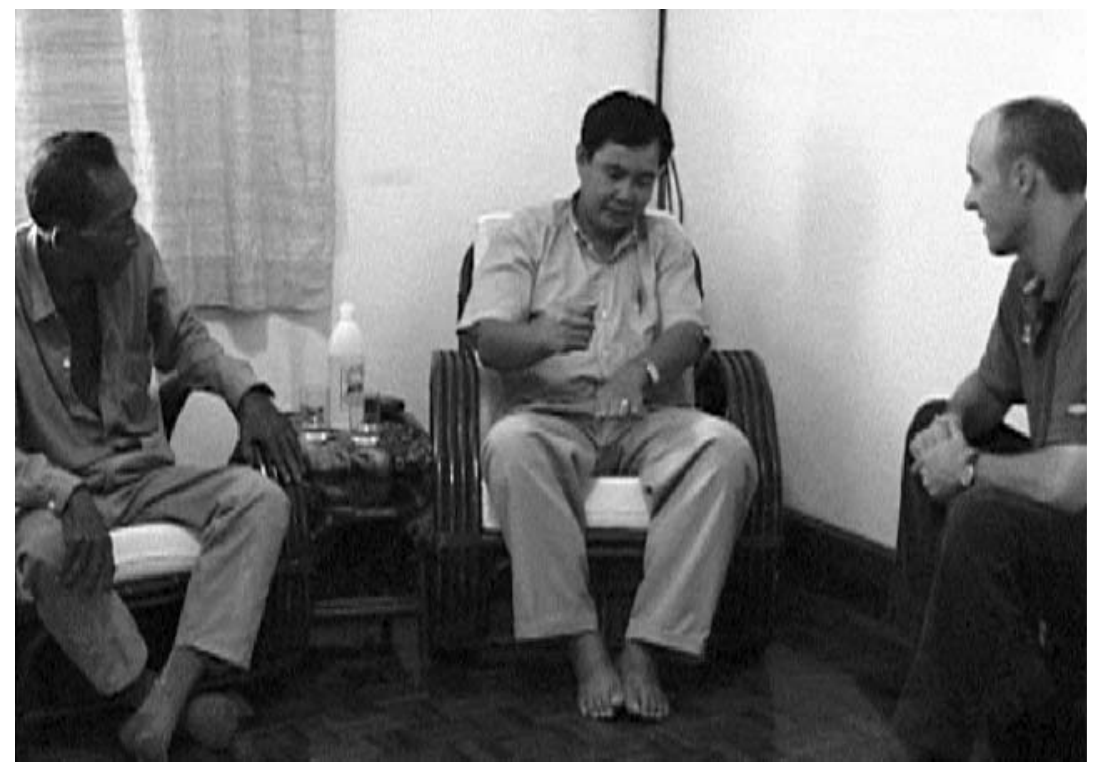

Figure 42. 'So, this is- is- is- is ...' 


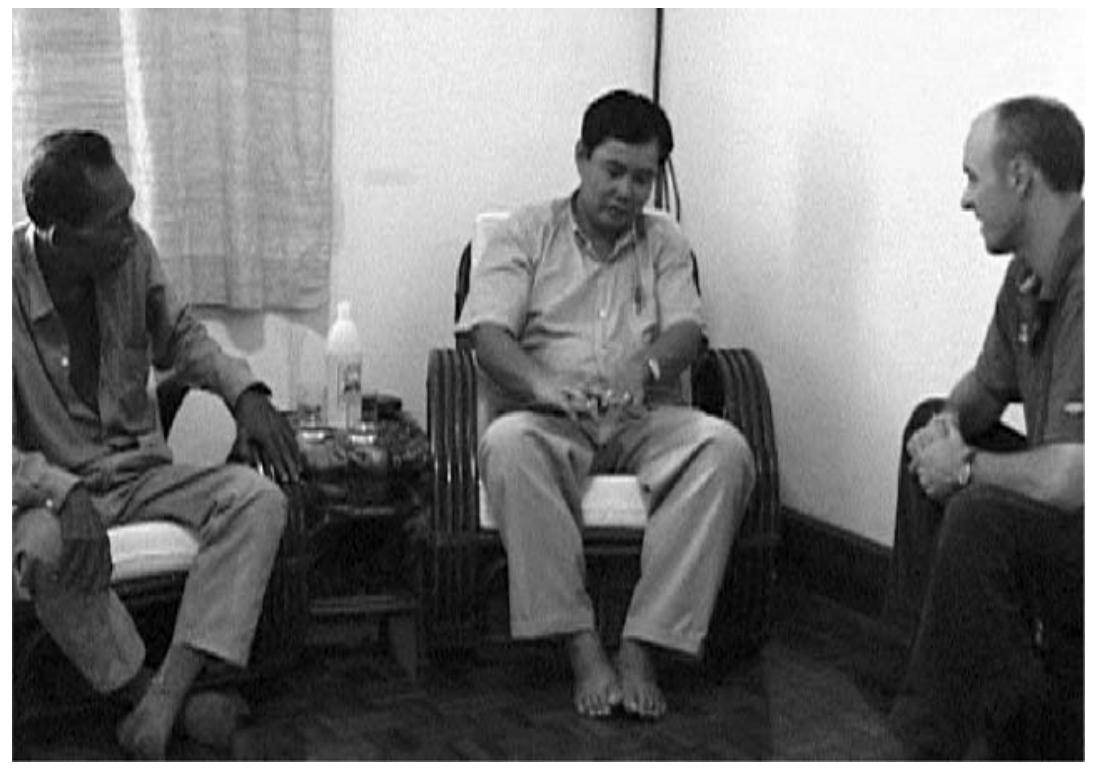

Figure 43. '... the earth.'

He says in clarification that by 'earth' he means the earth at the riverbed. Then he wants to say that the trap is lowered until there is a gap of 6 inches or so between the trap's base and the riverbed. In representing this, he makes a held gesture with his right hand (like the left hand, in a B-hand shape, palm-down, fingers pointing forward), poised 6 inches or so above the already held left hand (Figure 44). The right hand depicts the trap's base while the left hand depicts the riverbed. Note the gaze on the speaker's own gesture, here and throughout this section.

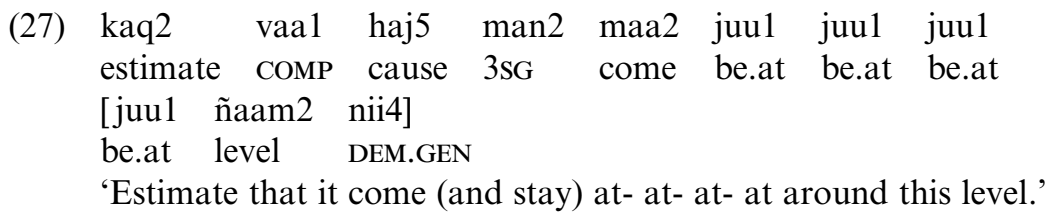

He repeats that the trap should stay at around the level depicted and then elaborates on the question of the space between the trap base and the river floor. As he makes the following statement he moves his right hand directly down, maintaining its posture (as in Figure 44), until it meets the left hand, depicting the non-desired situation in which the trap base touches the riverbed (Figure 45). 


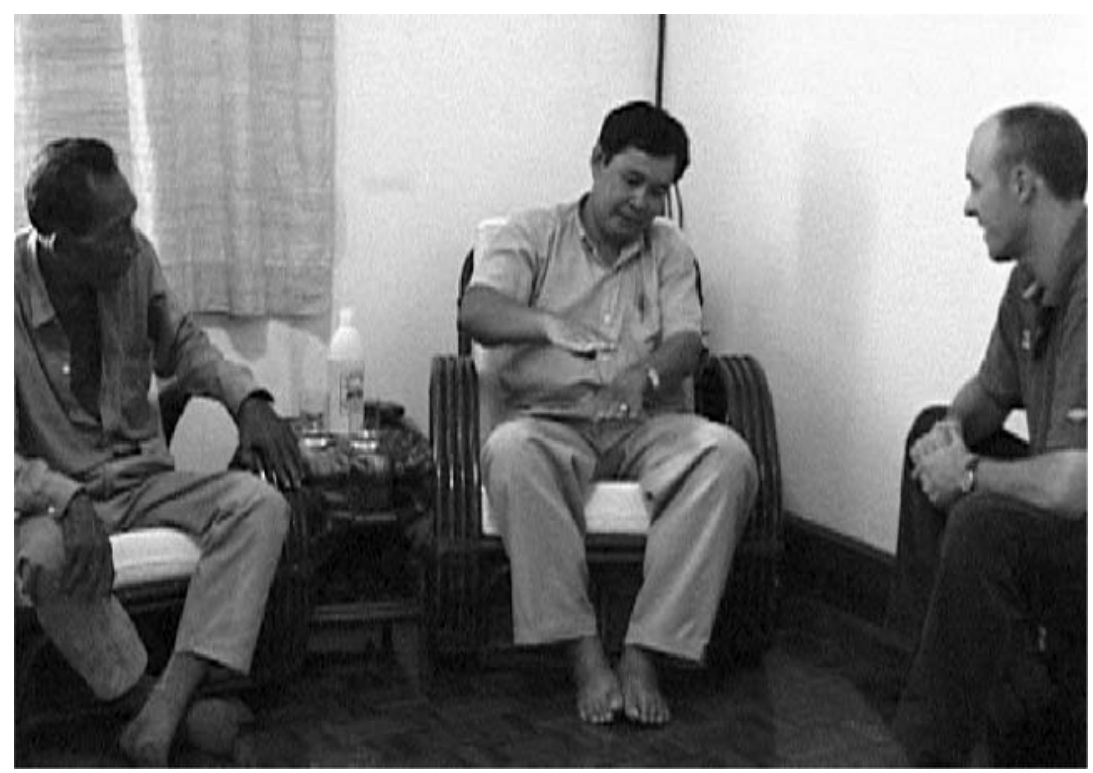

Figure 44. 'Estimate that it come (and stay) at- at-at-at around this level.'
(28) khan2 [cam1 laaj3] man2 ka0 khaw5 bò0 daj4 if close/tight very 3SG PCL enter NEG can 'If (it) is very close (to the riverbed), then it [i.e., the fish] can't get in.'

I then ask him to confirm that the fish are meant to enter the trap through the hole in the base. He replies 'yes' and then elaborates. With his held left hand still representing the earth floor of the river, he depicts with his right hand a fish swimming along the riverbed (Figure 46), in through the base of the trap (Figure 47), and up into the interior of the trap (Figure 48).

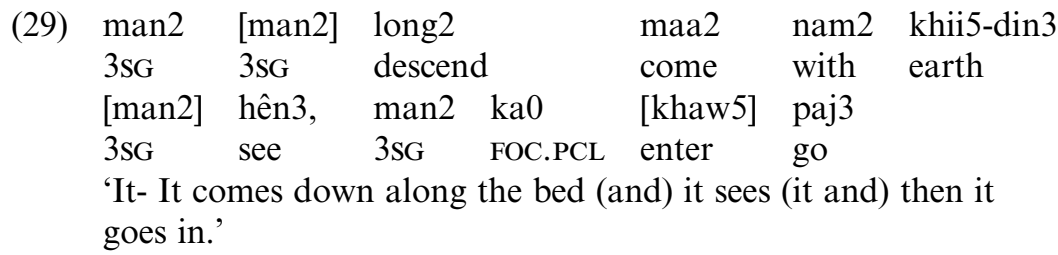

He then adds that the fish will eat the bait, before uttering a discourse marker qee5 'yeah', as if closing down this section of the discourse. In accordance with a closure of topic, he lets his right hand go to rest. Note 
96 N. J. Enfield

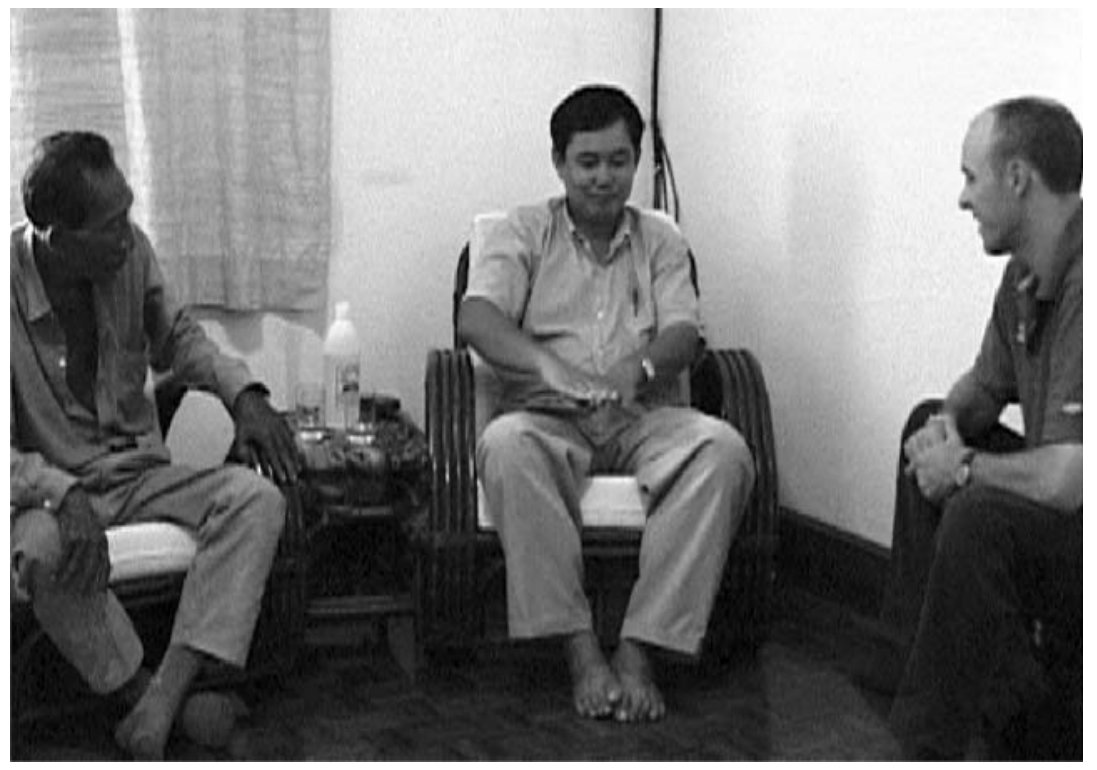

Figure 45. 'If (it) is very close (to the riverbed), then it [i.e., the fish] can't get in.'

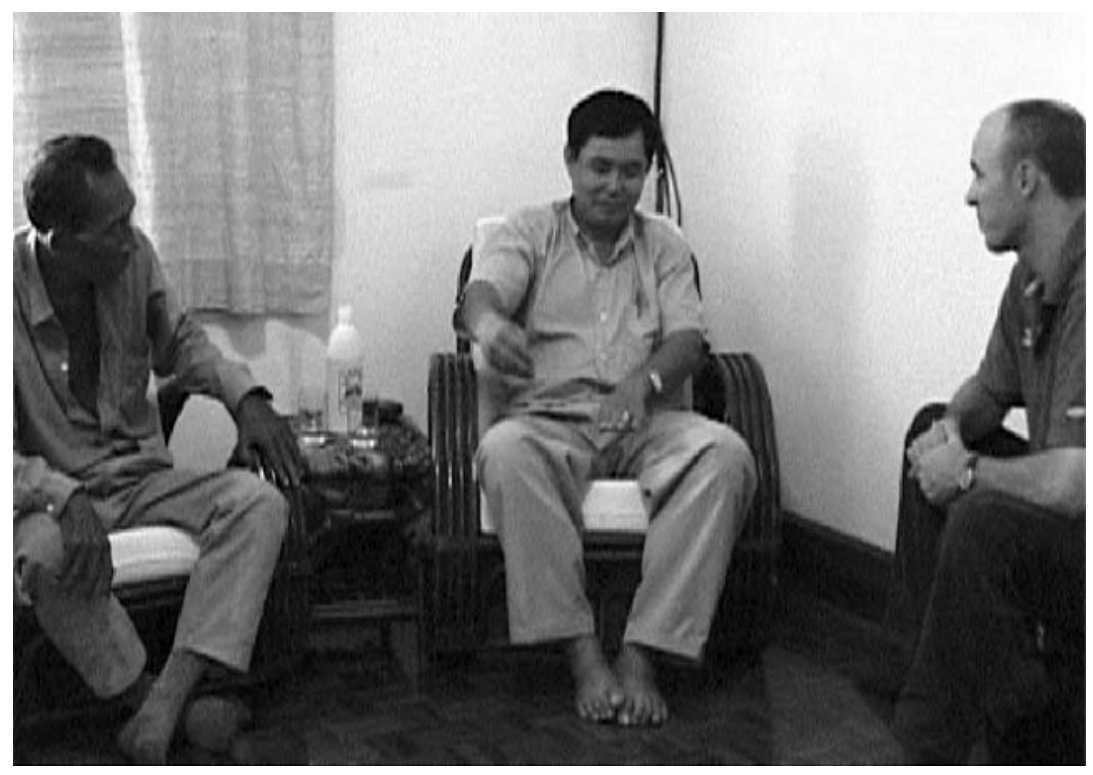

Figure 46. 'It- It comes down along the bed...' 


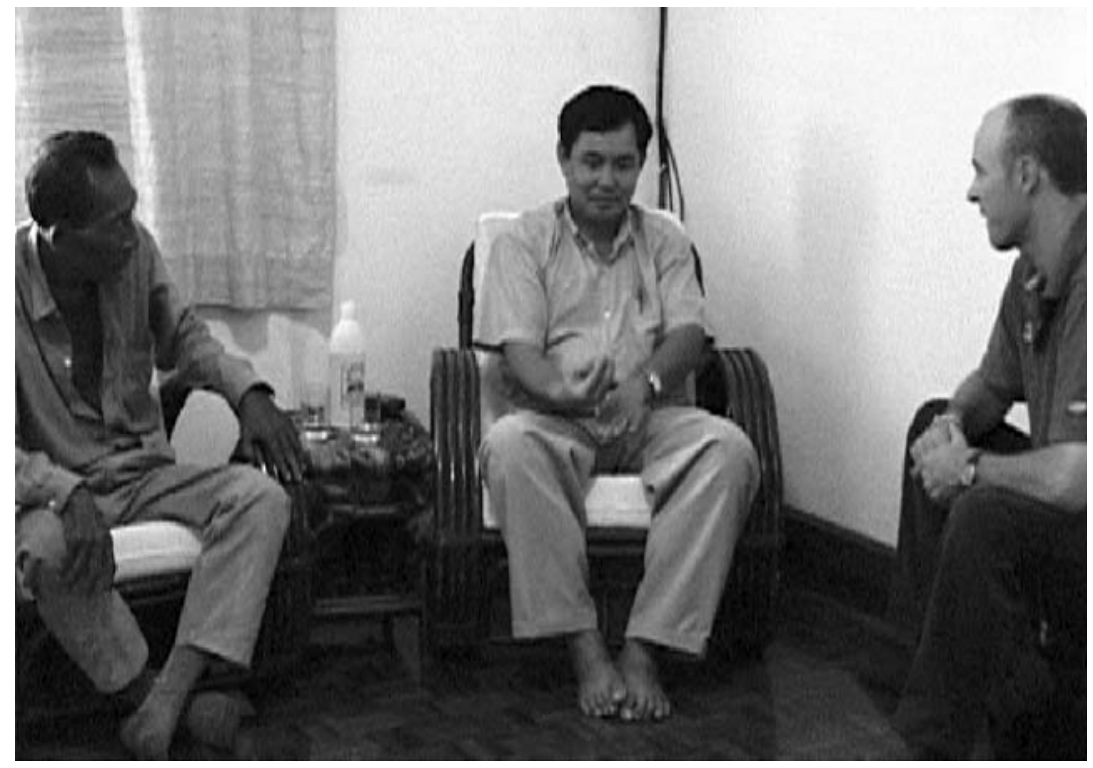

Figure 47. '... (and) it sees (it and) ...'

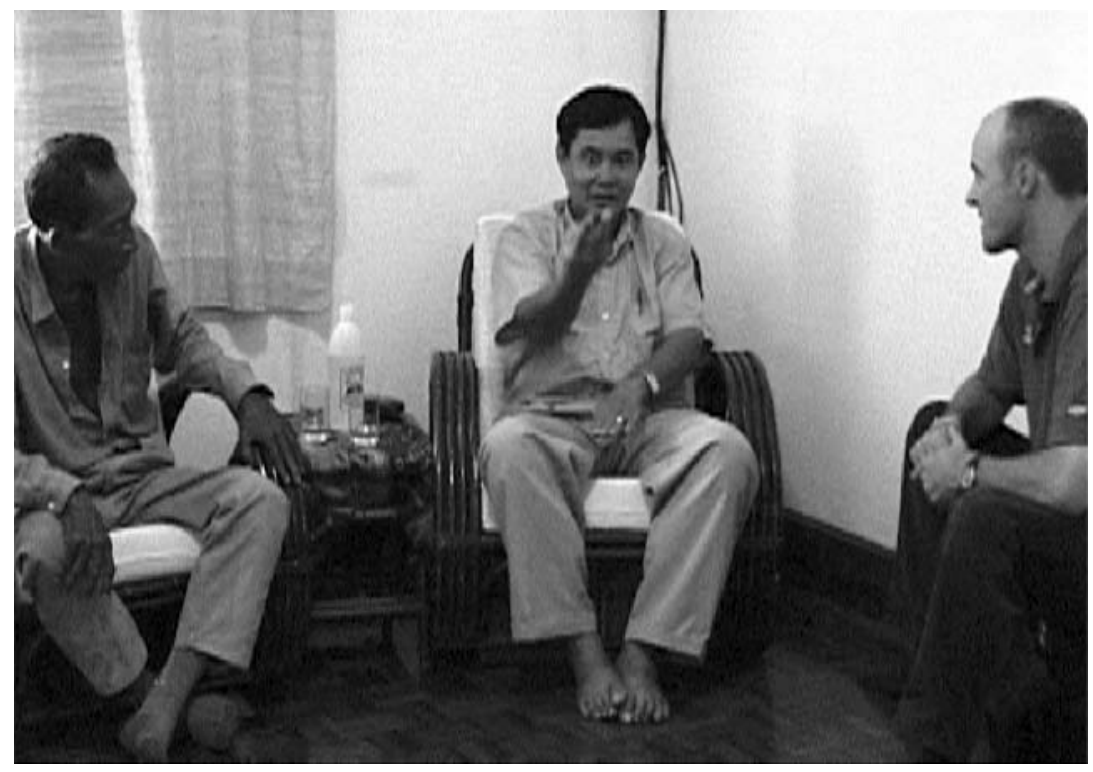

Figure 48. '... then it goes in.' 
that he does not rest his left hand - the hand that is currently representing a backgrounded but anchoring referent, the river floor below the trap - but keeps it in play (exactly as in the previous example; cf. Figure 24 and subsequent figures).

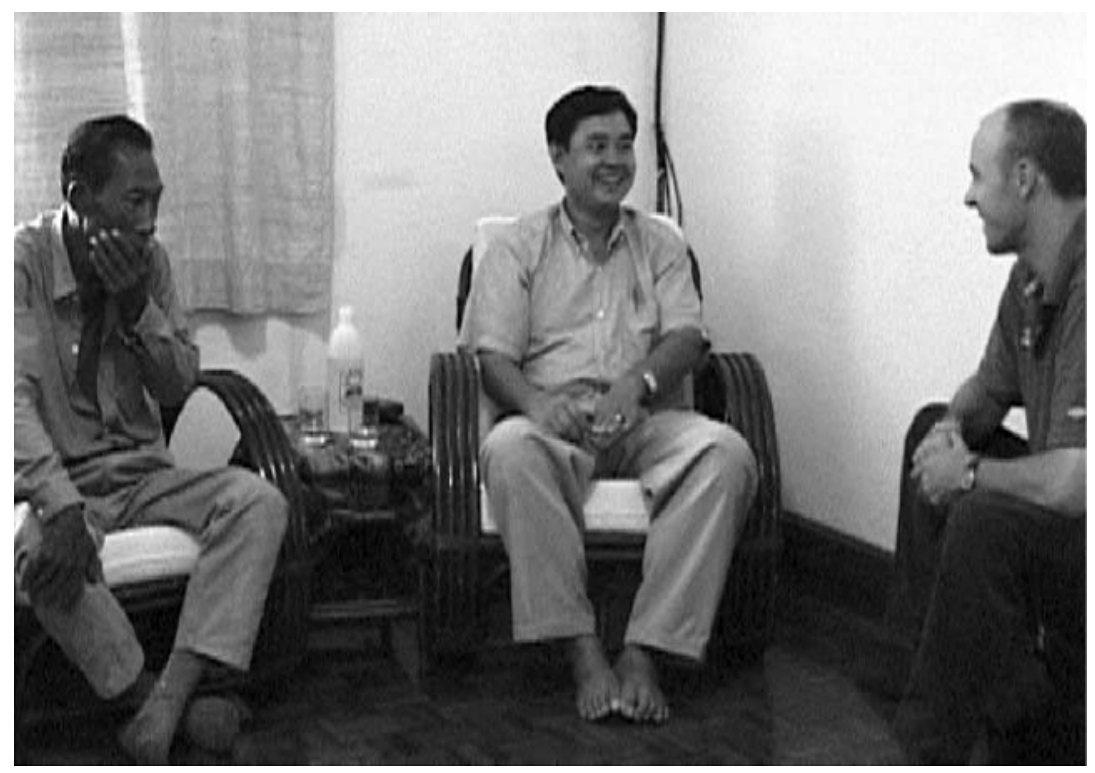

Figure 49. Speaker with right hand at rest, left hand still poised (representing backgrounded referent)

Then, I ask him to verify that the fish cannot get out. In reply, with left hand still held, he represents with his right hand a fish swimming around inside the expansive interior of the trap, using a high circulating counterclockwise sweep of his right hand (Figures 50 and 51).

(30) la0 man2 ka0 [huu4 thaang2 lò̀j2] dêj2 baat5-ni0 PCL 3SG FOC.PCL know direction float PCL PCL man2 ñaj1 dêj2- bò0 mèèn1 too3-nò̀j4 dêj2 3SG big PCL NEG be CLF-small PCL

'And they have a place to float around you know, it's big you know. It's not a small one, you know.'

The speaker's left hand has remained in play since Figure 42, held in the same position, and assuming a non-dominant anchoring role. It has provided a persistently perceptible signifier of a backgrounded feature of 


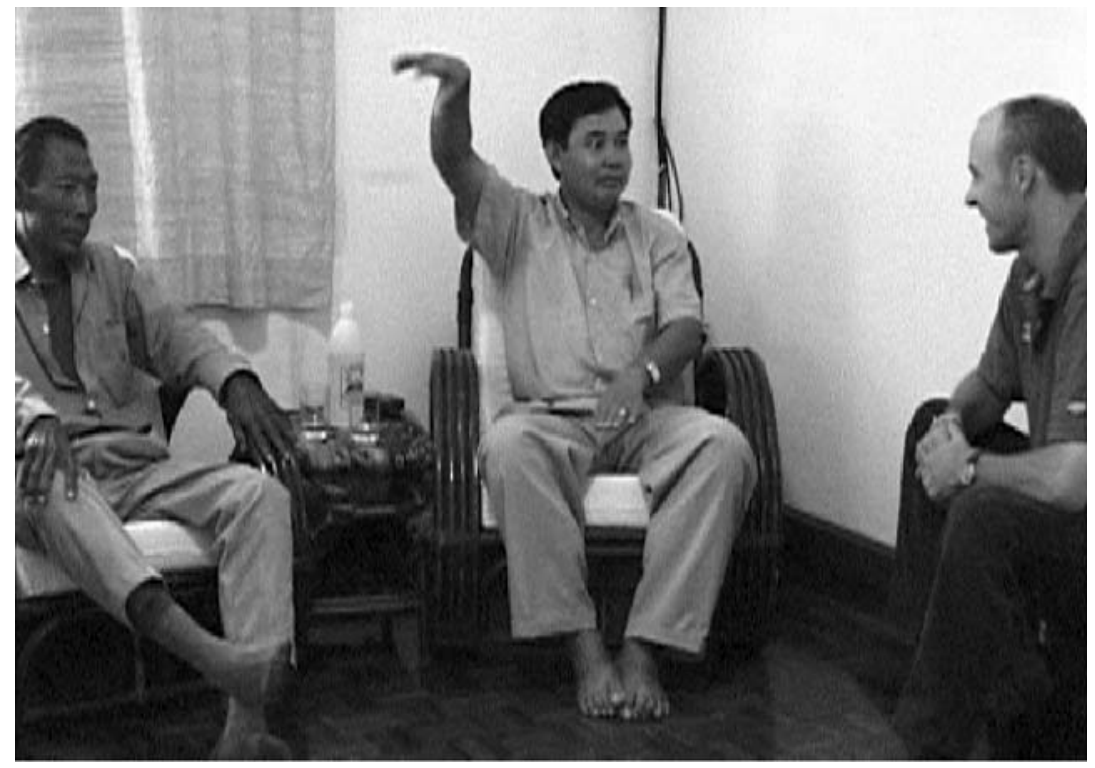

Figure 50. 'And they have a place to float around you know, ...'

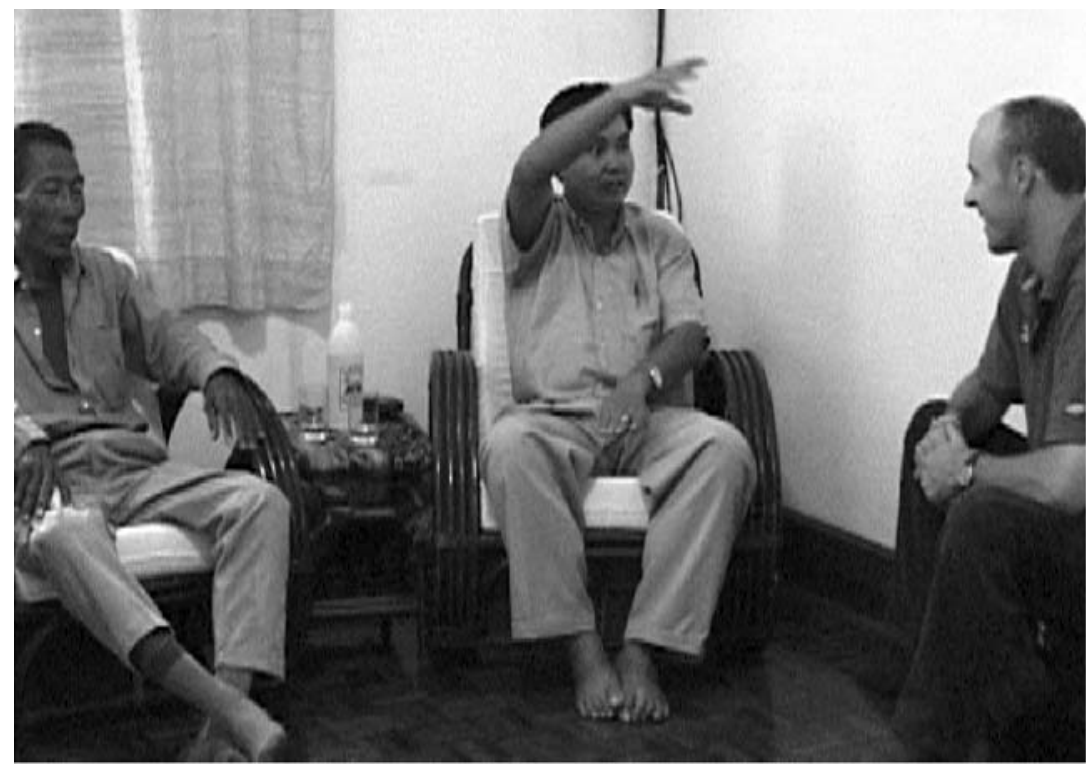

Figure 51. '... it's big you know. It's not a small one, you know.' 


\begin{tabular}{|c|c|c|c|}
\hline Illustration & HR & HL & Speech \\
\hline Fig. 41 & $\begin{array}{l}\text { enacting, lowering the trap } \\
\text { using the pole }\end{array}$ & $==\mathrm{HR}$ & $\begin{array}{l}\text { '(We) feed (it) down along the um the stick } \\
\text { and then (we) go (and)-' }\end{array}$ \\
\hline Fig. 42 & HOLD as previous & $\begin{array}{l}\text { depicting river } \\
\text { bed }\end{array}$ & 'So, this is- is- is- is the earth.' \\
\hline Fig. 43 & $\begin{array}{l}\text { touches HL, indexically, } \\
\text { including rub back and forth }\end{array}$ & $\begin{array}{l}\text { HOLD as } \\
\text { previous }\end{array}$ & '- um- the earth at the bottom of the water.' \\
\hline Fig. 44 & $\begin{array}{l}\text { depicting base of trap, } \\
\text { displaying size of gap }\end{array}$ & & $\begin{array}{l}\text { 'Estimate that it come (and stay) at-at- at- at } \\
\text { around this level.' }\end{array}$ \\
\hline Fig. 45 & $\begin{array}{l}\text { depicting base of trap, } \\
\text { showing lack of gap }\end{array}$ & & $\begin{array}{l}\text { 'If (it) is very close (to the riverbed), then it } \\
\text { can't get in.' } \\
\text { 'It goes in underneath?' 'Yes.' }\end{array}$ \\
\hline Figs. $46-48$ & $\begin{array}{l}\text { depicting fish, coming to base } \\
\text { of trap, up in through mouth, } \\
\text { and into centre of inside trap }\end{array}$ & & $\begin{array}{l}\text { 'It- it comes down along the bed (and) it sees } \\
\text { (it and) then it goes in. (And) it eats the } \\
\text { toasted rice in there. }\end{array}$ \\
\hline Fig. 49 & TO REST, falls to lap & & $\begin{array}{l}\text { 'Yeah.' } \\
\text { 'And then it can't get out?' }\end{array}$ \\
\hline Figs. $50-51$ & $\begin{array}{c}\text { Depicting fish, swirling } \\
\text { motion of fish floating around } \\
\text { inside trap }\end{array}$ & & $\begin{array}{l}\text { 'And they have a place to float around you } \\
\text { know, it's big you know. It's not a small one, } \\
\text { you know.' }\end{array}$ \\
\hline
\end{tabular}


the discourse (the earth at the riverbed), which has served as a structural anchor, both in discourse information structure and in spatial arrangement of the relevant entities and their subparts. The sequence depicted in Figures 41 through 51 can be diagrammatically represented as indicated in Figure 52.

The first two rows of Figure 52 show a symmetry-dominance construction in which the left hand plays the dominant role. In subsequent rows, the left hand takes on the non-dominant role, and the right hand elaborates throughout the rest of the sequence.

Continuing his description, the speaker now states that once set, the trap should be left for some time. One later goes back to 'visit' it and collect any fish that have become trapped inside. He states that when one goes to visit the trap, one first gently releases it from the stake by untying it. As he says this, he makes a one-handed gesture with the right hand, enacting untying the trap from the stake, yet with the left hand still poised in the position shown in Figures 42 through 51. (For reasons of space, this sequence is not shown here.) Finally, he frees his left hand from this long-held position, in order to facilitate a new two-handed gesture, an enactment of pulling up the trap out of the water, shown in Figure 53.

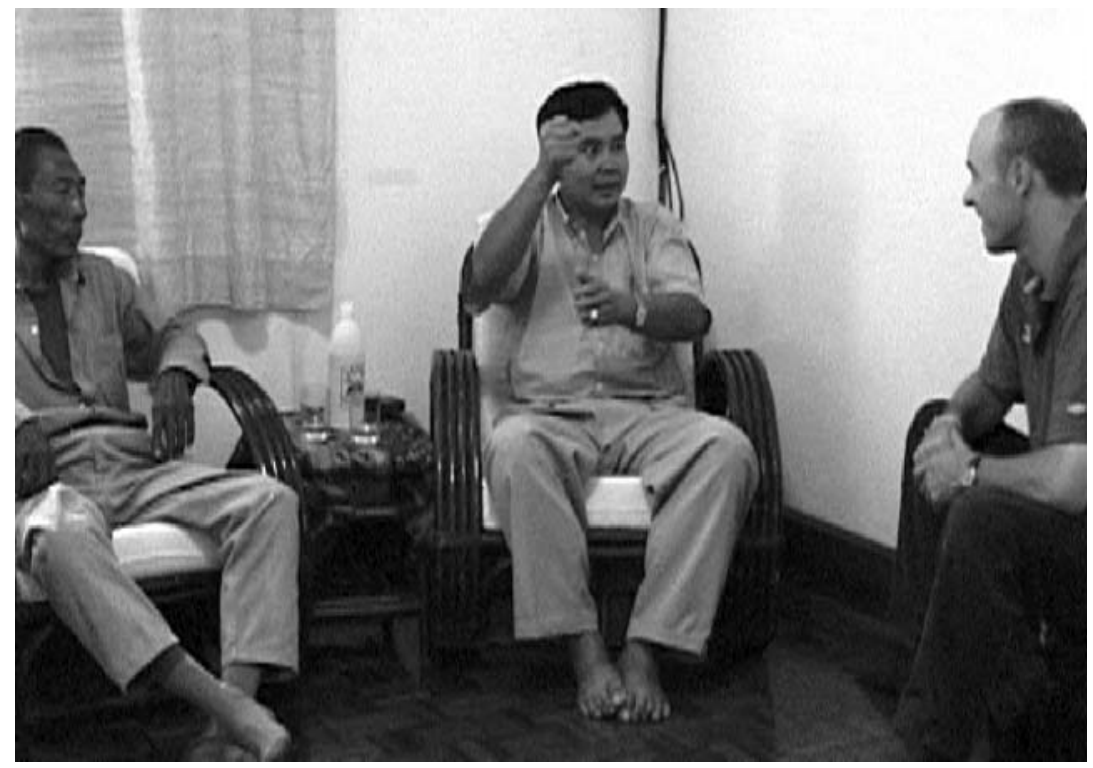

Figure 53. 'And (we) gently pull it up (using the stick).' 

(31) man2 la 0 khòòj saaw2 [khùn5 3SG PCL gentle manipulate.long.stick.as.tool ascend maa2 na0] come PCL
'And (we) gently pull it up (using the stick).'

He continues this action, repeating 'gently pull it up, gently pull it up'. Then, he describes what is happening to the fish while the trap is being lifted up through the water. Because the base hole is a fixed opening, it is possible for a fish to escape if it happens to be right above the hole when the trap is raised. The speaker's gestures resume the role of representing structures associated with the body of the trap. We first observe a new symmetrical gesture, with palms facing down, elbows up, representing the inside surface of the trap (Figure 54).

$$
\begin{aligned}
& \text { [phùun4 man2 kuang4 dêj2] } \\
& \text { floor 3sG broad PCL } \\
& \text { 'The base of it is broad, you know.' }
\end{aligned}
$$

This is followed by another symmetrical gesture, which prefigures a reference to the hole in the base of the trap, where the two hands depict the diameter and partial shape of a circular opening (Figure 55).

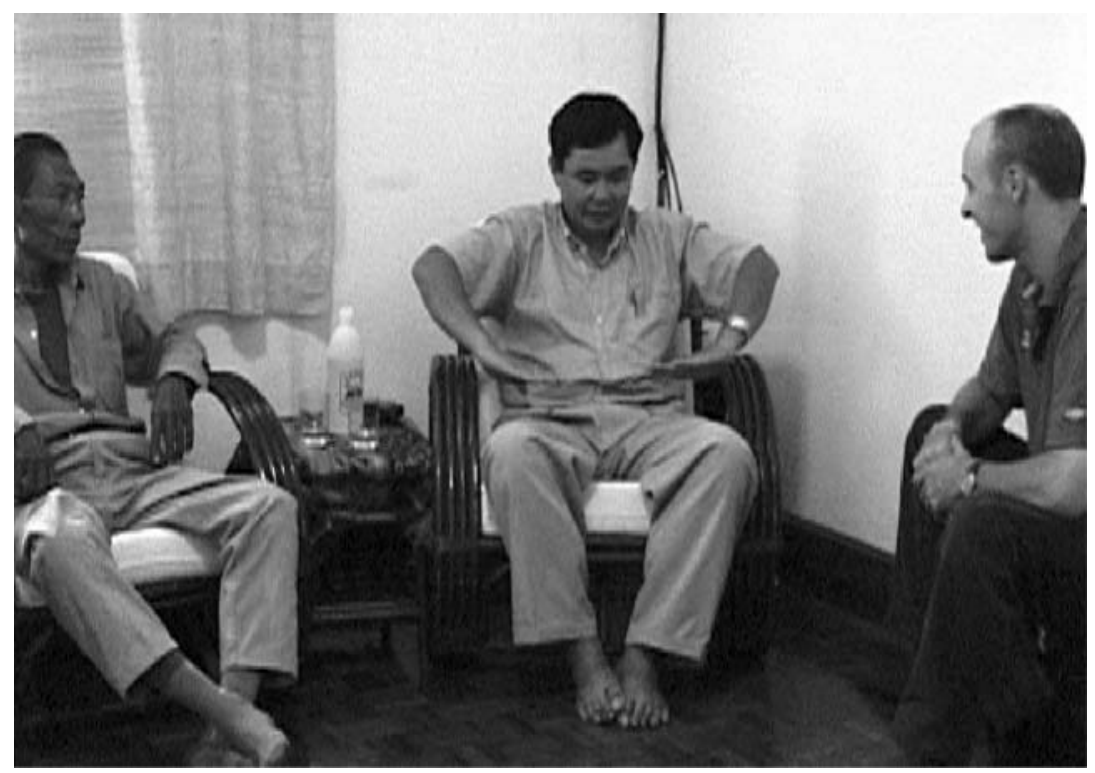

Figure 54. 'The base of it is broad, you know.' 


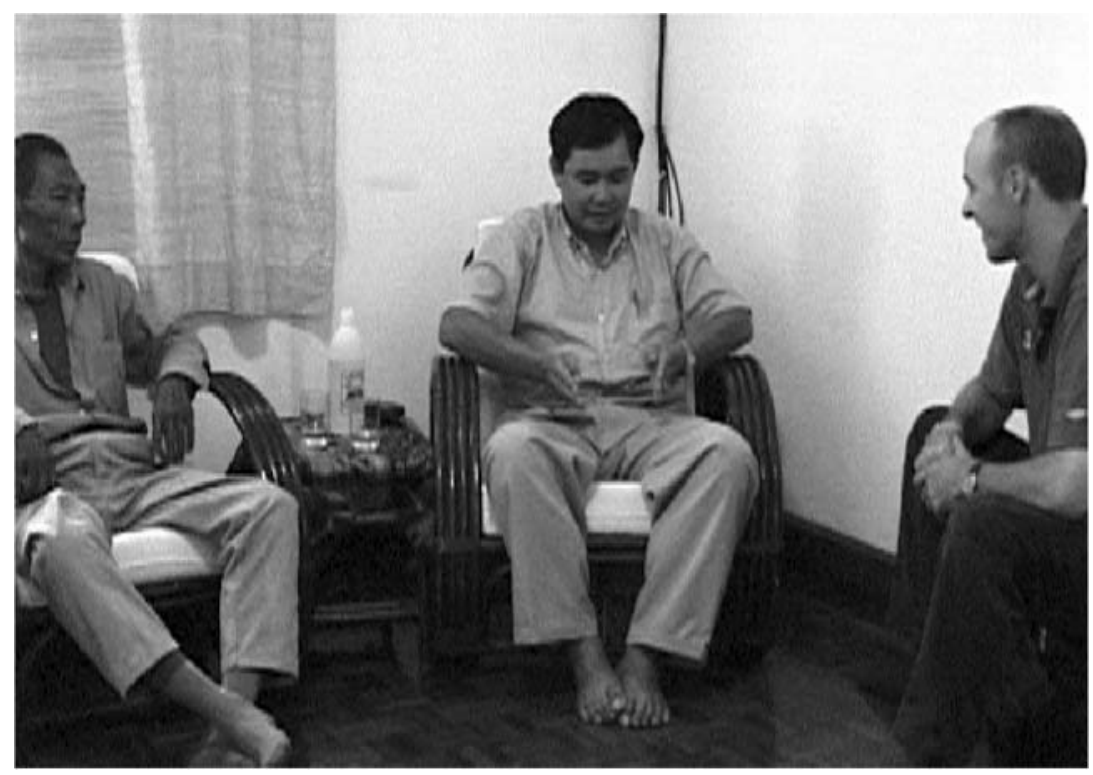

Figure 55. Symmetrical gesture, prefiguring reference to circular hole in trap base

This symmetrical gesture is the first phase of another symmetrydominance construction. In Figure 55, the speaker is representing the hole in the trap's base with his two hands. Next, the left hand is held where it is (now assuming a non-dominant role), while the right hand assumes a dominant role, making a circular motion (counter-clockwise) tracing the 'roundish' shape of the hole (Figures 56 and 57).

$$
\begin{aligned}
& \text { tèè1 vaa1 [bòòn1 paak5 ni0] man2 mon-mon2 } \\
& \text { but COMP place mouth PCL.TPC 3SG round-RDP } \\
& \text { 'But at the mouth, it's roundish.' }
\end{aligned}
$$

In Figures 56 and 57, the non-dominant hand plays the subordinate role of representing a backgrounded/topical structure that the focus of the current utterance (i.e., what the dominant hand represents) is about. The non-dominant hand iconically represents only a fragment of the circular opening that it is intended to signify. It metonymically evokes the fuller image of that referent already established in the symmetry phase that preceded it (Figure 55). The non-dominant hand provides an anchoring spatial point of reference for the dominant hand's movement, as well as providing continued perceptible signification of topical information (i.e., the larger structure that the focus of the utterance is about). The 
104 N. J. Enfield

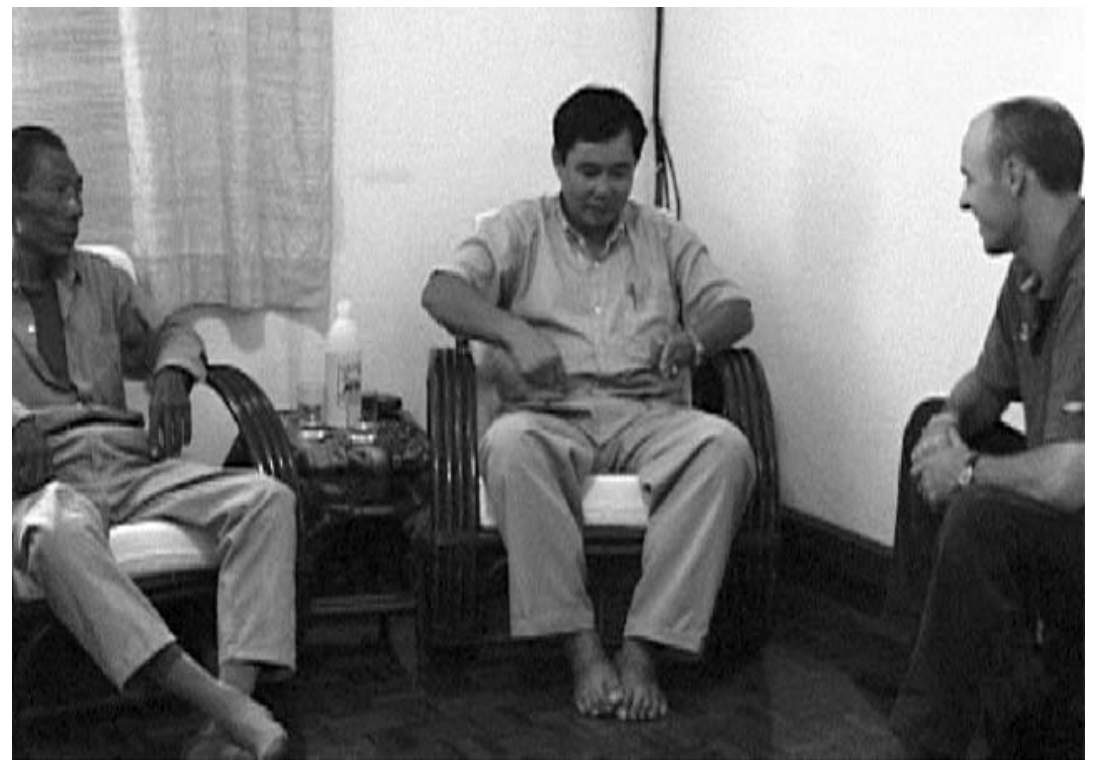

Figure 56. 'But at the mouth,...'

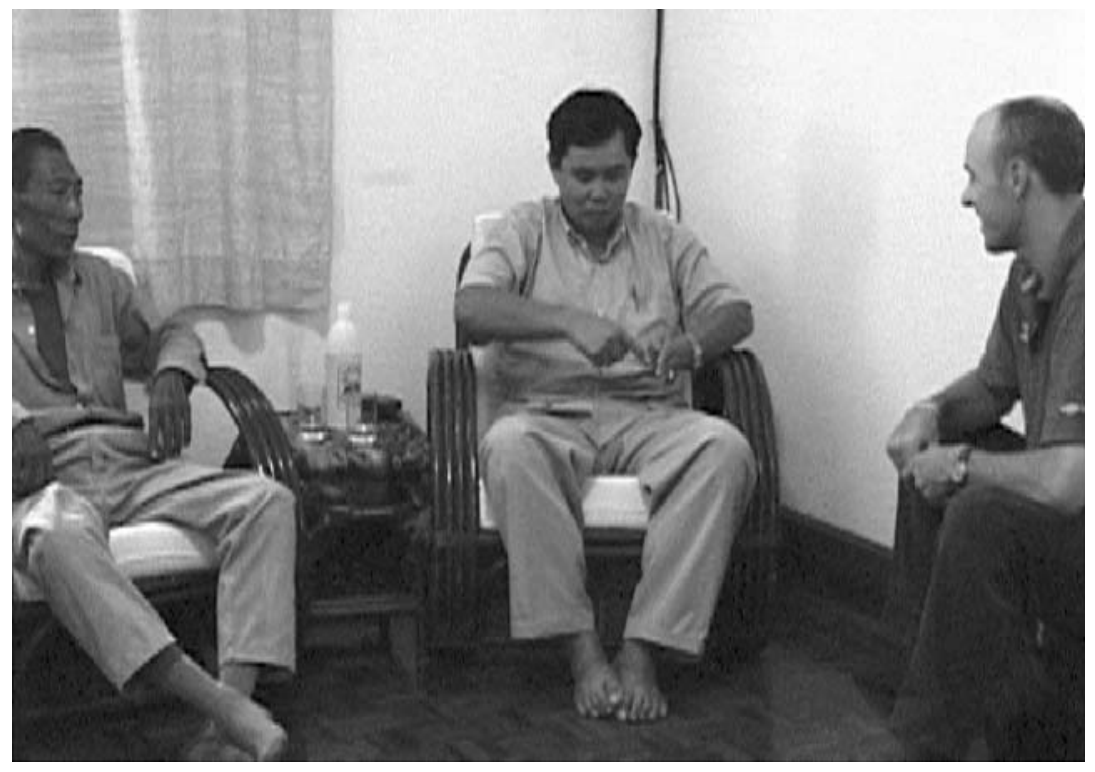

Figure 57. '...it's roundish.' 
brief symmetry-dominance construction illustrated in Figures 55 through 57 may be diagrammed thus:

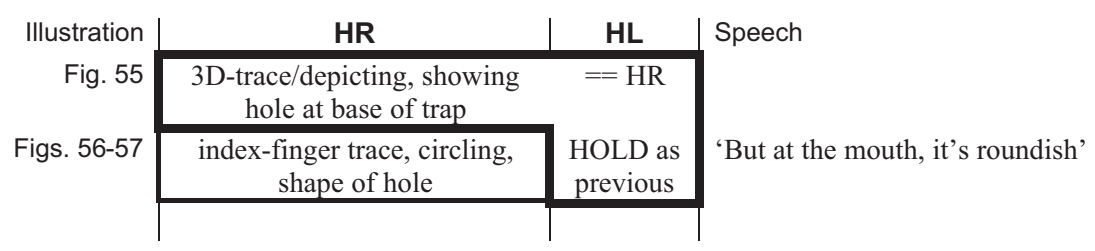

Figure 58. Diagram of the symmetry-dominance construction shown in Figures 55-57

The speaker now breaks this dominance phase, because he needs both hands for his next move. The subsequent gesture is symmetrical, depicting once again the 'tusks' that stick up from the base hole into the interior of the trap (Figure 59). The speech follows on directly from example (33).

(34) la 0 hêt1 [ngaa2] khùn5 juu1 nòò5-nùng1 dê0
PCL make tusk ascend be.at a.little
'And (they) make tusks coming up a little.'

The speaker now holds his left hand in place, moving into another dominance phase. The left hand continues to represent the full symmetrical structure established in Figure 59, namely the inward-tusked opening to the trap. Again, it does this by virtue of having been part of a fuller representation at an earlier phase. The held left hand provides a spatial and topical anchor for what the right hand now does, which is to depict the straight downward motion of a hypothetical fish that happens to be above the opening as the trap is raised, thus allowing the fish to escape, as depicted in Figures 60 and 61.
(35) tèè1 vaa1 khan2 [too3-daj3] man2 thùùk5 [pòòng1 but COMP if CLF-whichever 3sG strike opening han0] lè0 man2 ka0 si0 qòò 5 paj3 han0-lèq0 PCL PCL 3SG PCL IRR exit go PCL 'But if any one (of them), were it to strike the opening, then it'd certainly get out.'

With left hand still held, the speaker returns the right hand to recreate the symmetry that began this sequence (cf. Figure 59).

(36) tèè1 vaa1 [man2 bò0 suu1 thùùk5 han4] but COMP 3SG NEG tend strike PCL

'But they don't tend to strike (it).' 
106 N. J. Enfield

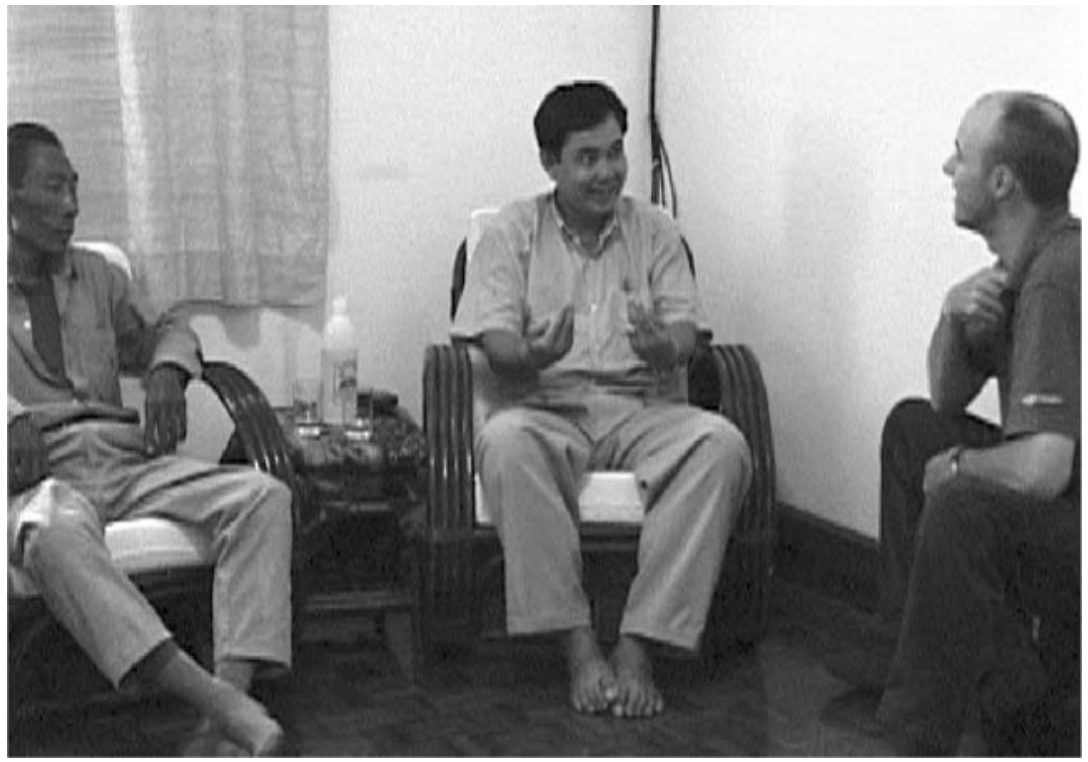

Figure 59. 'And (they) make tusks coming up a little.'

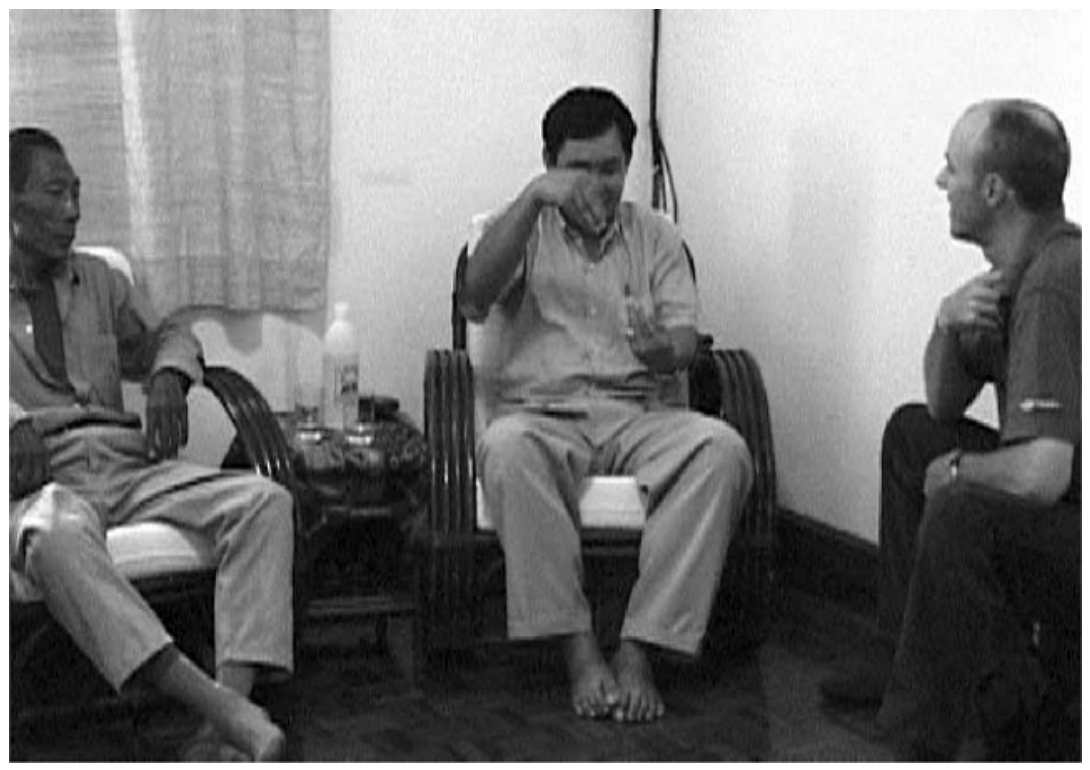

Figure 60. 'But if any one (of them),...' 


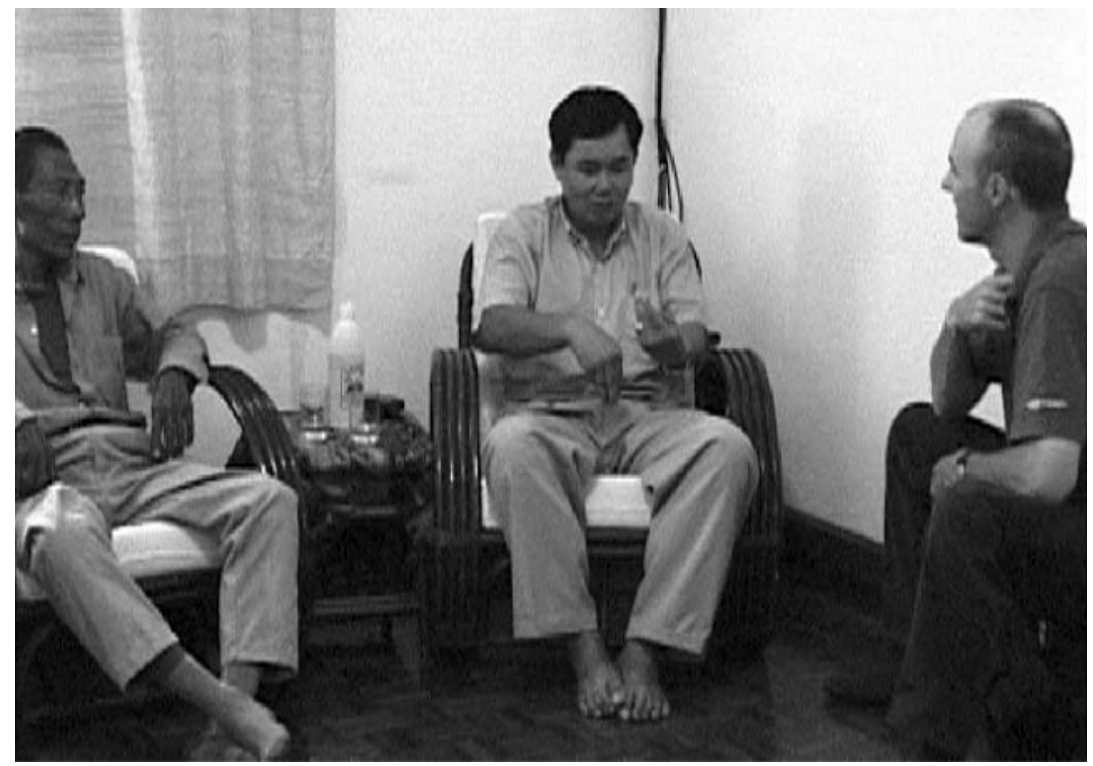

Figure 61. '... were it to strike the opening, then it'd certainly get out.'

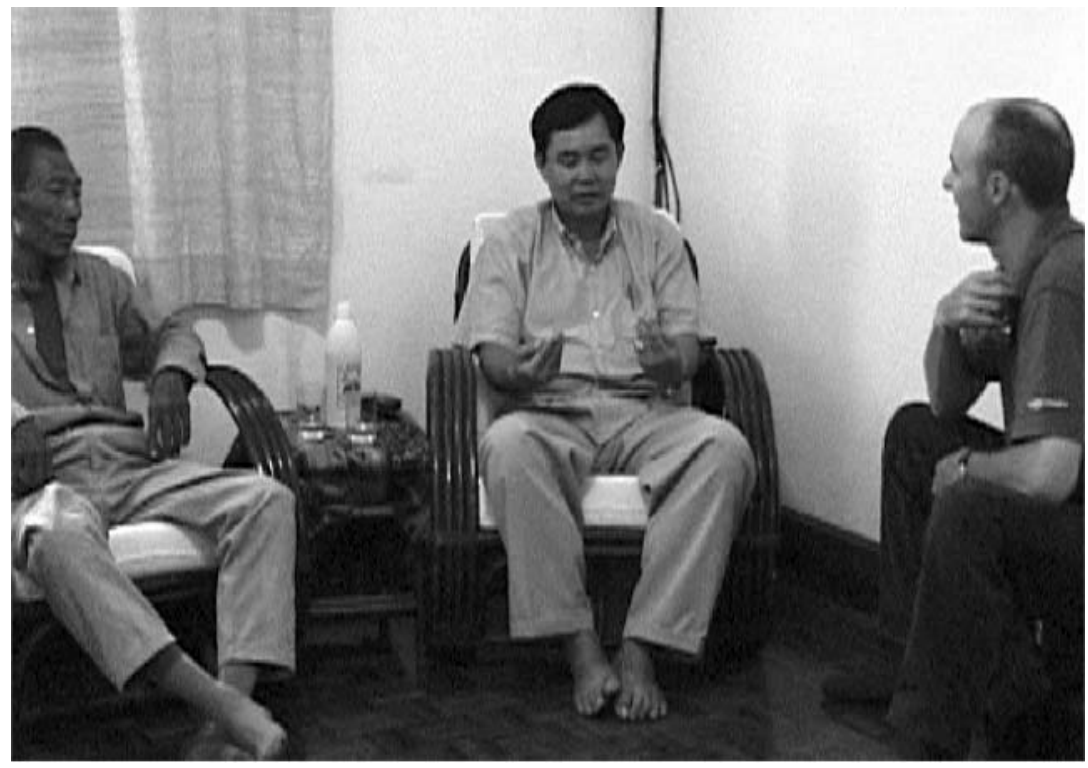

Figure 62. 'But they don't tend to strike (it).' 
The sequence depicted in Figures 59 through 62 may be diagrammed as shown in Figure 63.

The rest of the sequence (not shown here) involves a series of twohanded gestures enacting the removal of the trap from the water, and of the fish from the trap, finishing with the speaker resting his hands.

\section{Speaker 2}

The fourth and final segment to be discussed in this article is from a second speaker's description of the tum4 thoong2. This segment features close parallels to the sequence just examined, beginning with a symmetrydominance construction almost identical to that depicted in Figures 37 through 40 above. A two-handed depiction of the tusked opening in the base of the trap is followed by a left-hand hold and a series of elaborating gestures performed by the right hand, assuming the left hand as a spatial and topical anchor.

After the speaker has made a few preliminary remarks, I ask him whether bait is used and where the bait is placed. He replies that it is placed around the tusks on the floor of the trap's interior. Then he wants to elaborate. He explains that the trap is woven so as to have a platformlike floor surrounding the tusked hole at the base. He begins with a palms-up symmetrical gesture depicting the tusked nature of the hole at the trap's base (cf. the almost identical gesture by a different speaker shown in Figures 36 and 37 above). The tusks stick up and inside the trap, which means that whatever is placed on the platform around it (in the interior of the trap) will not fall through the hole (Figure 64).

$$
\begin{aligned}
& \text { kòò1 man2 [saan3 pên3 vok1 vok1 vok1] } \\
& \text { that's.why 3sG weave as 1-sii4 } \\
& \text { 'That's why it's woven, going vok vok vok like this.' }
\end{aligned}
$$

Now, in a replica of the symmetry-dominance construction illustrated in Figures 38 and 39 in the previous example above, the left hand is held in position, maintaining the job of depicting the tusked base hole, while the other hand takes the dominant role, indicating the area of the trap floor, around the hole in the trap's base, where bait is placed. This is done with a counter-clockwise-circling index-finger point (Figures 65 through 67 ), the left hand then returning to its former symmetry position (Figure 68; cf. Figure 64).

$\begin{array}{lllll}\text { (38) nii4 } \operatorname{man} 2 & \text { [pên3 saan2 } & \operatorname{mot} 2 & \text { dê0] } \\ \text { here } 3 \mathrm{sg} \text { be } & \text { platform } & \text { all } & \text { PCL } \\ \text { 'Here it's all a platform.' } & & \end{array}$




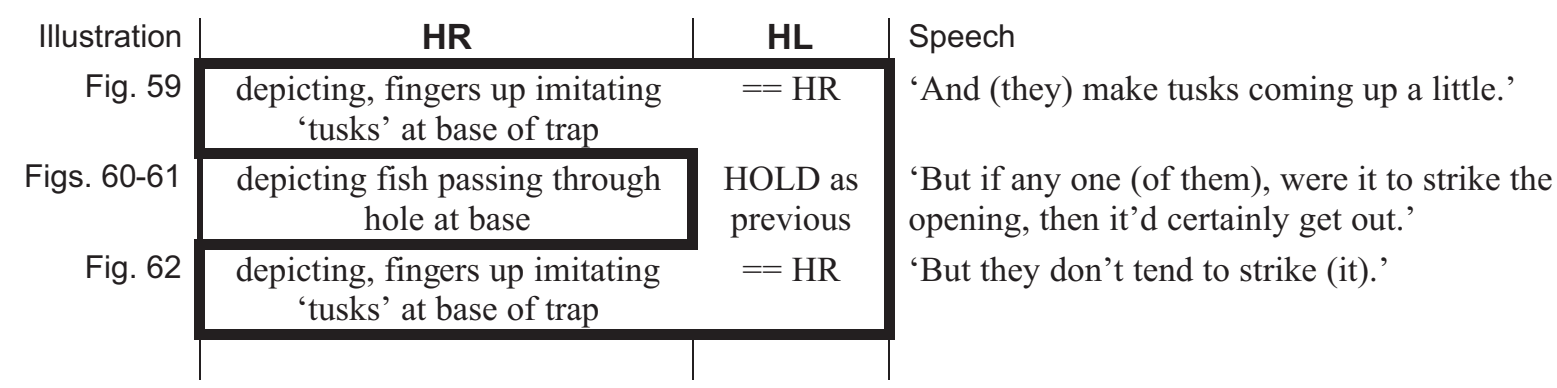

Figure 63. Diagram of the symmetry-dominance construction shown in Figures 59-62 
110 N. J. Enfield

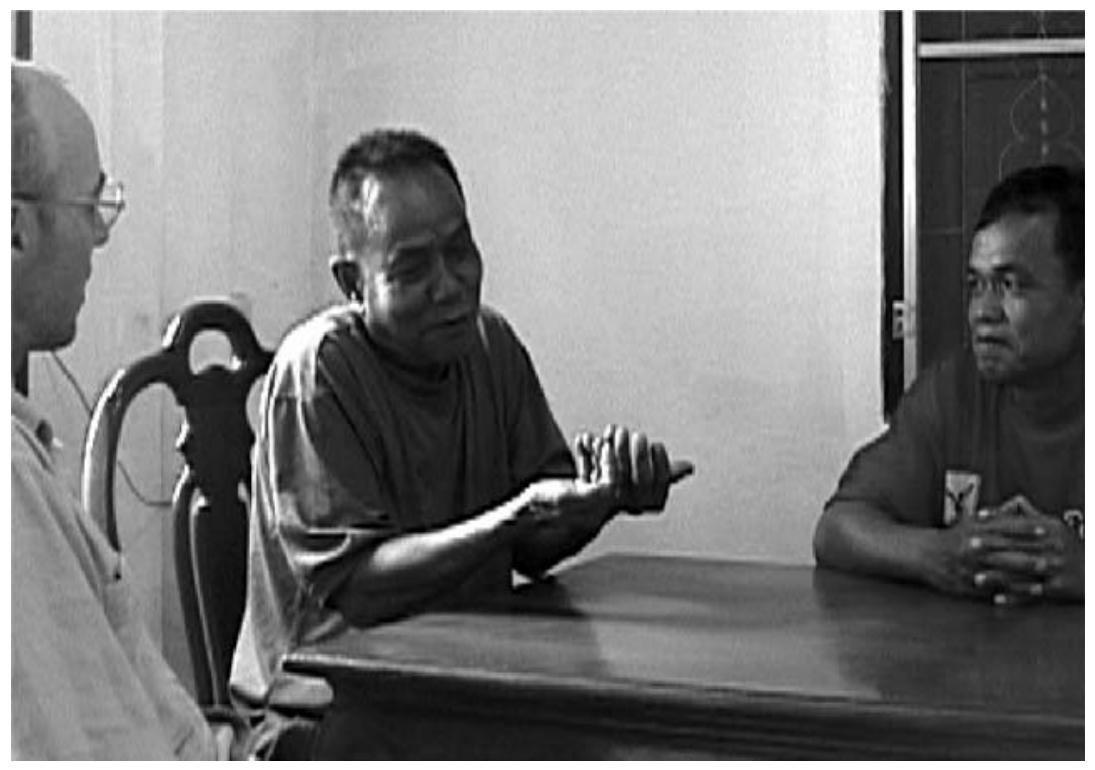

Figure 64. 'That's why it's woven, going vok vok vok like this.'

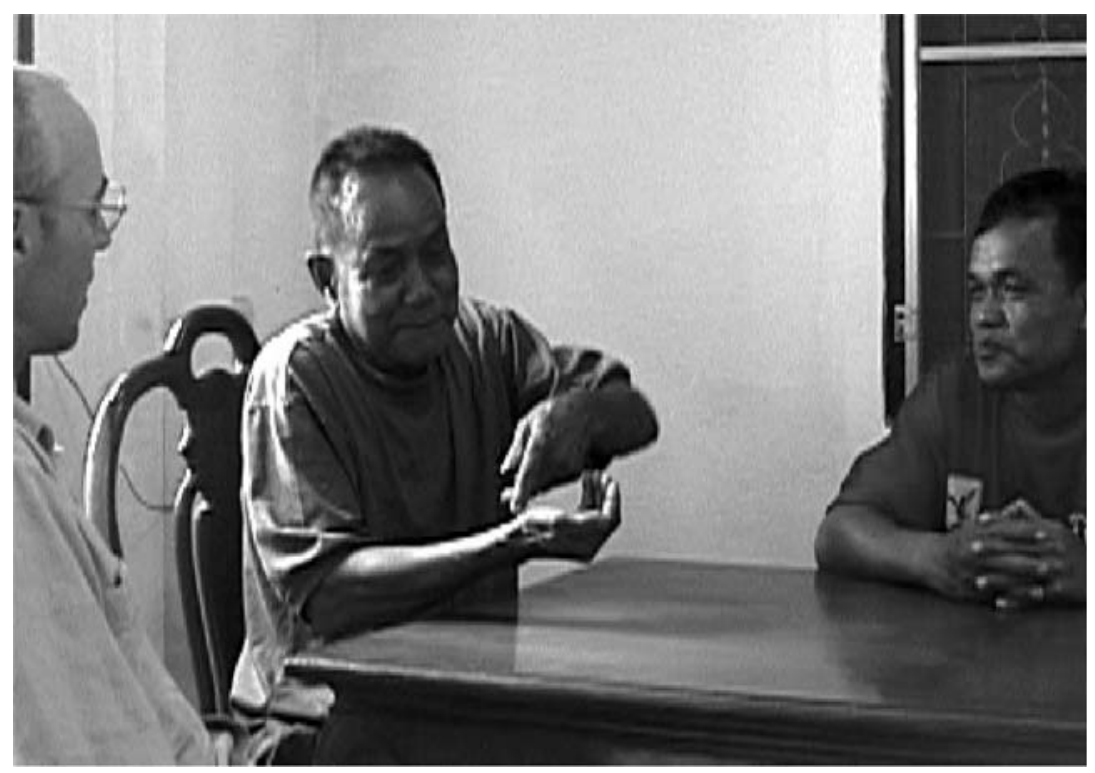

Figure 65. 'Here it's all a platform.', a. 


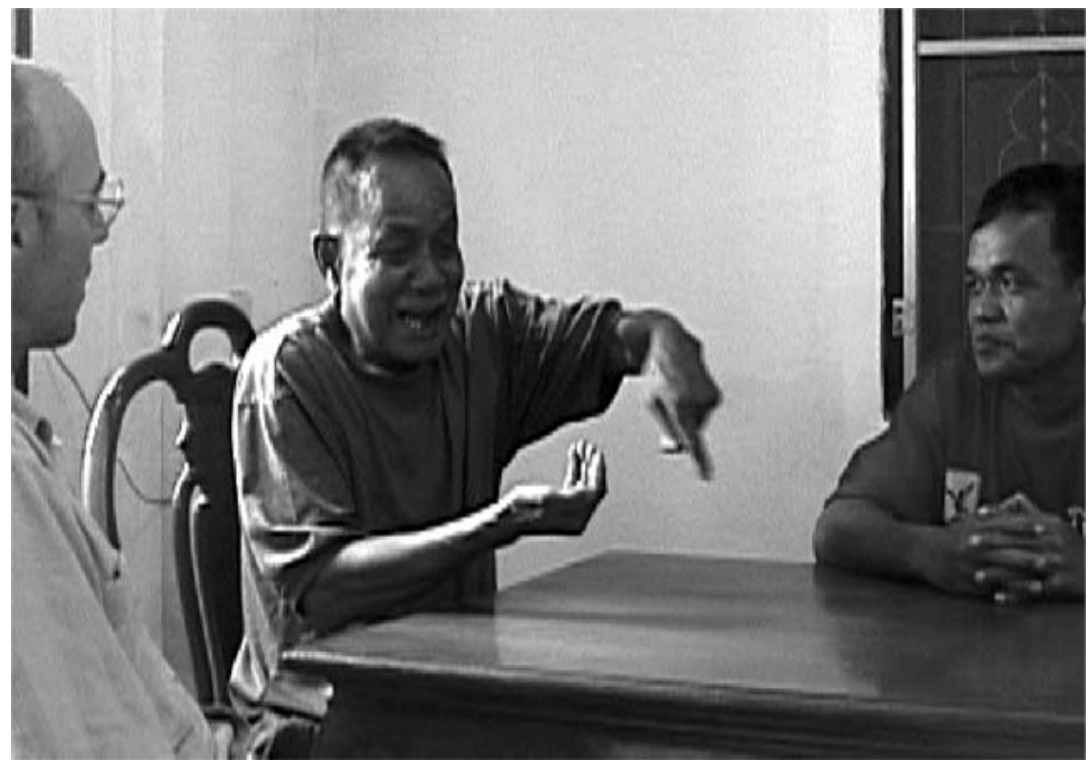

Figure 66. 'Here it's all a platform.', $b$.

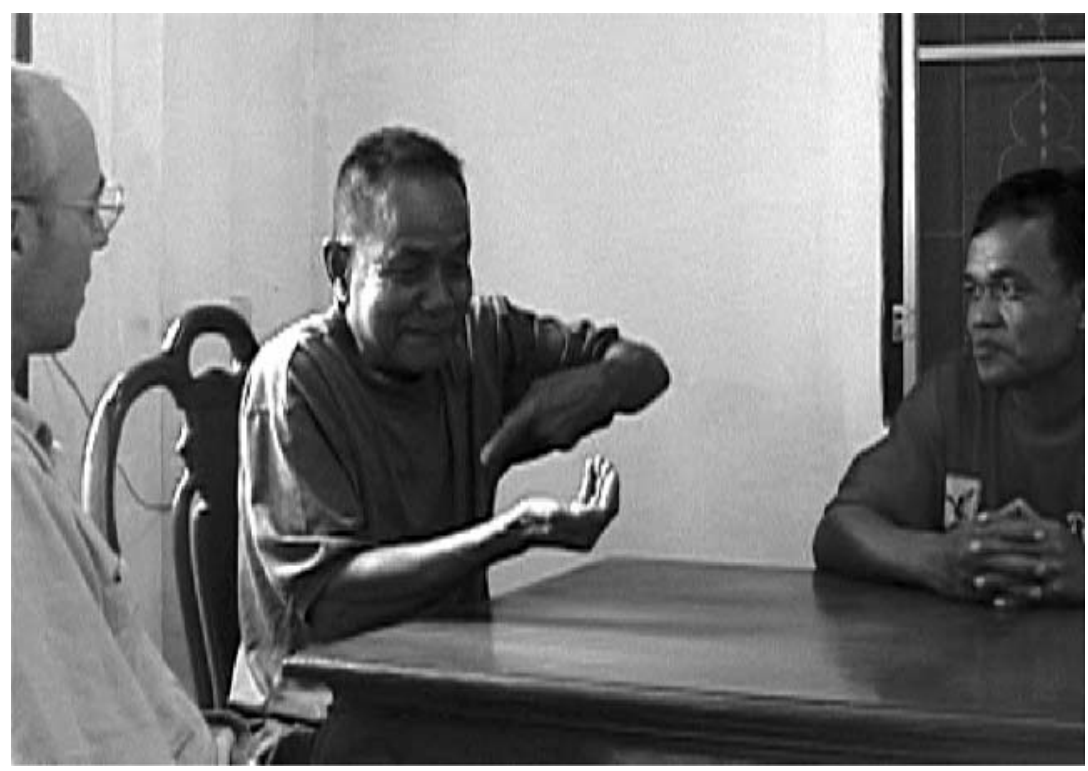

Figure 67. 'Here it's all a platform.', $c$. 


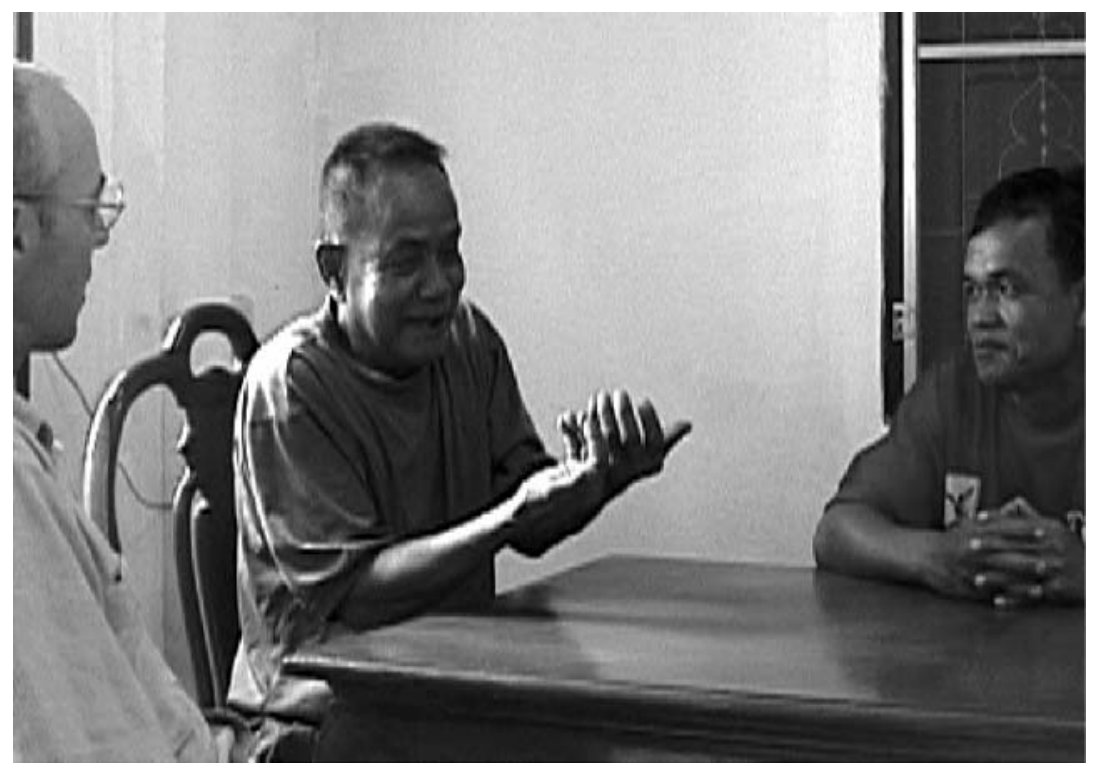

Figure 68. 'Here it's all a platform.', $d$.

Once again, the non-dominant hand in Figures 65 through 67 only literally signifies half of its original referent. It single-handedly depicts a two-handed image, a feat made possible only by a structural link in relations of form, meaning, and linear order between gestures in neighboring utterances. The right (here non-dominant) hand in Figures 65 through 67 maintains a discourse presence, conceptually, of the fuller structure depicted in Figure 64. If the speaker had three hands, he would not have to rely on this technique. In response to the limitations of the modality, he has segmented and linearized the information for the purpose of supplying it to his interlocutors in a coherent way.

This symmetry-dominance construction can be diagrammed as shown in Figure 69.

After further elaboration (not shown here), the speaker produces a different representation of the tusked opening, this time with palms turned inward, as indicated in Figure 70.

The symmetrical gesture shown in Figure 70 comprises the first stage of a final example of the symmetry-dominance construction. The left hand is now held still, continuing to represent the opening in the trap's base, while the right hand depicts new information, namely a fish going up into the interior of the trap through the base (Figures 71 and 72). 


\begin{tabular}{|c|c|c|c|}
\hline Illustration & HR & HL & Speech \\
\hline Fig. 64 & $\begin{array}{l}\text { depicting, tusks at base } \\
\text { of trap, palms out }\end{array}$ & $==\mathrm{HR}$ & $\begin{array}{l}\text { 'That's why it's woven, going vok } \\
\text { vok vok like this.' }\end{array}$ \\
\hline Figs. $65-67$ & HOLD as previous & $\begin{array}{l}\text { deictic, circling, pointing out } \\
\text { where bait lies }\end{array}$ & 'Here it's all a platform.' \\
\hline Fig. 68 & & $==\mathrm{HR}$ & \\
\hline
\end{tabular}

Figure 69. Diagram of the symmetry-dominance construction shown in Figures 64-68 
114 N. J. Enfield

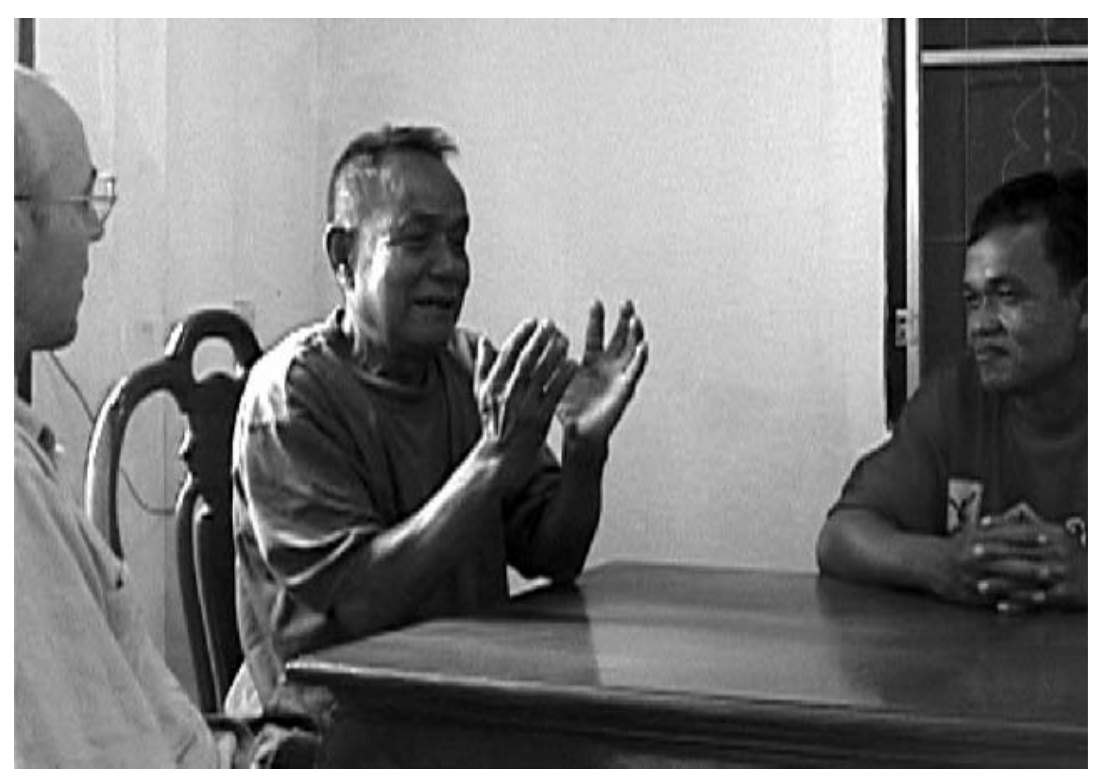

Figure 70. Palms-in representation of tusked opening in base of trap

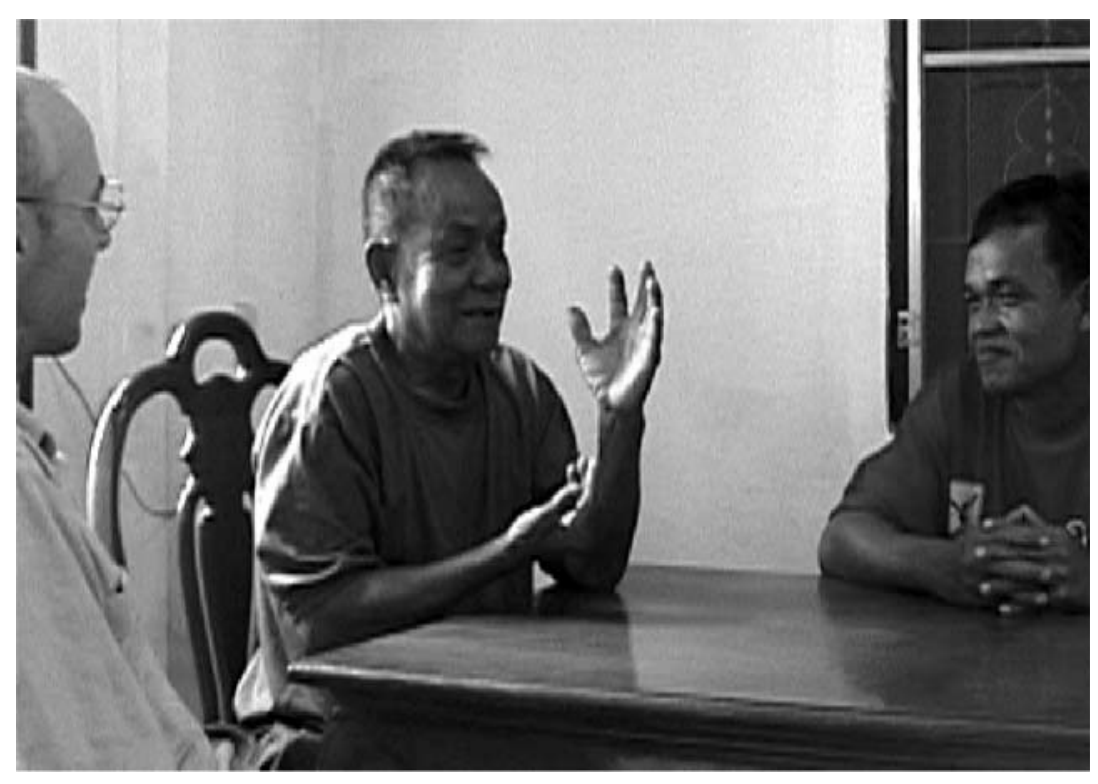

Figure 71. 'They go up...' 


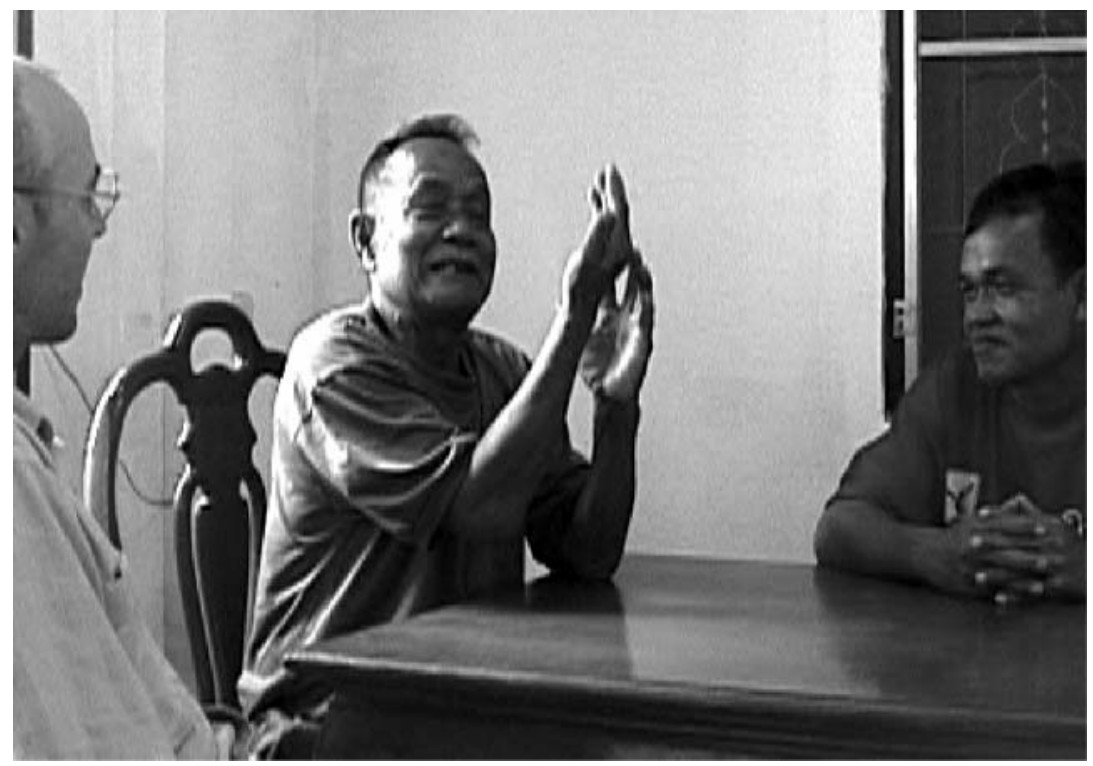

Figure 72. '... through this one.'

(39) man2 khùn2 [nam2 qan0-nii4]

3SG ascend with CLF-DEM.GEN

'They go up along/through this one.'

After a few further comments (not shown here), the speaker finishes off by bringing both hands to full rest, indexing a withdrawal of communicative effort and signaling a close to his contribution (Figure 73).

Figure 74 shows the sequence from Figures 70 through 73 in diagrammatic form.

This closes the descriptive sections of this study. Let us take stock of what these examples have revealed.

\section{Semiotics of the symmetry-dominance construction}

How does the symmetry-dominance construction convey the meanings it conveys? I note three important mechanisms. First, there is unity in symmetry. In the symmetry phase, the fact that the two hands formally match each other in shape, position, timing, and motion indexes a semantic unity. The message of the perceptible symmetry is that together the two 


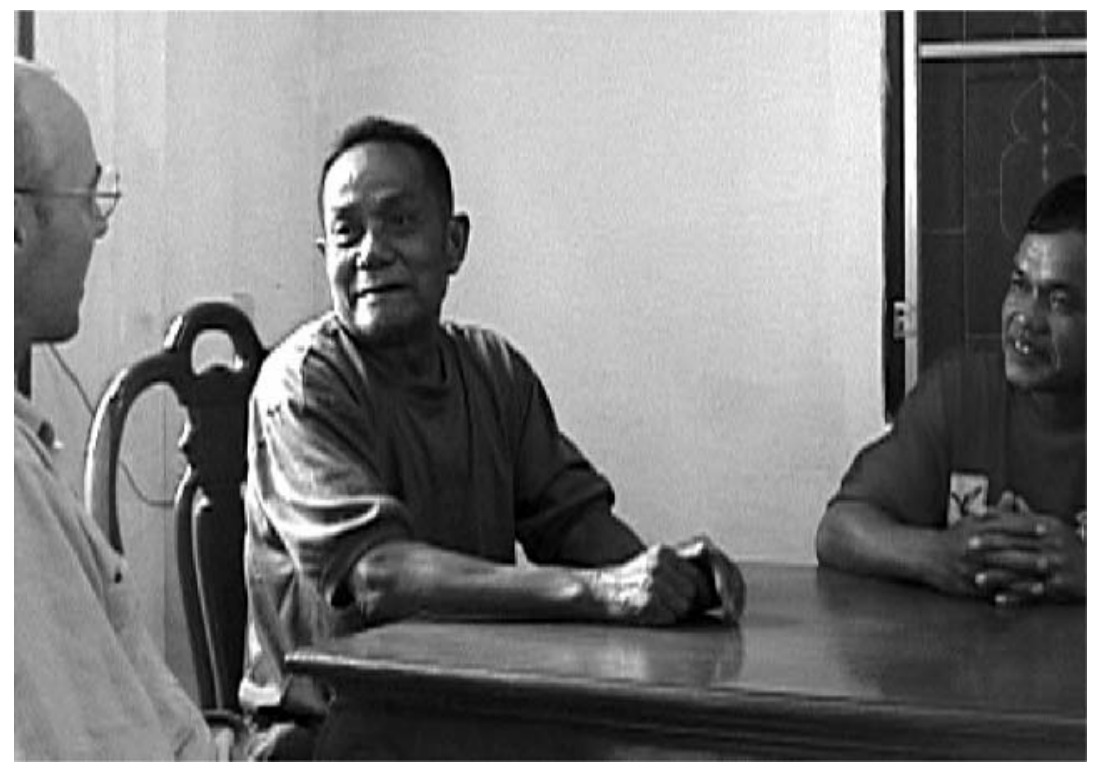

Figure 73. Hands to rest, signaling closure

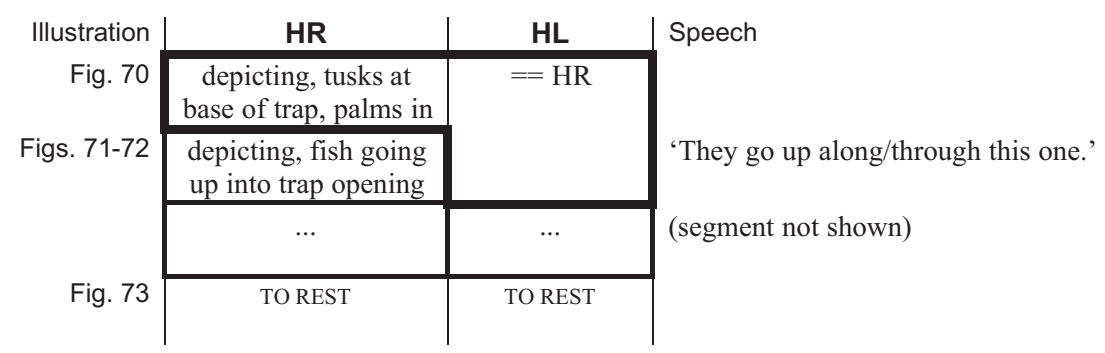

Figure 74. Diagram of the symmetry-dominance construction shown in Figures 70-73

hands are expressing a single idea. They are readily seen as one (and indeed are hardly seeable as separate).

Second, in the dominance phase, the non-dominant hand has a metonymic relation to the two-handed representation in the preceding symmetrical phase. As repeatedly exemplified above, during the dominance phase, the held hand indexes the full conceptual and spatial structure established in a preceding phase. In these examples, the "external representation' has no full form, but is imagined at the invitation of the speaker 
and sustained by whatever means necessary and sufficient. Clearly, partial signification is enough.

A third semiotic feature of this construction is its signification of information about discourse structure and the speaker's current communicative contribution. This relates to 'grounding of reference in perception' (Levy and Fowler 2000), the notion that co-speech gesture (among other types of signal) is a means of publicly displaying that one is expending energy in order to communicate. Moving the hands as part of one's communicative contribution is a genuine perceptible index that one is indeed making a communicative contribution. One's intentional involvement in a communicative project might otherwise be imperceptible, because in essence it inhabits the mental interior and would not be accessible without 'conversion from private to public' (Miller 1951: 3). It follows that to cease such effort is to publicly display that one is no longer, at that moment, devoting such effort to the task of communication. Accordingly, full relaxation of the hands after gesturing during speech is a powerful index of a closure boundary in discourse. ${ }^{4}$ Examples in the sequences discussed above include Figures 16, 31, and 73.

\section{Semiotics of the non-dominant hand: An interclausal function of the hold in gesture}

A defining component of the symmetry-dominance construction is the gesture hold. One known function of the hold in co-speech gesture is to make online adjustments to speech-gesture synchrony in order to avoid potential transgressions of a phonological synchrony rule (a 'strong urge to keep gesture and speech together'; McNeill 1992: 26). For example, a gesture whose stroke comes too early may enter a post-stroke hold until the relevant prosodic peak in accompanying speech arrives. But as the present study has shown, a gesture hold's scope of function is not confined to the boundaries of a single utterance. The above examples show that a gesture hold can inhabit a structural position in the temporally ordered supply of information not only within single utterances but also across utterances in a discourse. By structurally linking a new utterance (a composite of speech-with-gesture) with a preceding one, a gesture hold affords a coherent way to manually represent two ideas at the same time. The information represented by the held non-dominant hand is carried forward from a previous utterance, relevant to the current utterance but pragmatically backgrounded. Thus, the gestures simultaneously articulated during a dominance phase each perform distinct pragmatic functions with respect to the speech. This is a systematic exception to 
McNeill's proposed pragmatic synchrony rule, according to which 'if gestures and speech co-occur they perform the same pragmatic functions' (1992: 29).

\section{Comparing the phenomenon in gesture and sign language}

I would like now briefly to compare the present findings on co-speech gesture to similar findings in research on sign language. Sandler (1993, 2002) discusses the role of the non-dominant hand in lexical signs: It either copies the dominant hand's shape, position, and movement, or it is a passive and abstract anchor for a novel contribution by the dominant hand. Sandler says that while the non-dominant hand is semantically 'redundant', it nevertheless contributes prosodic information. In the articulation of lexical signs, the non-dominant hand may (a) mark 'the boundaries of the prosodic word' (by finishing off a two-handed sign while the dominant hand has already moved on to begin signaling a new sign), or (b) mark 'a prosodic constituent' by 'spreading' (holding in anticipation of an oncoming two-handed sign, waiting for the dominant hand to finish its current performance of a one-handed sign; Sandler 2002: 14-17). It is the third of Sandler's 'prosodic' functions of the non-dominant hand that is comparable to its role in the symmetry-dominance constructions described here. As Sandler puts it, at 'the discourse level', articulations of the non-dominant hand may 'break the bounds of the signs and sentences in which they originate by persisting in the signal to track and background referents and events' (Sandler 2002: 18; cf. Emmorey and Falgier 1999; Liddell 2003: ch. 8). Mathur (2002), similarly, describes the import of the non-dominant hand in one type of hold in sign language as representing semantic 'residue', persistent meaning carried forward from the sign in which it was first introduced (i.e. where 'some part of a sign is preserved through the articulation of the following signs'; Mathur 2002: 5). This accords with what I have suggested for the co-speech gesture data above. ${ }^{5}$

Gesture studies and sign language studies have an important but sensitive relationship. Since Stokoe (1960), one mission of sign language research has been to establish that the manual communicative conventions of Deaf communities meet all the criteria of full 'languages', valid expressions of the human language faculty, and in no way inferior to speech in their level of structuration or expressibility. One way of phrasing this would be to say that sign language is more than 'just gesture'. But this might imply in turn that gesture is unstructured, unsystematic, unconventional - all the things sign language is not. Co-speech gesture 
and sign language are two different things, but it remains the case that they share the manual/visuospatial modality, with its two, symmetrical articulators and its capacity for direct, three-dimensional analogic representation. Further, the essential distinction normally meant by the terms 'language' and 'gesture' must be defined without reference to modality (i.e. must be defined in terms of semiotic function), since both speech and hand movements are capable of expressing both conventional/discrete/ analytic and nonconventional/analog/imagistic meaning (Okrent 2002). Nevertheless, like most other linguists, sign language researchers exclude gesture when they refer to 'spoken language'. Zeshan (2000: 123) writes: 'A striking difference between signed and spoken languages is that a signer has two organs of articulation (the two hands) at his disposal which can be operated independently of each other to a large extent, whereas spoken languages have only a single vocal tract for articulation'. Similarly, Emmorey (2002: 146) says that the presence of two independent articulators is a 'unique aspect of sign language production' (emphasis added). She argues that a sign language is 'unique' with respect to a spoken language in that 'space itself is used to express spatial relationships ... [that are] isomorphic and in the same modality' (Emmorey 2001: 152). In one more example, Mathur (2002) says that the 'residue' effect he observes in holds 'is visible only in signed languages owing to the modality-specific nature of the articulators', with the result that there is 'no parallel to RESIDUE in spoken languages' (Mathur 2002: 5). Such statements would be valid if speech alone were the legitimate unit of comparison with sign language (cf. Taub, Piñar, and Galvan 2002). But as many authors have shown (Kendon 1972, 1980; Slama-Cazacu 1976; McNeill 1985, 1992; Engle 1998), spoken language is not just speech, but a composite of speech-with-gesture. From this perspective, the data presented in this article reveal semiotic effects arising systematically from affordances of the manual/visuospatial modality which are not 'unique to signed languages'. As I have stated elsewhere (Enfield 2003: 45-46), the legitimate unit of analysis is not speech alone but the speech-plus-gesture composite that speakers of spoken languages routinely employ.

\section{Conclusion}

Why are there no 'grammars of gesture'? For speech, our descriptive and comparative investigations are guided by a suite of historically established structural properties and domains (phonology, lexicon, morphology, syntax). Linguistics rests on a deep history of descriptive work, and this history is yet to be written for gesture. What are the types and/or 
levels of semiotic structuration of gesture? We have taxonomies of gesture types (Efron 1941/1972; Ekman and Friesen 1969; Kendon 1988; McNeill 1992, inter alia), and many statements and studies of specific functions of gestures and their components. But we have hardly scratched the surface of the iceberg that is the structural grammar of gestural forms. For this we need more description of nonverbal communication from a structural point of view, across different discourse domains and from different linguistic and cultural communities. ${ }^{6}$ The present study suggests that one place to look for combinatoric structure of gesture patterns is beyond the confines of the linguistic sentence or equivalent (cf. clause, intonation unit, utterance, idea unit, etc.). The 'discourse functions of gesture' are already a point of note in the literature (e.g., McNeill 1992: Ch. 7), but we have yet much to learn about how sequences of gestures are formally and functionally structured at that level.

The symmetry-dominance construction is an information-packaging technique based on semiotic principles afforded by the manual/ visuospatial modality. The extent to which this is equivalent to a grammatical construction in speech is open to discussion. It has some of the elements. Dominance sequences are structurally dependent on symmetry sequences. As the Lao fish trap descriptions exemplify, the construction is used when the informational structure to be conveyed is more than can be represented with a single gesture by a single human being (with two arms and one head). Speakers in these circumstances will segment, package, and supply the information in linear order, for essentially the same reasons that linearization occurs in speech. And the relation between the form of the gestures and the order in which they appear will not be random. The result is a gestural combinatorics, building structural dependencies in both the spatial and discourse domains, through the linearsegmented organization of gesture sequences.

\section{Notes}

* This article is dedicated to Wendy Sandler. I thank Wendy for many enjoyable meetings concerning the issues discussed in this article. I also thank Daniel Haun, Sotaro Kita, Pim Levelt, Steve Levinson, Jan Peter de Ruiter, and Ulrike Zeshan for useful comments and discussion. I gratefully acknowledge the support of the Max Planck Society and the MPI Nijmegen Technical Group. This work also owes a great deal to the intellectual environment provided by my colleagues in the MPI Nijmegen research projects 'Gesture' and 'Multimodal Interaction'.

1. As is well known from research on signed language of the Deaf, when no secondary symbolic code is available online, representational systems in the manual/visuospatial modality will readily grammaticize (Stokoe 1960; Klima and Bellugi 1975; Emmorey 2002). 
2. The position of right and left hand are as they would be for the viewer of a video recorded from in front of the speaker. The speaker's right hand is at the left for the viewer/reader.

3. The transliteration of Lao used here follows IPA standard except for the following: $e=$ schwa; $\hat{e}=$ high-mid front vowel; $\grave{e}=$ low front vowel; $\grave{o}=$ low back vowel; $\grave{u}=$ high back unrounded vowel; $n g=$ velar nasal; $\tilde{n}=$ palatal nasal; $q=$ glottal stop. Lexical tone is indicated by numeral, as follows: $1=\operatorname{mid}$ level (33); $2=$ high rising (35); $3=$ low rising (13); $4=$ high falling (51); $5=$ low falling (31). Interlinear glosses are as follows: $1 / 2 / 3$ (1st/2nd/3rd person); CLF (classifier); CT (class term); DEM (demonstrative); GEN (general); IRR (irrealis); NONPROX (non-proximal); PCL (particle); PFV (perfective); PL (plural); REL (relativiser); SG (singular). In the examples, square brackets around a strip of speech indicate temporal coincidence with the gesture depicted in an accompanying illustration.

4. See Kendon 1978 for the 'differential attention' that addressees pay to 'main track' gestures as opposed to 'disattend track' actions such as putting the hands at rest.

5. However, in contrast to the present analysis, Mathur claims that the function of keeping a hand in play with residual meaning is 'is to allow articulatory ease'. He writes, 'it is easier to keep the H2 [the non-dominant hand] in place until it is needed for the next two-handed sign' (Mathur 2002: 5). This contrasts directly with the above analysis according to which a held hand is a display of not conserving energy. I believe that it is physically more effort to keep one's hand raised, and although what the hand represents semantically is not focal in the current utterance, it nonetheless will be relevant as long as the 'residual' hand is there. To rest the hand would be to imply that the information it represents is no longer relevant. This is appropriate at a boundary of discourse closure, which is precisely where we do observe full rest of the hands.

6. A question to which we must also seek an answer is this: Is the symmetry-dominance construction used by speakers of all languages? I suspect the answer is yes.

\section{References}

Battison, R. (1978). Lexical Borrowing in American Sign Language. Silver Spring, MD: Linstok Press.

Claridge, G. F.; Sorangkhoun, Thanongsi; and Baird, Ian G. (1997). Community Fisheries in Lao PDR: A Survey of Techniques and Issues. Vientiane: IUCN.

Efron, David (1941/1972). Gesture, Race, and Culture. The Hague/Paris: Mouton.

Ekman, Paul and Friesen, Wallace V. (1969). The repertoire of nonverbal behavior: Origins, usage, and coding. Semiotica 1, 49-98.

Emmorey, Karen (2001). Space on hand: The exploitation of signing space to illustrate abstract thought. In Spatial Schemas and Abstract Thought, Merideth Gattis (ed.), 147-174. Cambridge, MA: MIT Press.

-(2002). Language, Cognition, and the Brain: Insights from Sign Language Research. Mahwah, NJ: Lawrence Erlbaum.

Emmorey, Karen and Falgier, B. (1999). Processing continuous and simultaneous reference in ASL. Linguistic Society of America Annual Meeting, Los Angeles, January 1999.

Emmorey, Karen; Tversky, Barbara; and Taylor, Holly A. (2000). Using space to describe space: Perspective in speech, sign, and gesture. Spatial Cognition and Computation 2, $157-$ 180.

Enfield, N. J. (2003). Producing and editing diagrams using co-speech gesture: Spatializing non-spatial relations in explanations of kinship in Laos. Journal of Linguistic Anthropology $13,7-50$. 
Engberg-Pedersen, Elisabeth (1994). Some simultaneous constructions in Danish Sign Language. In Word-order Issues in Sign Language, M. Brennan and G. Turner (eds.), 73-87. Durham, England: ISLA Publications.

Engle, Randi A. (1998). Not channels but composite signals: Speech, gesture, diagrams, and object demonstrations are integrated in multimodal explanations. In Proceedings of the Twentieth Annual Conference of the Cognitive Science Society, M. A. Gernsbacher and S. J. Derry (eds.), 321-327. Mahwah, NJ: Erlbaum.

Hockett, Charles F. (1960). The origin of speech. Scientific American 203, 89-96.

Kendon, Adam (1972). Some relationships between body motion and speech: An analysis of an example. In Studies in Dyadic Communication, A. W. Siegman and B. Pope (eds.), 177-210. New York: Pergamon Press.

- (1978). Differential perception and attentional frame in face-to-face interaction: Two problems for investigation. Semiotica, 24 (3/4), 305-315.

- (1980). Gesticulation and speech: Two aspects of the process of utterance. In The Relation between Verbal and Nonverbal Communication, M. R. Key (ed.), 207-227. The Hague: Mouton.

- (1988). Sign Languages of Aboriginal Australia: Cultural, Semiotic, and Communicative Perspectives. Cambridge: Cambridge University Press.

Klima, Edward S. and Bellugi, Ursula (1979). The Signs of Language. Cambridge, MA: Harvard University Press.

Levelt, Willem J. M. (1989). Speaking: From Intention to Articulation. Cambridge, MA: MIT Press.

Levy, Elena T. and Fowler, Carol A. (2000). The role of gestures and other graded language forms in the grounding of reference in perception. In Language and Gesture, David McNeill (ed.), 215-234. Cambridge: Cambridge University Press.

Liddell, Scott (1995). Real, surrogate, and token space: Grammatical consequences in ASL. In Language, Gesture, and Space, K. Emmorey and J. Reilly (eds.), 19-41. Mahwah, NJ: Lawrence Erlbaum Associates.

-(2003). Grammar, Gesture, and Meaning in American Sign Language. Cambridge: Cambridge University Press.

Lyons, John (1972). Human language. In Non-verbal Communication, Robert A. Hinde (ed.), 48-85. Cambridge: Cambridge University Press.

Mathur, Gaurav (2002). On the syntax-phonology interface in ASL: The case of hold. LSA Annual Meeting, January 4, 2002.

McNeill, David (1985). So you think gestures are nonverbal? Psychological Review 92, 350-371.

- (1992). Hand and Mind: What Gestures Reveal about Thought. Chicago: Chicago University Press.

-(ed.) (2000). Language and Gesture. Cambridge: Cambridge University Press.

Miller, George A. (1951). Language and Communication. New York: McGraw-Hill.

Miller, C. (1994). Simultaneous constructions in Quebec Sign Language. In Word Order Issues in Sign Language, M. Brennan and G. Turner (eds.), 89-112. Durham, England: ISLA Publications.

Okrent, Arika (2002). A modality-free notion of gesture and how it can help us with the morpheme vs. gesture question in sign language linguistics (Or at least give us some criteria to work with). In Modality and Structure in Signed and Spoken Languages, Richard P. Meier, Kearsy Cormier, and David Quinto-Pozos (eds.), 175-198. Cambridge: Cambridge University Press.

Sandler, Wendy (1993). Hand in hand: The roles of the non-dominant hand in sign language phonology. The Linguistic Review 10, 337-390. 
-(2002). From phonetics to discourse: The non-dominant hand and the grammar of sign language. Paper presented at LabPhon 8, New Haven, CT.

Slama-Cazacu, Tatiana (1976). Nonverbal components in message sequence: 'Mixed syntax'. In Language and Man: Anthropological Issues, William C. McCormack and Stephen A. Wurm (eds.), 217-227. The Hague/Paris: Mouton.

Stokoe, William (1960). Sign Language Structure: An Outline of the Visual Communication Systems of the American Deaf (= Studies in Linguistics, Occasional Papers 8). Silver Spring, MD: Linstok Press.

Taub, Sarah F.; Piñar, Pilar; and Galvan, Dennis (2002). Comparing spatial information in speech/gesture and sign language. Presentation at First Congress of the International Society for Gesture Studies, Austin, Texas, June 2002.

Thorpe, W. H. (1972). The comparison of vocal communication in animals and man. In Non-verbal Communication, R. A. Hinde (ed.), 27-48. Cambridge: Cambridge University Press.

Zeshan, Ulrike (2000). Sign Language in Indo-Pakistan: A Description of a Signed Language. Amsterdam: John Benjamins.

N. J. Enfield (b. 1966) is a member of the Scientific staff, Language and Cognition Group at Max Planck Institute for Psycholinguistics. His principal research interests are gesture and language, social intelligence and interaction, and field linguistics. His major publications include Ethnosyntax: Explorations in Grammar and Culture (2002, editor); Linguistic Epidemiology: Semantics and Grammar of Language Contact in Mainland Southeast Asia (2003); and 'Demonstratives in space and interaction: Data from Lao speakers and implications for semantic analysis' (2003). 
